Department of Psychology and Logopedics

Faculty of Medicine

Doctoral programme in Psychology, Learning and Communication

University of Helsinki

Finland

\title{
WHEN AND WHY IS "EXTRAVERSION" ASSOCIATED WITH SOCIAL POPULARITY?
}

\author{
Ville-Juhani Ilmarinen
}

ACADEMIC DISSERTATION

To be presented, with the permission of the Faculty of Medicine of the University of Helsinki, for public examination in Auditorium XII, University main building, on 2 June 2018, at 12 noon. 


\section{Supervisors}

University lecturer, docent Markku Verkasalo

Department of Psychology and Logopedics, University of Helsinki, Finland

Professor Jan-Erik Lönnqvist

Swedish School of Social Science, University of Helsinki, Finland

Pre-examiners

Professor Mitja Back

Department of Psychology, University of Münster, Germany

Professor Anu Realo

Department of Psychology, University of Warwick, United Kingdom

Department of Individual and Social Psychology, University of Tartu, Estonia

Opponent

Lecturer, PhD René Mõttus

Department of Psychology, The University of Edinburgh, United Kingdom

ISBN 978-951-51-4315-O (pbk.)

ISBN 978-951-51-4316-7 (PDF)

Unigrafia

Helsinki 2018 


\section{ABSTRACT}

Examinations of the relationship between individuals' personal characteristics and the social positions that individuals receive in everyday peer networks have often found an association between extraversion and popularity. This thesis assesses the conditions (when) and mechanisms (why) of this association.

Four research questions focus on when the link between extraversion and popularity is present. The study examines whether extraversion is already associated with popularity among seven- to eight-year-olds (Study I), if extraversion is associated with popularity in a less talkative and more stereotypically introverted culture as well (i.e. in Finland; Studies I and II), whether the association is more reflective of the popularity of extraverts or the unpopularity of introverts (Studies II and III), and if the size of the surrounding social ecology is an important precondition of this association (Study III). In addition, the study considers two why research questions. Studies II and III examine if dyadic combinations of extraversion could serve as popularity particles that would explain why extraverts are ultimately more popular in the group, whereas Study I evaluates the mediating role of oral fluency between extraversion and popularity among children.

The association between extraversion and popularity is found to be highly generalizable, as it is present among young and adult Finns as well as in social networks of varying sizes. In addition, the association is linear and unilateral: introverts are unpopular as much as extraverts are popular, and dyadic combinations of extraversion are not significant in explaining this phenomenon. Finally, the higher oral fluency of extraverts partially explains their popularity in middle childhood.

The discussion focuses on the causality of this association and engages with the ontological status of trait extraversion throughout the thesis. The research also highlights the role of popularity and social networks in accounting for the coalescence of extraversion. 


\section{TIIVISTELMÄ}

Yksilön persoonallisuuden ominaisuuksien ja sosiaalisten verkostojen välisten yhteyksien tutkimuksessa on usein havaittu yhteys ulospäinsuuntautuneisuuden (ekstroversio) ja vertaissuosion välillä. Tämä väitöskirja tarkasteli, milloin ja miksi tämä yhteys ilmenee.

Väitöskirjassa selvitettiin neljän tutkimuskysymyksen kautta, milloin yhteys ekstroversion ja suosion välillä havaitaan: havaitaanko yhteys jo 7-8 vuotiailla (Tutkimus I), onko se olemassa myös vähemmän puheliaassa ja stereotyyppisesti sisäänpäin suuntautuneemmassa (introversio) suomalaisessa kulttuurissa (Tutkimukset I ja II), vaikuttaako ympäröivän sosiaalisen verkoston koko yhteyteen (Tutkimus III), ja osoittaako yhteys ekstroverttien korkeaa vai introverttien matalaa suosiota (Tutkimukset II ja III)? Lisäksi tämän yhteyden syitä tarkasteltiin kahden tutkimuskysymyksen avulla. Tutkimuksissa II ja III tarkasteltiin, vaikuttaako muiden introversio tai ekstraversio siihen, että ekstrovertit ovat suositumpia? Lisäksi selvitettiin, onko puheen sujuvuus lapsilla yksi selittäjä tälle yhteydelle (Tutkimus I).

Yhteys ekstroversion ja suosion välillä havaittiin hyvin yleistyväksi - se havaittiin suomalaisilla lapsilla ja aikuisilla ja riippumatta verkoston koosta. Lisäksi yhteys ilmensi niin ekstroverttien suosiota kuin introverttien matalaa suosiota, eivätkä nämä yhteydet selittyneet sillä, että ekstrovertit suosisivat toisiaan tai introvertit suosisivat ekstroverttejä. Ekstroverttien sujuvampi puhe kuitenkin osittain selitti tätä yhteyttä 7-8 -vuotiailla.

Pohdinnassa perehdytään tämän yhteyden mahdollisiin syysuhteisiin. Lisäksi piirteiden ontologista statusta pohditaan läpi koko väitöskirjan. Tämän ohella perehdytään siihen, voivatko suosio ja vertaisverkostot selittää, miksi piirteet kuten itsevarmuus, sosiaalisuus ja positiivinen emotionaalisuus usein ilmenevät yhdessä, jonka seurauksena ekstroversio-faktori myös havaitaan. 


\section{ACKNOWLEDGEMENTS}

Olen äärimmäisen kiitollinen kaikille, jotka ovat mahdollistaneet tämän opinnäytetyön ja siihen liittyvien osajulkaisujen valmistumisen. Ensinnäkin haluaisin kiittää ohjaajaani dosentti Markku Verkasaloa siitä, että hän rekrytoi minut tutkimusassistentiksi projektiinsa melkein kymmenen vuotta sitten. Sillä samalla tiellä edelleenkin olen, enkä usko, että mikään muu polku olisi itselleni ollut yhtä mielekäs. Kiitos Markulle myös kaikista muista järjestelyistä, kuten opetusmahdollisuuksista, jotka ovat mahdollistaneet sekä työni edistymistä että omaa oppimistani tutkijan työhön.

Samoista tutkimusprojekteista, joissa olin avustajana, sain myös opinnäytetöilleni ohjaajan, professori Jan-Erik Lönnqvistin. Jannen tarjoama ohjaus on tukenut uravalintaani ja edistänyt työskentelyäni hyvin keskeisesti. Olin aivan hukassa urasuuntautumisteni suhteen ennen opinnäytetöitäni, mutta niiden kautta tutkimukseen tutustuminen sai minut ensimmäistä kertaa todella innostumaan jostain. Se on suoraan Jannen tarjoaman innostavan ohjauksen ansiota. On ensinnäkin kiitettävä siitä, että hän sietää tilastollisia intohimojani ja vitkastelujani niiden parissa, mutta toisaalta myös siitä, että hän onnistuu saamaan minut viemään käsikirjoituksia eteenpäin, ainakin joskus. Jannen ohjauksessa ja hänen työtään seuraamalla olenkin oppinut kirjoittamisesta aivan valtavasti. Lisäksi on mainittava erittäin inspirovat lounaat, joissa hän jaksaa keskustella kanssani niistä tutkimuksen ja tilastoanalyysien epämääräisistä sivupoluista, joihin aina kulloinkin olen hairahtunut. Havaitsin joskus konferenssimatkalla olevani hyvin yksinäinen, kun jatko-opiskelijoiden ryhmässä muut kertailivat huonoja kokemuksia ohjaajistaan. Veti hiljaiseksi, kun muut valittivat esimerkiksi siitä, että ohjaajat eivät ole kommentoineet tekstejä kuukausiin tai oppilaat kokevat olevansa pelkästään ohjaajansa pelinappuloita Akatemia-pelissä. Itse en ole kokenut Jannen ohjauksessa mitään vastaavaa. Janneltahan laadukkaat kommentit saa melkein liiankin nopeasti, koska useasti toiveissani olisi pitempikestoinen tekosyy perehtyä johonkin uuteen R-pakettiin. On ollut suuri ilo ja kunnia olla Jannen ohjattavana. Odotan jo innolla, että pääsen jatkamaan yhteistyötä hänen kanssaan taas syksyllä.

Haluan kiittää myös muita yhteistyötahoja, jotka liittyvät välittömästi sekä tähän työhön että muihin tutkimusprojekteihin, joissa olen ollut mukana. Apulaisprofessori Mari-Pauliina Vainikaista ja Koulutuksen arviointikeskusta siitä, että olemme saaneet erinomaista ja ainutlaatuista aineistoa käyttöömme työnne avulla. Dosentti Sointu Leikasta luottamuksesta tarjota yhteistyötä omista kiinnostavista projekteistaan, joista olen oppinut myös muista asetelmista kuin kenttätutkimuksista ja päässyt seuraamaan muita keskeisiä oman alan tutkimus- ja menetelmälinjoja lähietäisyydeltä. Innolla odotan jo tulevaa yhteistyötämme saman projektin alla. 
Yhtä henkilöä, jolla on ollut suora vaikutus myös tämän työn syntymiseen, en valitettavasti voi enää henkilökohtaisesti kiittää. Ensimmäinen kansainvälinen konferenssi, johon tältä alalta osallistuin, oli Londonissa Kanadassa (ISSID 2015), jossa myös edesmennyt professori Sampo Paunonen työskenteli. Vaikka työskentelimmekin samaan aikaan käsikirjoituksen parissa (tämän työn tutkimus II), tämä ei ollut keskiössä tuolla reissulla vaan se, että Sampo ystävällisesti otti minut isännöitäväkseen, vaikka mistään tällaisesta ei ollut aiemmin sovittu. Hän esitteli minut muille tutkijoille, näytti kotiseutuaan ja yliopistoaan, ja kertoi näkemyksiään ja kokemuksiaan alastamme rehellisesti. Tämä Sampon mahdollistama avartava ensimmäinen kokemus konferensseista on ollut minulle erittäin tärkeä myöhemmillä reissuilla.

Keskeinen rooli työni tukemisessa on tietenkin ollut myös työn rahoittajilla, eli Jenny ja Antti Wihurin Rahastolla (2014-2016) ja PsyCo tohtorikoulun paikalla (2017). Kiitos, että olette nähneet tutkimussuunnitelmani tukemisen arvoisiksi. Tutkijan työtä mahdollistava rahoitus ei ole itsestään selvää. Olen hyvin iloinen, että Wihurin rahasto tukee väitöskirjoja ja kiitollinen, että näitä resurssejanne on päätynyt myös käytettäväkseni.

Haluan kiittää myös vanhempiani Maaretia ja Jussia siitä, etteivät he ole koskaan kovin voimakkaasti kyseenalaistaneet valintojani, vaikka aika mielivaltaisia ne ovatkin suurilta osin olleet. Uskallus esimerkiksi opiskelualan vaihtoon, joita tein kaksi ennen psykologiaa, perustunee tunteeseen turvaverkon olemassa olosta epäonnistumisen sattuessa, ja minulle tällainen etuoikeutettu tunne on teidän ansiostanne sattunut. Ilman sitä tätäkään työtä tuskin olisi olemassa. Kiitän vanhempiani sekä myös puolisoni äitiä Anne Niemelää lastenhoitoavusta, jonka avulla tämänkin työn tekemistä on huomattavasti mahdollistettu. Kiitän myös veljeäni Pyryä, jonka seura on minulle myös erittäin harvinainen etuoikeus siinä, että yhteinen huumorimme mahdollistaa kaiken työhön liittyvän unohtamisen silloin kun sellainen on tarpeen ja myös silloin kun se ei ole tarpeen.

Viimeiseksi, vaikka työn ja perheen yhteen sovittamiseen liittyy usein vaikeuksia, olisi näiden kahden yhtäaikainen olemassaolo minulle tällaisessa muodossa mahdotonta ilman ihanaa puolisoani Iina Lyytistä. En usko, että minulla voisi olla sekä rakas oma perhe että tämä valmis työ ilman häntä. Olen äärimmäisen kiitollinen suurista ponnisteluistasi perheemme eteen sekä siitä, että olet ollut rinnallani epävarmoina ja tuskaisina aikoina. Myös silloin (valitettavan usein) kun olen ajatuksissani täysin muissa maailmoissa, töihin ja muihinkin asioihin liittyen. Tekemäsi uhraukset ja antamasi tuki ovat korvaamattomia.

Helsingissä toukokuussa 2018, Ville Ilmarinen 


\section{CONTENTS}

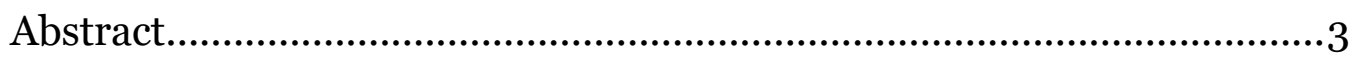

Tiivistelmä ..........................................................................................

Acknowledgements …………………......................................................

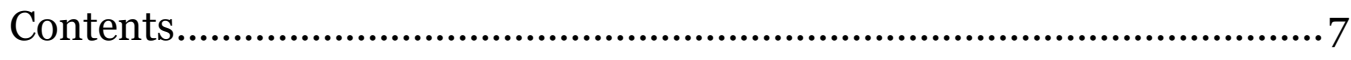

List of original publications ………………………………..................... 10

Abbreviations ..........................................................................................

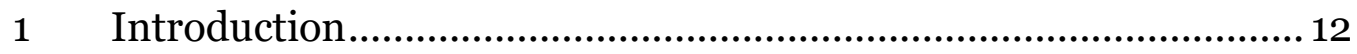

$1.1 \quad$ Personality traits ..................................................................... 13

$1.2 \quad$ Extraversion .......................................................................... 17

1.2.1 Conceptual precursors: From Hippocratic-Galenic types to

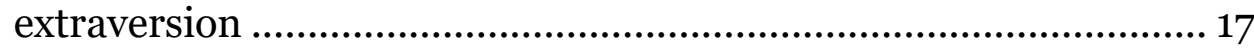

1.2.2 Clarified concept of extraversion in current trait models ... 19

1.2.3 Extraversion in light of 21st-century criteria for personality traits 20

1.2.3.1 Consistency over time and situations ........................ 20

1.2.3.2 Observability and inter-rater agreement .................. 21

1.2.3.3 Convergent validity.......................................................22

1.2.3.4 Universality.................................................................22

1.2.3.5 Behavioral genetics.....................................................24

1.2.3.6 Extraversion as a useful descriptive summary.........27

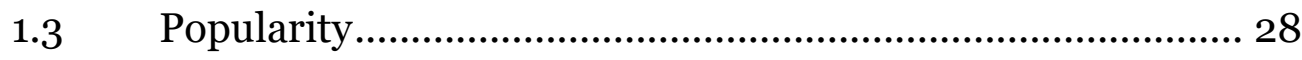

1.3.1 Peer nomination technique and sociometric popularity.....29

1.3.2 Dyadic relationships as popularity particles …………….... 30

1.4 Extraversion and popularity in peer networks......................... 31

1.4.1 When is extraversion associated with social popularity?.... 31 
1.4.1.1 Is extraversion already associated with popularity in middle childhood?

1.4.1.2 Is extraversion associated with popularity in a less talk-oriented culture as well?

1.4.1.3 Dimensional continuity: Are extraverts popular or introverts unpopular?

1.4.1.4 Socio-ecological sensitivity: Does the number of peers in a social network influence the association between extraversion and popularity? .......................................................37

1.4.2 Why is extraversion associated with popularity? ................ 38

1.4.2.1 Is the association between extraversion and popularity driven by dyadic combinations of extraversion? . 38

1.4.2.2 Mediating mechanisms: oral fluency as a mechanism under extraversion-popularity association in middle childhood........................................................................... 41

2 Study objective and research questions ............................................ 44

2.1 When is extraversion associated with popularity? .................. 44

2.2 Why is extraversion associated with popularity? .....................45

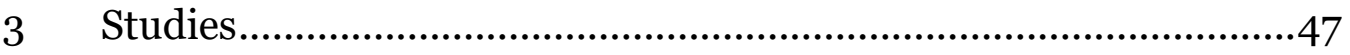

3.1 Study I ...................................................................................47

3.1.1 Methods...................................................................................47

3.1.1.1 Participants and procedure ………...............................47

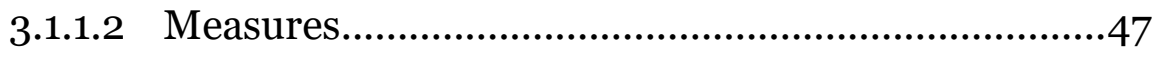

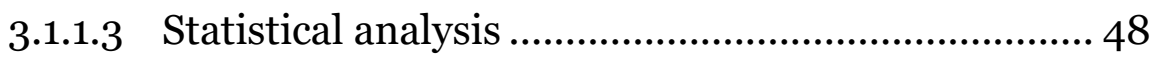

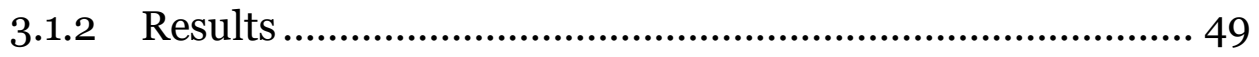

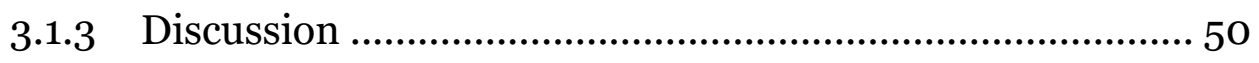

$3.2 \quad$ Study II................................................................................ 51

3.2.1 Methods............................................................................... 51

3.2.1.1 Participants and procedure........................................... 51

3.2.1.2 Measures ........................................................................ 51 
3.2.1.3 Statistical analysis: Polynomial regression analysis and RSA with the social relations model...............................52

3.2.2 Results ...............................................................58

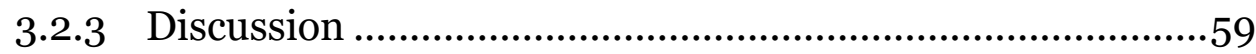

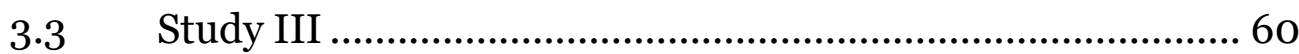

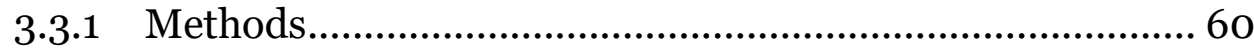

3.3.1.1 Participants and procedure ................................... 60

3.3.1.2 Measures ............................................................ 60

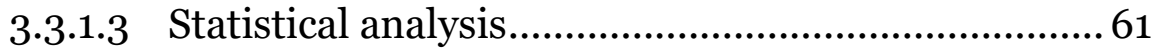

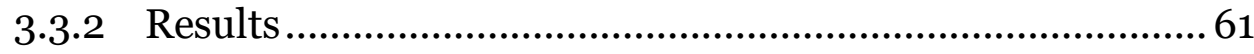

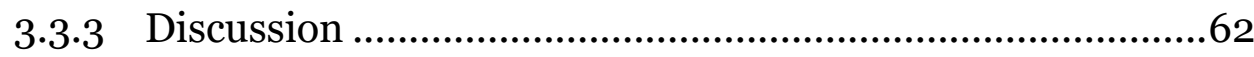

$4 \quad$ General discussion ............................................................6 63

4.1 Does extraversion predict popularity? ...............................63

4.2 Does popularity predict extraversion? ...............................66

4.3 Is the causation between extraversion and popularity bidirectional? ............................................................................6 67

4.4 What can the results reveal about extraversion? ................. 68

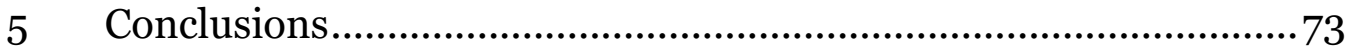

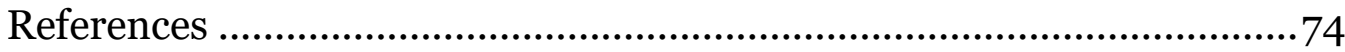




\section{LIST OF ORIGINAL PUBLICATIONS}

This thesis is based on the following publications:

I Ilmarinen, V. J., Vainikainen, M. P., Verkasalo, M., \& Lönnqvist, J. E. (2015). Why are extraverts more popular? Oral fluency mediates the effect of extraversion on popularity in middle childhood. European Journal of Personality, 29, 138-151.

II Ilmarinen, V. J., Lönnqvist, J. E., \& Paunonen, S. (2016). Similarity-attraction effects in friendship formation: Honest platoon-mates prefer each other but dishonest do not. Personality and Individual Differences, 92, 153-158.

III Ilmarinen, V. J., Vainikainen, M. P., Verkasalo, M., \& Lönnqvist, J. E. (2017). Homophilous friendship assortment based on personality traits and cognitive ability in middle childhood: The moderating effect of peer network size. European Journal of Personality, 31, 208-219.

The publications are referred to in the text by their roman numerals. 


\section{ABBREVIATIONS}

$\begin{array}{ll}\text { FFM } & \text { Five-Factor Model } \\ \text { FFT } & \text { Five-Factor Theory } \\ \text { SNP } & \text { Single-nucleotide polymorphism } \\ \text { GWAS } & \text { Genome-wide association study } \\ \text { RMSEA } & \text { Root-mean square error of approximation } \\ \text { CFI } & \text { Comparative fit index } \\ \text { SRMR } & \text { Standardized root mean square residual } \\ \text { TLI } & \text { Tucker-Lewis Index } \\ \text { LOS } & \text { Line of similarity } \\ \text { LODS } & \text { Line of dissimilarity } \\ \text { PA1 } & \text { First principal axis } \\ \text { PA2 } & \text { Second principal axis } \\ \text { CI } & \text { Confidence interval } \\ \text { RSA } & \text { Response surface analysis }\end{array}$




\section{INTRODUCTION}

Humans live in social networks in which they are surrounded by other people. These networks are pervasive and assume various forms: families, schools, work places, hobbies, as well as online social networks. Together, these create social systems that are best understood in terms of the people and their social ties in these networks.

A common property of many social networks is that individuals already have individual characteristics before network membership. These attributes are, for example, many biological and psychological trait dispositions of individuals. These characteristics have the power to influence how a network forms, and they therefore can also impact the positioning of different individuals in the networks.

This thesis focuses on the personality characteristic known as 'extraversion' and its role in everyday social networks that consist of peers, i.e. other individuals of a similar age and formal status. Research has already demonstrated that extraversion has a role in whether individuals attain social status (Anderson, John, Keltner, \& Kring, 2001), acceptance (Wolters, Knoors, Cillessen, \& Verhoeven, 2014), liking (Ciarrochi \& Heaven, 2009), and preference (Hubers et al., 2016) in a group of peers. These findings can all be combined under a general observation that extraversion is associated with peer popularity. This thesis attempts to further disentangle this association by examining when and why such association is present.

Determining under which circumstances the association between extraversion and popularity is observed entails a series of tests of the generalizability of this association. Previous studies have focused mostly on adolescents and young adults as well as on Northern American and Central European populations. This thesis extends these approaches by investigating if the association is already present among seven- to eight-year-old children as well as in two samples of the stereotypically introverted and less talkative Finnish population and culture. The research also examines if the size of the social network influences the association, as it is possible that extraverts are especially popular in social networks that contain many peers. In addition, the study tests whether this association is more reflective of the popularity of extraverts or the unpopularity of introverts.

The second aim of this thesis is to better understand which processes and mechanisms could explain why extraverts are more popular. Special focus is on dyadic relationships as antecedents of popularity in a peer group. This dyadic approach assesses if there are systematic dyadic patterns wherein extraverts typically prefer other extraverts or introverts typically prefer extraverts. These dyadic popularity particles could then account for popularity attainment in a group. Finally, the thesis investigates if oral fluency could be a mechanism for why extraverts attain peer popularity in the sample of seven- 
to eight-year-olds, an age group in which abilities for fluent speech have more pronounced individual differences.

Recently, researchers have widely discussed and challenged the broad trait approach to personality (Baumert et al., 2017; Mõttus, 2016; Wood, Gardner, \& Harms, 2015). In view of this, the thesis begins with an introduction to the trait approach and its current state (Chapter 1.1.) followed by a review of extraversion in light of several important personality trait criteria and a conceptualization of extraversion for the present thesis (Chapter 1.2.). Chapter 1.3. then provides an introduction to sociometric peer popularity. In Chapter 1.4., the introduction concludes with the presentation of six focal research questions to consider when and why extraversion is associated with popularity.

\subsection{PERSONALITY TRAITS}

During the last century, researchers have predominantly described and studied individual differences in behavior from the viewpoint of the trait approach. Personality traits refer to relatively stable individual characteristics (behaviors, feelings, and cognitions) in which individuals differ, and these differences can be psychometrically measured (McCrae \& Costa, 2008). The trait approach has not been the only endeavor to understand the individuality and uniqueness of humans. It differs from many other prominent approaches to human personality in that it is nomothetic; thus, it seeks to establish general laws and generalizations by means of quantitative methods. By contrast, psychoanalytic or humanistic approaches are idiographic, so they focus on the individual and maintain that each person is unique and should be studied in a unique way (Barenbaum \& Winter, 2008).

Initially, the trait approach strongly resembled a psychometrical assessment of intelligence, as it used testing and test items as the methodical tools. This approach still remains a relevant and leading approach to personality traits (Barenbaum \& Winter, 2008). Most often, such assessment takes place by individuals providing self-reports on a set of questionnaire items, each of which addresses one of several broader personality traits. Although the trait approach differentiates itself from other approaches to personality, there have also been a plethora of different trait approaches and trait-based models of personality, especially during the mid-2oth century (Barenbaum \& Winter, 2008; John, Naumann, \& Soto, 2008). Some of these approaches are more focused on identifying general traits from lexicon, building on the idea that all terminology related to human behavior is encoded in the language (Allport \& Odbert, 1936), whereas others are more based on careful statistical analysis of a pre-existing set of personality questionnaires. At some point between the 1950s and the 1970s, the quantity and diversity of trait approaches led to attempts to combine these various models under a general integrative trait approach. Such paradigm model for personality 
structure was consensually established around the late 1980 s and early 1990 s (John et al., 2008). Most importantly, this approach was able to integrate heterogeneous approaches using both lexical (Goldberg, 1990) and questionnaire-based approaches (McCrae \& John, 1992). The most general, broad traits that these models incorporate and describe are neuroticism, extraversion, openness to experience, agreeableness, and conscientiousness (John et al., 2008). This model is often referred to as the five-factor model (FFM) or "Big Five" model (McCrae \& John, 1992).

The FFM as a model of personality structure was further refined into the five-factor theory (FFT) of personality, which builds on several crucial criteria that are significant for a paradigmatic personality trait model (McCrae \& Costa, 2008). As part of the FFT, the FFM describes five broad trait factors that are independent of one another and have strong temporal stability (individuals do not change substantially on any of these traits during their life span). Moreover, each broad trait consists of narrower traits (often referred to as facets), and even these facets are thought to comprise more particular units that describe meaningful independent differences. These trait units at the lower level are referred to as nuances (McCrae, 2015; Mõttus, Kandler, Bleidorn, Riemann, \& McCrae, 2017). As an example, trait extraversion consists of narrower facets of gregariousness, warmth, assertiveness, activity, excitement seeking, and positive emotion, and each of these again features narrower sets of nuances, such as being talkative and persistence in the face of frustration under assertiveness. This property of the model is also referred to as the trait hierarchy, whereby all facets and narrow behaviors under a particular broad trait correlate with each other, i.e. they often occur together within the same individual. The FFT further posits that an unobservable latent trait at the highest level of the trait hierarchy explains this correlation, following which this common cause accounts for the correlations between traits belonging to the same factor or domain (i.e., assertiveness and gregariousness correlate because of extraversion). Support for this particular proposition, and for the FFT in general, has derived from the universality of the personality structure (the same five factors tend to emerge in different nations and cultures) (McCrae, Terracciano, \& 78 Members of the Personality Profiles of Cultures Project, 2005; Rolland, 2002; Schmitt, Allik, McCrae, \& Benet-Martínez, 2007), the moderately strong heritability for each of the five traits (there is substantial genetic influence on the trait levels of individual) (Vukasović \& Bratko, 2015), the non-specificity of trait structure to self-report questionnaires (the structure emerges from "other" ratings as well, and self and others agree with each other on personality ratings of a target), as well as the previously mentioned temporal consistency (McCrae \& Costa, 2008). In addition, these five broad traits also predict many meaningful life outcomes (Ozer \& Benet-Martínez, 2006).

Despite seemingly comprehensive evidence that these five broad traits most accurately describe personality and effectively explain behavior, recent advances in personality psychology have caused some turbulence regarding 
trait approaches in general and the FFT in particular (Baumert et al., 2017; Mõttus \& Allerhand, 2017; Wood et al., 2015). In fact, these models and theories have been criticized since a form of consensus surrounding the five broad traits started to emerge (Pervin, 1994), but the evidence in the recent years has again highlighted this issue. First, advances in behavioral genetics have unambiguously indicated that single or even multiple genes that correspond to the activity of neurotransmitters in the central nervous system do not explain meaningful variance in the five broad personality traits (Chabris et al., 2013; Munafò \& Flint, 2011). Thus, personality traits do not result from genetic differences in a narrow set of key genes with large explanatory strength. This heavily opposes the idea of a latent trait as a unitary cause under correlated traits that belong to same domain. This is not to say that personality traits would not have any biological basis or that traits would not be heritable, but the biological unitary under a broad set of correlated behaviors is highly unlikely.

Second, evidence of a personality trait hierarchy - that there are different levels to personality traits that all share an underlying latent causal unit - has been opposed by the finding that even the narrowest-bandwidth units in personality hierarchy, i.e. nuances, have the same properties as the broad personality traits (Mõttus et al., 2017; Mõttus, Kandler et al., 2017). Therefore, even nuances are heritable and temporally stable, and the ratings provided by the self and other on single narrow-bandwidth traits agree. This would not necessarily pose a problem from the viewpoint of the FFM because items are thought to reflect the latent causal traits in the hierarchical models (McCrae \& Costa, 2008). However, more importantly, these properties are retained also after removing the broad traits from these narrow nuances (Mõttus et al., 2017; Mõttus, Kandler et al., 2017). This suggests that especially narrow personality traits, such as a tendency to enjoy roller coasters or to try new foods, exist independently of the broad traits. These narrow traits also incrementally explain outcomes of the broad traits, which also supports their social importance (Mõttus et al., 2017; Mõttus, Bates, Condon, Mroczek, \& Revelle, 2017). Thus, there are separate, narrower traits that exhibit properties that are similar to, yet independent of, those of broad traits. Therefore, these units cannot serve as interchangeable indicators of broad traits or as characteristic adaptations (McCrae \& Costa, 2008) but are instead personality traits of their own, according to many properties that traits are necessitated to have (Eysenck, 1991).

Finally, despite increasing evidence for the universal structure of the FFM (McCrae et al., 2005; Rolland, 2002; Schmitt et al., 2007), there are also notable exceptions to this universality when studied among smaller-scale societies that are isolated from other societies. Among Tsimane foragerhorticulturalists, the five-factor structure was generally not supported based on low-scale reliabilities, the number of personality dimensions emerging from exploratory factor analyses, self-spouse agreement in personality ratings, and incongruence to structures found in other societies (Gurven, von Rueden, 
Massenkoff, Kaplan, \& Lero Vie, 2013). Because there has also been an ongoing debate for many decades (even before the introduction of the FFM and "Big Five"; Eysenck, 1991) about the structure of personality in regard to the number of traits (Ashton \& Lee, 2007; De Raad et al., 2014) and existence of meta-traits above the five broad traits (Digman, 1997), the universality of the structure may not actually be as comprehensive as often stated (McCrae \& Costa, 2008). The lack of universality also undermines the common causality of latent universal factors that would give rise to similar sets of behaviors in every part of the world.

To summarize, evidence has started to accumulate that suggests there is not a common cause of traits that are correlated under a certain broad factor. This view is also apparent in statements that the unitary cause of broad traits is an illusion (Asendorpf, 2016), that latent factors are fictitious (Revelle \& Elleman, 2016), and that broad traits are not "real" (Mõttus \& Allerhand, 2017). Traits nevertheless tend to correlate, and they therefore frequently arise as broad factors in statistical approaches to psychological structures. Thus, some other explanations for this coalescence of traits should be sought. Even if broad traits are not "real", it is unclear why traits such as assertiveness, sociability, positive affect, enthusiasm, and activity correlate with one another to form the personality factor known as extraversion. According to the recent findings presented above, the reason for this covariance pattern (also referred to as coalescence; Mõttus \& Allerhand, 2017) cannot be extraversion and its biological correspondents in the central nervous system. This also indicates that traits are emergent, not correspondent (Baumert et al., 2017). Thus, elements that are typically called traits are functions of their constituents, and constituents that occur together in the same individuals do not all share common etiologies. Researchers have already proposed some approaches to address this problem and to better understand the explanatory components of personality (Cramer et al., 2012; McCrae, 2015; Mõttus \& Allerhand, 2017; Wood et al., 2015). However, when seeking out personality trait research that has accumulated over recent decades, the question simultaneously arises of whether the broad trait factors are of any utility in personality research.

The ontological status of broad traits is not quite so ambiguous that they would be completely fruitless for personality research. Although the explanatory potential of broad traits is limited, they are still useful for broadly describing sets of narrower traits that tend to correlate with one another as well as for predicting outcomes (Freese, 2016; Ozer, 2016). This is all accompanied by the tradeoff of being unable to specifically identify the explanatory mechanisms, even if one or several of the constituents in combination form the broad factor. Ozer (2016) has provided the example that it is beneficial for an insurance company to adjust car insurance prices according to area postal codes even though such postal codes are not explanations for why certain cars and drivers ultimately need the insurance more often. There are several of these causes, however, embedded in the summary that the postal code provides. In a similar way, it is thus justifiable 
to use broad traits in examinations of associations with outcomes. Nevertheless, it is important to note that although these summaries encompass the explanation in some way, the explanation is not the broad trait factor. The explanation could be one of the constituents of the factor, but the constituents themselves do not generally share a common cause, and therefore they cannot all be explanations at the same time, opposing the view of trait theory (Cattell, 1943; McCrae \& Costa, 2008). In addition, factor approaches such as the "Big Five" have offered an approachable and parsimonious vocabulary for personality psychology (Freese, 2016), and it remains to be seen how future personality research will remain cumulative and interesting if there are hundreds of different trait terms in use, as the Big Five and FFM were introduced only a few decades ago (John et al., 2008). In sum, broad personality factors can be employed as useful summaries and to predict outcomes of interest, but as a tradeoff, the explanatory mechanisms remain highly ambiguous under this approach.

This thesis, however, is not about trait theory or personality structure per se; rather, it attempts to disentangle the association between two particularly broad variables: extraversion and peer popularity. Because of this focus on extraversion, the next chapter presents the general criteria for definition as a personality trait (Eysenck, 1991) in conjunction with a discussion of how extraversion fulfills these criteria.

\subsection{EXTRAVERSION}

After a brief historical overview, this chapter explains trait extraversion through a focus on how extraversion fulfills both the classic criteria for a personality trait as established by Eysenck at the beginning of the 1990 s (Eysenck, 1991) as well as more contemporary criteria stemming, for instance, from recent research in molecular genetics.

\subsubsection{CONCEPTUAL PRECURSORS: FROM HIPPOCRATIC-GALENIC TYPES TO EXTRAVERSION}

The earliest precursors of individual differences that resembled extraversion were present in the works of Hippocrates and Galen of Pergamon. The former introduced the belief that the balance of bodily fluids was significant in describing individual differences in behavior, and the latter further delineated these differences by establishing various temperament types due to an excess or deficiency of these humors (Elphick, Halverson, \& Marzal-Wisniewska, 1998). Two of the Galenic temperamental types (which are conceptually different from traits in that they describe certain individuals, not dimensions of individual differences) could be understood as conceptually correspondent to extraversion and introversion (the polar opposite of extraversion). The 
sanguine type that was believed to be a behavioral manifestation of excess blood matches with extraversion, whereas the melancholic type as a behavioral manifestation of excessive black bile relates to introversion (Elphick et al., 1998). Modern descriptions of individual differences have retained this antique trait terminology, including sanguine and melancholic temperaments (Eysenck, 1963; Van der Werff, 1985). The proposed modern mechanisms for individual differences, however, did not concern balance of humors in the human body anymore, but were nevertheless attempting to assign distinct biological processes to extraversion (Cloninger, Svrakic, \& Przybeck, 1993; Eysenck, 1963; Gray, 1970).

Carl Jung coined the terms extraversion and introversion in the early 2oth century (Jung, 2014). His conceptualizations of these terms did not pertain to the concept of a trait as much as to individual types that have different orientations toward the objective world. Jung's concept of the extraverted attitude type entailed being highly dependent on and attentive to the objective world, whereas his concept of the introverted attitude type was more concerned with the inner world (Wilt \& Revelle, 2017). Jung's ideas were notably more nuanced and surpassed mere descriptions of these attitudes types, including the neuroses associated with each type and the role of libido in these attitudes (Jung, 2014). As was typical for early personality theories, however, these ideas could not be formally tested by the scientific method or were refuted if it was possible (Eysenck, 1985; Eysenck, 1991).

In the first decade of the 2oth century, Gerardus Heymans presented another approach that is relevant for understanding the history of extraversion. His approach is considered the first to involve data collection and analysis, rather than being wholly philosophical or theoretical (Lombardo \& Foschi, 2002). Heymans collected perceptional data on characteristics of patients who visited family doctors and used a crude statistical method (Van der Werff, 1985) that resembled factor analysis, according to Wilt and Revelle (2017). These analyses highlighted three personality dimensions that differentiated between eight temperamental types in a model known as Heymans' Cube (Van der Werff, 1985). Re-analysis of the data by Van der Werff (1985) has revealed that one of these dimensions also bears a strong resemblance to extraversion-introversion, although the trait labels that Heymans used strongly correspond to the ancient Hippocratic-Galenic tradition. Heyman's approach, although attempting to apply a more psychometrical approach to personality, also did not use the trait concept but instead employed characteristics that resembled traits to categorize individuals into certain types.

Although 1937 is generally considered the year of origin for personality psychology as a discipline (Allport, 1937), the full incorporation of extraversion into the personality literature during the 2oth century is likely attributed to Hans Eysenck, as Wilt and Revelle (2017) have noted. Eysenck strongly engaged with personality traits and had a predominantly biological foundation for trait extraversion, and he attempted to validate his ideas with 
experiments in addition to extensive work with questionnaires (Eysenck, 1963; Eysenck, 1991). Eysenck was central in shifting personality psychology into the mainstream, and because extraversion-introversion was prevalent in his models, these traits became very widely known by psychologists during his era. Another important figure in the studies of trait extraversion is Jeffrey Gray, who also maintained ideas about neurobiological processes that produce extraversion as a stable manifest behavior (Gray, 1970). Eysenck also delineated the call for a personality paradigm by defining 14 principles that it should encompass (Eysenck, 1991). Ironically, however, he precisely proposed these criteria for the purpose of criticizing the model that would later become the paradigm, the FFM (John et al., 2008).

Other key figures for 20th-century studies on trait psychology and extraversion in particular were Guilfords (Guilford \& Braly, 1930) and Raymond Cattell (Cattell, 1943), of whom the latter completed extensive factor analytical work that built on the earlier lexical work of Allport and Odbert (Allport \& Odbert, 1936). Cattell also had his own label for trait extraversion, namely invia-exvia, and heavily promoted trait theory in which the same common cause would explain correlations between traits (Cattell, 1943).

\subsubsection{CLARIFIED CONCEPT OF EXTRAVERSION IN CURRENT TRAIT MODELS}

Almost all of the personality trait models and various types of questionnaires utilized during the 2oth century included some form of extraversion. In the integrative approach to personality structure, which united these separate personality approaches under an overarching model and terminology and led to the FFM, factor I represents extraversion because it has the broadest bandwidth in comparison to the other four factors (John et al., 2008). Thus, in terms of its magnitude, it is the most relevant trait to explain individual differences in behavior. A brief description by John and colleagues (2008, p. 120) most effectively explains the content of this broad extraversion: "Extraversion implies an energetic approach toward the social and material world and includes traits such as sociability, activity, assertiveness, and positive emotionality." The same idea is also present in the various facets and constituent structures of extraversion, which include traits such as assertiveness, leadership, gregariousness, social confidence versus anxiety, activity, positive affect, behavioral approach, social attention, ascendance, venturesomeness, adventurousness, unrestraint, sociability, excitement seeking, expressiveness, social boldness, and liveliness (Ashton, Lee, \& Paunonen, 2002; John et al., 2008; Lee \& Ashton, 2004; Wilt \& Revelle, 2017). There are, however, certain discontinuities between the popular approaches to extraversion. The most notable is the inclusion of the warmth facet under extraversion in the FFM (McCrae \& John, 1992). By contrast, other broad trait approaches include it in agreeableness (Saucier \& Ostendorf, 1999). Regardless, the trait content in extraversion is usually highly congruent 
between approaches (John et al., 2008). Disparities in conceptualizations mostly concern the weight assigned to sociability and assertiveness (Denissen \& Penke, 2008), but most trait models conclude that these two correlated traits, alongside positive emotionality, are the main facets or constituents of extraversion.

As with all personality traits, extraversion is envisioned as a dimensional continuum with two poles. When describing and communicating psychological constructs and phenomena, it is often more convenient to use shorter labels, and it is likely for that reason that extraversion is so widely employed. Nevertheless, it is important to understand that the construct itself should depict its other pole - introversion - with equal weight, and to a similar degree as it describes extraversion. Introversion and extraversion are the two poles of a continuum, along which most individual fall in the middle; therefore, the terms "introvert" or "extravert" would be poor descriptors for most individuals. Accordingly, in this thesis, the term extraversion refers to the entire introversion-extraversion trait continuum, and extravert and introvert refer to an individual who is positioned at the higher and lower end, respectively, of this continuum.

\subsubsection{EXTRAVERSION IN LIGHT OF 21ST-CENTURY CRITERIA FOR PERSONALITY TRAITS}

This section builds on Eysenck's 1991 paradigm criteria (Eysenck, 1991) in light of more recent literature to present research on the consistency, observability, convergent validity, universality, and behavioral genetics of trait extraversion. Subsequently, the section provides a synthesis and specification of how extraversion is understood in the present thesis.

\subsubsection{Consistency over time and situations}

The consistency criterion posits that extraversion should be stable so that the rank ordering of individuals in a group or population does not change substantially with the passage of time (Eysenck, 1991). With such consistency, individuals do not fluctuate significantly in their average behaviors, and it is logical to use trait-like descriptions for these behaviors. This type of consistency has been the focus of longitudinal studies that have measured extraversion of individuals at a minimum of two points in time and measured consistency as the correlation between the scores at the different points.

There is ample evidence that extraversion is stable over time (Roberts \& DelVecchio, 2000), which indicates that those who are extraverted or introverted will retain their respective quality in the future. The consistency of extraversion, however, is not equivalent throughout one's lifespan. Instead, it tends to increase during development but plateau between the ages of 50 and 70 (Roberts \& DelVecchio, 2000). Consistency is also moderately strong 
during childhood (Spengler, Gottschling, \& Spinath, 2012), which suggests that individual differences in extraversion are stable across lifespan and that the stability is strongest between middle and old age. An important side note is that this consistency is not necessarily based entirely on genetic influence, and environmental influences may also contribute to stability (Briley \& Tucker-Drob, 2014; Briley \& Tucker-Drob, 2017).

Consistency could also be understood as the stability of an individual's levels of extraverted behaviors across situations when measured repeatedly over a shorter time span (e.g. multiple times per day) (Fleeson, 2001). This short-interval consistency signifies that all individuals exhibit variance in their extraversion-related behaviors yet there should be a consistent mean level of these behaviors that differentiates individuals comparably to one-shot trait measures of extraversion (Fleeson, 2001). In addition, the mean levels of repeated measures should also correlate with independent trait measures of extraversion to further validate the consistency criterion. Findings from repeated measurements of the extraverted behavior of multiple individuals demonstrate that there are indeed robust individual differences in mean levels of extraverted behaviors, but these also tend to be less consistent than behaviors that are relevant for other "Big Five" traits (Catterson, Eldesouky, \& John, 2017; Heller, Komar, \& Lee, 2007; Leikas \& Ilmarinen, 2017; Sun, Stevenson, Kabbani, Richardson, \& Smillie, 2017; Wilt, Bleidorn, \& Revelle, 2017). Moreover, support for a correlation between individual mean levels of behaviors and independent trait measures is mixed (Heller et al., 2007; Leikas \& Ilmarinen, 2017), perhaps owing to the smaller sample sizes that are typical in experience sampling research.

In sum, there is notable consistency in extraversion across the entire life span when examined as a correlation between trait extraversion measures across two or more time points. There is also support for individual differences in extraversion levels of the average behaviors. However, recent evidence has suggested that this consistency is not as strong as rank-order consistency, which indicates that everyone exhibits all types of behaviors in the introversion-extraversion continuum during their average day, despite differences in individuals' mean levels. In addition, it is noteworthy that the between-person consistency of extraverted behaviors is usually lower than for other trait-relevant behaviors, and behavior mean levels may not correspond strongly to trait mean levels. More research on the repeatedly measured behaviors is nevertheless needed before establishing conclusions.

\subsubsection{Observability and inter-rater agreement}

For psychological trait constructs, it has long been a concern that their properties should be examined from the perspective of whether self-rating measures are correlated with other ratings (self-other agreement). Furthermore, it is similarly worthwhile to assess whether two or more perceivers of the same target are in agreement with each other (other-other 
agreement or consensus). Inter-rater agreement signifies that the psychological construct can be detected with normal sensory processes.

In comparison to other personality traits, extraversion is in a class of its own as far as how perceptible it is. Meta-analysis of self-other and other-other correlations of ratings of a target person's level of extraversion (Connelly \& Ones, 2010) have demonstrated that extraversion has the highest other-other correlation of all traits $(\mathrm{r}=.51)$. In addition, these reliabilities were not significantly different between types of informants (from incidental acquaintances, $\mathrm{r}=.48$, to family members, $\mathrm{r}=.53$ ), and even the source of information was not particularly significant: audio clues had equal coefficients, $r=.53$, to clues with highest coefficients (audio plus visual; $r=$ .57). Also, the self-other agreement for extraversion $(\mathrm{r}=.51)$ was the highest of the "Big Five" traits, alongside conscientiousness $(r=.50)$. Thus, extraversion is a good trait as assessed by its observability, and an excellent trait as assessed as it observability in relation to other broad personality traits.

\subsubsection{Convergent validity}

A classical psychometrical approach to examine support of trait validity is construct validity, which can be further delineated into convergent and discriminant validity (D. T. Campbell \& Fiske, 1959). Convergent validity indicates that different measures of the same traits do measure the same construct, and they therefore correlate. Discriminant validity, in contrast, conveys that measures of different traits do not correlate because they should measure separate constructs. Here, only the evidence of convergent validity is presented since it is the more important of the two, especially for a metaanalysis of evidence across a heterogeneous set of scales that are thought to measure the same construct. A meta-analysis (of which many are referred to in this thesis) of extraversion should be grounded in the fact that extraversion is extraversion across all the studies included in the meta-analysis. In a metaanalysis of 103 convergent validity coefficients, extraversion generally had the highest convergent validity of the "Big Five" personality traits (Pace \& Brannick, 2010). The average coefficient, .56, indicates that although there is a moderate correlation between various measures of extraversion, there are also notable differences, and meta-analyses should note this partial incommensurability.

\subsubsection{Universality}

The universality criterion dictates that extraversion as a personality trait should be ubiquitous to humans, i.e. it should exist in all cultures and nations (Eysenck, 1991). Studies have rarely focused on the universality of extraversion itself, but studies on the universality of personality structure have been more common (see Chapter 1.1). Indeed, a simple case for the universality criterion 
could derive from the commonality of the FFM for personality structure, and therefore also of extraversion, among almost all cultures (McCrae et al., 2005; Rolland, 2002; Schmitt et al., 2007). However, among the Tsimane foragerhorticulturalists, where the five-factor structure was generally not supported, a conceptually uniform extraversion factor was also absent (Gurven et al., 2013). The structure of personality among the Tsimane was constructed with two very broad trait factors, pro-sociality and industriousness, and extraversion items loaded strongly on the pro-sociality factor alongside agreeableness items and other items with socially desirable content (Gurven et al., 2013). Inconsistent mixing of extraversion and agreeableness items has additionally been observed in other cross-cultural investigations of personality structure (Rolland, 2002) and encoded in widely used personality instruments (John et al., 2008), which indicates that socio-ecological contexts may have an influence on the structuring of more narrow behaviors related to extraversion and agreeableness. The authors of the Tsimane personality study have noted that the structure could be dependent on typical social niches and possibilities for relational mobility in different cultures (Gurven et al., 2013). Also, a lexically driven approach to cross-cultural similarity has often found three major factors at the highest level of the factor structure, one of which is extraversion (alongside agreeableness and conscientiousness) (De Raad et al., 2014).

In addition, the structure of personality models across cultures, research has also examined the universality of the facet structure of extraversion (Lucas, Diener, Grob, Suh, \& Shao, 2000). More specifically, Lucas et al. (2000) have evaluated whether the facets of affiliation, ascendance, and venturesomeness as indicators of reward sensitivity would form a central constituent of extraversion and if social interaction would be a redundant constituent of this broad trait. This model was supported across 39 countries. The results demonstrate that reward sensitivity correlates with pleasant affect, and not the sociability facet of extraversion, in all cultures. Thus, reward sensitivity could be a core constituent of extraversion. This concept of reward sensitivity as a central feature of extraversion has also gathered support from other sources (L. Campbell, Simpson, Stewart, \& Manning, 2003; Smillie, 2013), and it is encompassed in some more novel biologically driven theories of extraversion (Depue \& Collins, 1999). However, other scholars have argued that the most central constituent is social attention, while reward sensitivity would still be relevant and enjoyment of social interactions more peripheral (Ashton et al., 2002).

Thus, extraversion is probably not a perfectly universal trait. Nevertheless, it could be more widely present than other FFM traits or the entire factor structure of personality, especially if some variation in its form is allowed. However, its structure is not homogeneous across all cultures, especially when the analysis includes indigenous cultures. 


\subsubsection{Behavioral genetics}

A key inquiry for the entire field of psychology of individual differences is the origin of these observed individual differences. In a general sense, this concerns whether variation in extraversion could be attributed to genetic and environmental influences.

Quantitative behavioral genetics refers to the field of research that attempts to differentiate phenotypic variance, such as individual differences in introversion-extraversion, into heritable components as well as into environmental components (shared and non-shared environments). The most typical behavioral genetic studies are twin studies that calculate the similarities between identical and non-identical twins in extraversion; a larger correlation among identical twins evidences heritability in the phenotype, which indicates genetic influence. There are also other types of studies that incorporate information about relatedness between individuals (such as adoption and family studies) for establishing the proportion of heritability in extraversion. With quantitative methods, it is not possible to specify which particular genetic influences are causal to the phenotype. Still, these methods provide statistical estimates of heritability, i.e. how much of the phenotypical variance could be attributed to genetic differences. In fact, understanding the variance in these components is more difficult than these variance proportions imply (Johnson, Penke, \& Spinath, 2011), but they serve as helpful starting point to understand the nature of phenotypic traits, such as extraversion.

The recent meta-analysis (Vukasovic \& Bratko, 2015) has synthesized the literature across studies on the heritability of extraversion and compared differences between twin studies and other types of family designs. Analysis of all studies has revealed that, similarly to virtually any type of human trait (Polderman et al., 2015), extraversion is heritable. The average estimate for the heritability of extraversion was .42, indicating that $42 \%$ of the variability in extraversion can be attributed to genetic influences. The estimates from twin studies were higher (47\%) than for family and adoption studies (22\%), suggesting possible non-additive genetic influences on extraversion (Vukasović \& Bratko, 2015). These non-additive genetic influences, epistasis and dominance, are interactions in the same genetic locus or between different genetic loci, respectively, and they are not transferred from one generation to the next but are instead present among the same generation (Johnson et al., 2011).

Following the well-documented quantitative heritability of extraversion and ideas of a clearly defined biological basis of extraversion (Eysenck, 1963; Gray, 1970), literature has suggested that certain genes could largely explain the heritable variance in extraversion (Cloninger et al., 1993). These genes have been called candidate genes because they are involved in key neurotransmitter systems (e.g. dopaminergic and serotonergic) and are reactive to psychoactive drugs (Sanchez-Roige, Gray, MacKillop, Chen, \& Palmer, 2017). Studies on extraversion have especially focused on singlenucleotide polymorphisms (SNPs; variation in single base-pair location in 
DNA; Munafò \& Flint, 2011) in the D4 dopamine receptor. Despite early enthusiasm for these findings, meta-analytical synthesis of the studies has revealed that these particular genetic components did not replicate across studies (Chabris et al., 2013; Munafò \& Flint, 2011). These findings strongly refuted the proposition of a clearly defined genetic etiology for extraversion that would also heavily and predominantly correspond to dopaminergic systems in the brain. The lack of support for the importance of candidate genes concerns not only extraversion but also numerous other psychological traits (Chabris et al., 2013; Munafò \& Flint, 2011). After this observation, it was concluded that the quantitative heritability in traits is probably explained by many different genetic loci with minuscule effects from each, and that the sample sizes used at that point were unable to capture these effects, i.e. there was low statistical power.

Another type of behavioral genetic study design has recently emerged that uses the genetic data from the entire genome of individuals and examines if variation in genetic variants is associated with phenotypical variation (Visscher et al., 2017). Fortunately, these studies have included extraversion more often than other personality traits (Sanchez-Roige et al., 2017) (except for neuroticism). Such studies are more powerful than candidate gene studies in terms of both statistical power to detect important SNPs and the number of SNPs examined. These genome-wide association studies (GWASs) test the associations between genes and extraversion throughout the genome, which in total comprise hundreds of thousands of SNPs.

Such GWASs have thus far provided only mixed support in determining the heritability of extraversion or detecting significant SNPs. Meta-analysis of several GWASs (total $n=63,000$ ) to examine extraversion did not find any support for effects from a single SNP (van den Berg et al., 2016). Nevertheless, based on the non-significant genetic architecture of extraversion that derived from the data used for the meta-analysis, it was possible to predict a small proportion of variance in extraversion in an independent sample (procedure known as polygenic scoring). In another synthesis of studies, polygenic scores of extraversion were only able to predict less than $0.5 \%$ of a common phenotypic correlate of extraversion, i.e. life satisfaction, in a set of independent samples (Weiss et al., 2016). This could also indicate that this phenotypical link has few genetic components.

Another genome-wide meta-analysis of extraversion has concluded that the genetic architecture under extraversion replicated across two samples (Lo et al., 2016). The meta-analysis also identified two SNPs that each reached a very conservative significance threshold that genome-wide studies use to control error rates when testing thousands of SNPs. However, these replicable SPNs could again explain only a minuscule proportion of variance in extraversion. Furthermore, the meta-analysis calculated the explanatory power of all examined SNPs on extraversion (SNP heritability: Visscher et al., 2017), and it found that all SNPs could explain $18.1 \%$ of the variance in first set of studies and $4.9 \%$ of the variance in the second set of studies. This 
indicates that studies of molecular behavior genetics have also achieved some proportion of the heritability in quantitative behavioral genetic studies. However, given that twin studies have reported a heritability of $42 \%$, a large proportion of heritability in extraversion is still missing. This missing heritability is often attributed to insufficient statistical power, even with samples of tens of thousands of participants, as well as to the underrepresentation of non-additive genetic influences (genetic interactions) and rare genetic variants in these analyses (which mostly use those SNPs that are highly common in a population) (Lo et al., 2016; Plomin, 2013; van den Berg et al., 2016).

Finally, a very recent study that has not yet been formally published (Hill et al., 2018) has been able to address certain shortcomings of other genomewide studies by incorporating relatedness information in addition to genetic data in the analysis. This approach allows for the examination of five sources of variance in extraversion: genetic influences based on common genes, genetic influence based on genes that are only present among closely related individuals (rare genetic variants), influence of family environments, influence of sibling environments, and influence of environments shared by couples. This approach covers some of the missing heritability in neuroticism, cognitive ability, and education, but similar incremental prediction from rare alleles to extraversion was not observed (Hill et al., 2018). For extraversion, common genetic variants explained $13 \%$, and family environments accounted for $9 \%$ of the variance. Other components were unable to explain any additional variance in extraversion (the non-significant rare-genetic component explained $5 \%$ of variance in extraversion, indicating that the sample size around 20,000 may not have been sufficiently large to significantly detect this).

To summarize the behavioral genetic findings of extraversion, it is worthwhile to strongly weight according to the latest evidence from genomewide molecular genetic studies. Moreover, it is crucial to understand how and why these differ from family studies. Highly powered studies have only recently emerged, and although sample sizes are increasing, they might still have too low of a power to accurately estimate the heritability of extraversion. The replicable single SNP hits are still rare, especially compared to neuroticism, which even larger samples have studied to identify many new genetic loci that are also expressed in the brain (Luciano et al., 2017; Nagel et al., 2017). The proportion of explained variance by SNPs in extraversion is above zero, but only slightly (Hill et al., 2018; Lo et al., 2016). Thus, much of the heritability that quantitative behavioral genetics identifies (Vukasović \& Bratko, 2015) is still missing for extraversion. Nevertheless, current evidence generally implies that there is not specific genetic etiology for extraversion but that complex traits, such as extraversion, are not independent of genetic variation. Therefore, each single influence is minuscule, and there are possibly many of these minuscule influences. Furthermore, there could be non-additive 
effects that these methods do not yet capture (Turkheimer, Pettersson, \& Horn, 2014).

However, the problem of behavioral genetics of extraversion could also result from the ontological status of extraversion, given that broad trait factors are fictitious (Asendorpf, 2016; Revelle \& Elleman, 2016). For example, the ambiguity of broad extraversion could shade an estimation of quantitative heritability and attempt to find this same variation from SNPs. It could encompass some constituents for which genetic examinations are worthwhile, but because the etiology of broad extraversion is not common to all its constituents (Mõttus et al., 2017; Mõttus, Kandler et al., 2017), it may not be fruitful to seek SNPs and heritability for the summary of all the constituents. Indeed, the findings from molecular genetics may suggest that extraversion is a different type of trait than, for example, schizophrenia (Visscher et al., 2017), intelligence (Hill et al., 2018), and even neuroticism (Luciano et al., 2017; Nagel et al., 2017). The key point is that extraversion itself is not a unitary trait. In view of the pervasive lack of statistical power in molecular genetics (Visscher et al., 2017), a better understanding of the coalescence of traits under the extraversion domain could help to narrow down the traits for which the SNPs should be sought.

\subsubsection{Extraversion as a useful descriptive summary}

The review of extraversion presented above suggests that extraversion is best conceptualized as a descriptive summary. This would imply that extraversion is a summary of its constituents (Jonas \& Markon, 2016) and not an underlying common cause of correlated traits (Cattell, 1943; McCrae \& Costa, 2008). The descriptivist view acknowledges the correlated traits but is ambiguous and agnostic about their etiology (Freese, 2016). Current evidence suggests that many of the constituents of extraversion may have unique etiologies and are therefore traits of their own (Mõttus et al., 2017; Mõttus, Kandler et al., 2017).

A descriptivist concept of extraversion includes all of the facets, items, biological correlates, and motivational theories under the same domain. It sums a set of behaviors, feelings, motivations, and cognitions that often occur together (coalescence of traits). Thus, it is a vast summary. Most, if not all, of these constituents are correlated to a degree. These correlations may indicate direct influences between constituents as well as feedback loops (Cramer et al., 2012; Mõttus \& Allerhand, 2017; Wood et al., 2015). However, a descriptive summary neither answers questions considering causal order nor differentiates explanatory components. These are also the main limitations of descriptivist summaries and the reason they cannot serve as a general paradigm of personality.

Extraversion can still be useful for personality research as a summary. It is justified to describe correlated behaviors under the same label as well as to predict outcomes and other interesting phenomena with this summary or to 
predict this summary with other variables (Ozer, 2016). Nevertheless, it is important to understand that extraversion does not explain, or extraversion is not explained in, these statistical associations. Some of its constituents are probably involved in the explanatory part, but these should be sought by different means (Mõttus, 2016).

To conclude, in this thesis, the term extraversion is the focal characteristic and is simply the sum of an individual's scores on all separate but correlated extraversion constituents that are measured. Unlike in trait theory concepts, it does not refer to a level of a latent variable but instead describes how much of the characteristic domain the individual has as a sum. Accordingly, the sum for extravert is high, and the sum for introvert is low. It is also important to note that statistical analyses that employ latent variable modeling, a method also used in the present thesis, do not commit one to a trait theorist or common cause view of extraversion. Latent variables can also be used as parsimonious descriptive summaries (Jonas \& Markon, 2016).

\subsection{POPULARITY}

This thesis examines popularity for associations with extraversion. Popularity is a characteristic of an individual that reflects whether the individual is generally liked, accepted, and preferred in a group (Bukowski, Pizzamiglio, Newcomb, \& Hoza, 1996). In social network research terminology, its closest correspondent is in-degree centrality, which indicates how many others in the network have direct ties with the target person (Kadushin, 2012). It can alternately be understood as a sum of positive (and sometimes also as a lack of negative) relationship dispositions that other group members have toward the target person (Back et al., 2011). If the relationship dispositions are generally positive, i.e. others tend to prefer the target person, then the target individual has a high popularity on a group level. The form of popularity on which this thesis focuses is peer popularity. In this form, the group consists of individual who are roughly the same age, and there are not any formal status hierarchies (as opposed to, for example, work organizations and families).

Peer popularity is a unilateral concept that does not directly indicate or overlap with reciprocated social relationships, such as friendships, but is a quantitative indicator of an individual's relationship with her or his group. Because group members differ in their degree of popularity, and these differences tend to be moderately stable (Anderson et al., 2001; Jiang \& Cillessen, 2005), popularity could also be conceptualized as one form of an individual's social status that reflects his or her position and social value within the group (Anderson, Hildreth, \& Howland, 2015). Status is closely related to social power but is differentiated by voluntariness: status is admitted voluntarily, whereas admitting power may not be voluntary (Anderson et al., 2015). This differentiation therefore applies to popularity and social power as well; it is generally not possible to be popular if others do not 
voluntarily admit that popularity. Popularity structures tend to form spontaneously within groups after their establishment (Fournier, 2009) (for example, during the first days in an entirely new school classroom or among university freshmen). Within-group status hierarchies are also ubiquitous and universal among humans, so it is likely that popularity structures may also follow these general lines (von Rueden, 2014). Group cooperation is arguably easier if there is an agreed-upon hierarchy, and this could be beneficial for all individuals in the group, independent of their standing in the group hierarchy (Price \& Van Vugt, 2014).

\subsubsection{PEER NOMINATION TECHNIQUE AND SOCIOMETRIC POPULARITY}

Because popularity in a peer group is admitted by other group members, its measurement also involves the viewpoint of others. The commonly used procedure for defining an individual's popularity characteristics in the group is sociometric nomination, or a rating procedure in which group members nominate or rate each other by relevant items. The content of these items as well as combinations of multiple items have been used to calculate various forms of sociometric status measures, such as peer acceptance, peer rejection, and peer neglect (A. F. Newcomb, Bukowski, \& Pattee, 1993). Previously, the various status concepts were categorical, as each individual in a group was assigned to one of the status categories (especially for locating and providing interventions for rejected children). More recent approaches have employed more continuous forms of measurement to give each individual a score on popularity (Cillessen \& Rose, 2005).

In addition to using continuous concepts of popularity, the item content of sociometric nominations also may reflect at least two types of popularity. Sociometric popularity is measured by items such as "this person is likeable," "I like this person," or "I like to play with this person," whereas perceived popularity is measured by items such as "how popular is this person?" or "what is the social status of this person?" (Cillessen \& Rose, 2005; Parkhurst \& Hopmeyer, 1998). Although these distinct forms of popularity are often correlated, they also have different covariates (Cillessen \& Rose, 2005; Mayeux, Houser, \& Dyches, 2011; Rodkin, Ryan, Jamison, \& Wilson, 2012). However, among the younger age groups on which part of this thesis focuses, these concepts are less differentiated (Cillessen \& Mayeux, 2004; Rodkin et al., 2012). This is also reflected in conceptualizations of popularity among seven-year-olds compared to adolescents. Seven-year-olds describe popular children as those who are liked by others, those who behave pro-socially, those who are less overtly aggressive, and those who are preferred playmates, whereas adolescents' descriptions of popular children include mentions of physical appearance, self-presentation, studentship, and peer affiliations (Xie, Li, Boucher, Hutchins, \& Cairns, 2006). 
The studies in this thesis use sociometric methods for measuring popularity. In Studies I and III, which used samples of seven- to eight-yearold children, the ensuing measure of popularity is likely to reflect both the degree to which the child is liked and preferred as well as the centrality and visibility. Study II employs an adult sample of military cadets; each individual in a military platoon rated the extent to which he liked each of the other platoon members, which suggests that popularity in Study II signifies the degree to which the cadet is liked and preferred and does not so much concern visibility or centrality. These distinctions or differences should not be crucial for the present research, as previous research has associated extraversion with both sociometric and perceived forms of popularity (Hubers et al., 2016; van der Linden, Scholte, Cillessen, Nijenhuis, \& Segers, 2010; Wolters et al., 2014).

\subsubsection{DYADIC RELATIONSHIPS AS POPULARITY PARTICLES}

This thesis directs special attention to dyads as lower-level, within-group units that are particles of an individual's popularity score. Although sociometric popularity is a group-level average for each individual, it is also a sum of unilateral preference across all the dyadic relationships that an individual could have within a group (Back et al., 2011; Lubbers, van der Werf, Kuyper, \& Offringa, 2006). Because each group member has the possibility to prefer the person, such dyads could be considered particles comprising the total account of popularity. Those who have plenty of these particles are more popular individuals in the group, while those who have only a few are less popular. Personality literature has frequently considered dyadic relationships to be the outcome relationship measure, but it could also be worthwhile to understand them as smaller units forming the popularity of an individual. It may be especially interesting if the equation also includes characteristics of others in predicting why some individuals become more or less popular. Thus, in addition to focusing on the personal characteristics of the target person, attention should directed to the characteristics of those who admit popularity and preference (raters) and especially to the combinations of personality characteristics between target and rater. Also, because it has been suggested that variation in introversion-extraversion between individuals and followerleader patterns in a group could be understood from similar evolutionary viewpoints (Lukaszewski \& von Rueden, 2015; Price \& Van Vugt, 2014), it is particularly intriguing to consider the dynamics of dyadic combinations of extraversion as correlates of admitting, receiving, and reciprocating preference and popularity in a social network. It is plausible that there are systematic ways in which dyads function according to standings on extraversion and are aggregated across all the dyads of which an individual is a member (there are $n-1$ dyads for each individual in a group of size $n$ ) to influence her or his popularity. Therefore, these dyadic patterns could explain why extraverts are more popular. 


\subsection{EXTRAVERSION AND POPULARITY IN PEER NETWORKS}

The present thesis aims to disentangle the associations between three types of characteristics and dispositions: (a) individual characteristics, i.e. a person's level of extraversion, (b) network disposition, i.e. a person's popularity in the peer group and the sum of (c) relationship dispositions, which others have toward the target person. The central themes concern two questions: when is extraversion associated with popularity, and why is extraversion associated with popularity? This more focused approach can advance comprehension of this association as well as investigate the potential roles of popularity and peer relations with regard to extraversion. The following chapters introduce six research questions, of which four are when questions and two are why questions. They additionally review the literature in relation to previous findings regarding this association under the relevant research questions.

\subsubsection{WHEN IS EXTRAVERSION ASSOCIATED WITH SOCIAL POPULARITY?}

The question of when refers not only to the developmental time period during which extraversion may be associated with popularity but also more generally to which conditions such association may exist under, e.g. developmental periods, groups or sub-populations, or larger-scale social environments. In other words, it refers to the generalizability or specificity, or both, of this effect, and inquires whether extraversion is associated with popularity during various developmental periods and in different types of social groups and contexts or if this association is particularly present at a specific age or in a specific type of social environments. The when question also refers to the dimensional continuity of this association, i.e. at which points along the introversion-extraversion continuum the association is present. In other words, it asks whether this association is more between extraversion and popularity, between introversion and unpopularity, or between both of these. This thesis addresses four of these when questions by examining four types of circumstances: age, sub-populations, locations on the introversionextraversion continuum, and socio-ecological contexts.

\subsubsection{Is extraversion already associated with popularity in middle childhood?}

Although several studies have examined and found an association between extraversion and popularity (Ciarrochi \& Heaven, 2009; DesJardins, Srivastava, Küfner, \& Back, 2015; Feiler \& Kleinbaum, 2015; Jensen-Campbell et al., 2002; Jensen-Campbell \& Malcolm, 2007; Lubbers et al., 2006; Scholte, van Aken, Marcel A. G., \& Van Lieshout, 1997; Stopfer, Egloff, Nestler, \& Back, 
2013; van der Linden et al., 2010; Wortman \& Wood, 2011), few studies have assessed this association before adolescence. A study that differentiated between two types of popularity measures, namely sociometric and perceived popularity, has found that self-ratings of extraversion were associated with perceived popularity in adolescence, yet no associations between extraversion and sociometric popularity were found in middle childhood (mean age 9.39) or in adolescence (mean age 12.05) (Andrei, Mancini, Mazzoni, Russo, \& Baldaro, 2015). However, the measurement method of popularity in this study may have obscured the results. Nominations were sent and received only in regard to a particular type of situation (taking a classmate along on an imaginary school trip), and therefore the nominations may only narrowly overlap with the general popularity of an individual.

Another study has examined the association between extraversion and popularity prior to adolescence by measuring popularity during four phases from kindergarten (age 5) to third grade (age 8) and extraversion at age 12 (Lansford, Yu, Pettit, Bates, \& Dodge, 2014). Although popularity was already relatively stable during this young age (correlations between .40 and .50), none of the popularity measures was correlated with later extraversion (rs ranging from -.05 to .04). However, the longitudinal setting that had a fourto seven-year lag between the measurements of popularity and extraversion may have limited evidentiary value, possibly also because popularity was measured before extraversion and not vice versa. Besides these two studies, which either mostly focused on other research questions (Lansford et al., 2014) or used narrow measurements of popularity with possibly limited ecological validity (Andrei et al., 2015), no research has examined the associations between extraversion and popularity in middle childhood. Given that that the beginning of elementary school entails daily participation in durable peer environments for virtually all individuals, it is possible that individual differences in extraversion are decisive for who attains popularity in the newly forming groups.

This thesis extends the generalizability of this association across age groups to the youngest population in which it has been studied: seven- to eight-yearold children. The developmental period during which the study takes place, namely middle childhood (spanning from around age 6 to age 11), is considered central to and fertile for the development of peer relations in general. The evolutionary literature has additionally noted this idea. For social primates in this period (also referred to as juvenility) that falls between weaning and sexual maturity, social learning, ability to navigate social networks and gathering respect among peers are typical (Del Giudice, Angeleri, \& Manera, 2009). The evolutionary significance of this period has also been derived from comparative psychology studies that have evidenced that the length of this developmental period is associated with both complexity of social networks and the sizes of brain areas that are related to social problem solving (in primates with more complex social networks and larger non-visual neo-cortex, the juvenility period also lasts longer) (Joffe, 1997). This could 
signify that, in order to survive and eventually reproduce, a long middle childhood is needed for humans because of the necessity to learn language and understand social hierarchies (Del Giudice et al., 2009; Joffe, 1997; Locke \& Bogin, 2006).

In addition to the evolutionary views, developmental literature also supports the importance of middle childhood for establishing peer relations. For example, the development of social cognition and self-concept in relations to others is known to occur at high rate during this period (Harter, 1999). Also, perspective taking and social comparisons as well as gossiping with peers become notably more prevalent during middle childhood compared to earlier developmental periods (Eccles, 1999; Parker, Rubin, Erath, Wojslawowicz, \& Buskirk, 2006). The social importance of this period is further reflected in how the self-descriptive trait terms become remarkably more interpersonal during middle childhood (Rosenberg, 1979).

In the youth sample of the present thesis as well, the sociometric nominations consider various contexts across which the popularity of an individual is aggregated. Thus, the measurement is ecologically valid as a general peer popularity measure. Generalizability of the association is already supported across age groups from early adolescents (Jensen-Campbell et al., 2002) to individuals in their late twenties (Feiler \& Kleinbaum, 2015). This thesis extends this developmental generalizability to middle childhood.

\subsubsection{Is extraversion associated with popularity in a less talk- oriented culture as well?}

Studies have pronouncedly examined the association between extraversion and popularity among adolescents (Wolters et al., 2014) and young adults (DesJardins et al., 2015). These examinations have most often considered students in school classrooms (Jensen-Campbell et al., 2002; JensenCampbell \& Malcolm, 2007; Scholte et al., 1997; van der Linden et al., 2010) or university students (possibly most frequently psychology freshmen, although the particular discipline of the students is rarely reported) (Anderson et al., 2001; DesJardins et al., 2015; Selfhout et al., 2010) as the population under study. Although it is convenient to collect data each year from a fresh group of students from a researcher's own department, this procedure does not improve the generalizability of the results. In general, the amount of psychological studies that are conducted with Western, educated, industrialized, rich, and democratic (WEIRD) populations is massively disproportionate to how many people are actually WEIRD (Henrich, Heine, \& Norenzayan, 2010). Although tackling such bias is already highly difficult, the first step should be realizing this bias in studies that have replicated an effect and considering the boundaries of its generalizability. The second step should be an attempt to extend these boundaries. Strong and rigorous tests for the generalizability of an effect should be conducted with a non-WEIRD population (Henrich et al., 2010), but as such possibilities are often absent, 
smaller extensions to previous findings could also be considered important, at least as replications.

In this thesis, all examinations regarding the association between extraversion and popularity consider a Finnish population. Although Finland fulfills all the characteristics of a WEIRD population, and therefore does not provide a strong test of generalizability, the association has not (to the author's knowledge) been previously studied among Finnish populations or in any of the other Nordic countries. There are also other properties of Finland that make this examination interesting. Consistent with the stereotype of the shy and quiet Finn (Carbaugh, Berry, \& Nurmikari-Berry, 2006) and Finnish proverbs that emphasize the value of silence (e.g., "vaikeneminen on kultaa," which can be translated into "silence is golden"), there is generally less talk in Finland than in other countries, and even Finns who live in other countries (such as Sweden) talk less and with longer pauses between talking turns than people from other cultures (Tryggvason, 2006; Tulviste, Mizera, De Geer, \& Tryggvason, 2003). Given that one of the behaviors in the domain of extraversion is talkativeness and that extraversion has been associated with many types of speech and language variables (Mehl, Gosling, \& Pennebaker, 2006; Pennebaker, Mehl, \& Niederhoffer, 2003), it could be that extraversion and talkativeness, being less normative, do not contribute to popularity in groups of Finns. In accordance with this idea, recent results have suggested that the widely reported association between extraversion and life satisfaction is culture-sensitive. This association is strong only in North America and is weaker or non-significant in other cultures (Japan, Germany, and United Kingdom: Kim, Schimmack, Oishi, \& Tsutsui, 2017). Thus, it is possible that there is also cultural sensitivity in the association between extraversion and popularity, especially since many of the previous studies have used North American samples (e.g., DesJardins et al., 2015; Jensen-Campbell et al., 2002; Jensen-Campbell \& Malcolm, 2007).

Besides focusing on a rarely studied national culture, the present study also examines a neglected sub-population, namely military cadets. Although the all-male sample that this thesis used also contained freshmen and young adults, there are some distinct characteristics of a military-cadet sample, and especially of the environment that bounds their social network. Military cadets are nested in platoons (each consisting of 10 to 20 cadets), and they live, work, and study in the same facilities with their platoon-mates for the duration of their training. This social context is unique for testing whether extraversion is also associated with popularity when the social network endures for long periods of time in the daily lives of the subjects. In addition, it could be that certain extraverted behaviors, such as talking, are not as socially respected or desirable as in other type of cultures; for example, the "strong, silent type" masculine ideal may be particularly strong in a military context. Therefore, the Study II among military cadets could be considered a replication attempt and a test of the generalizability of extraversion-popularity association to an understudied population and social context. 
Finally, participation in the studies of this thesis did not involve selfselection of participants. Thus, all individuals in a classroom or military platoon were participating in the research. This is a desirable property, especially when considering extraversion, since research volunteers are more extraverted than individuals who do not partake in studies that involve volunteered participation (Lönnqvist et al., 2007).

\subsubsection{Dimensional continuity: Are extraverts popular or introverts unpopular?}

In the case that the psychological variables of interest are considered continuous, questions regarding the generalizability of an association can also be directed toward the focal variables. In statistical approaches to bivariate associations and multivariate analyses, the linearity of the association is one of the central assumptions (Hair, Anderson, Tatham, \& Black, 1998). In the event of two continuous measures, such as extraversion and popularity, the linearity assumption signifies that the association should be present with equal weight along the entire variable continuum. In other words, if there is a positive association between extraversion and popularity, additional levels of extraversion should be associated with equal increases in popularity at the introverted end, at the middle, and at the extraverted end of the continuum. This would also refer with equal weight to the observation that extraverts are popular, introverts are unpopular, and that individuals in the middle of introversion-extraversion continuum are average in popularity. It is a feasible presumption that such possibilities for non-linear associations are often treated as nuisance and only inspected visually from residual plots, if at all, to confirm that assumptions in a regression analysis hold. However, whether an effect is linear or non-linear is an interesting question itself, especially if the linear association has already gained some support in the literature and there is lack of testing for non-linearity. Literature that has reported on linear associations between extraversion and popularity has thus far ignored the possibility of non-linearity.

This thesis evaluates the possibility that the extraversion-popularity association is stronger at one of the poles of the introversion-extraversion continuum. It is possible that studies that have rhetorically reported on the higher popularity of extraverts have instead reported about a more specific association: the unpopularity of introverts or very high popularity of extreme extraverts. It should be noted that because the linear association has already gained support (Anderson et al., 2001; Jensen-Campbell et al., 2002; JensenCampbell \& Malcolm, 2007; Scholte et al., 1997), it is unlikely that the association would be purely curvilinear (U-shape or inverted U-shape), but there could be a curvilinear component or an inflection point to the linear association between extraversion and popularity (Hair et al., 1998). Prior to testing the non-linearity of the bivariate association, it is important to consider the extent to which the sample is representative of the population (Imhoff \& 
Koch, 2017). The sample must include the entire range of the population, as only under such circumstances can the inflection points of the association be concluded, if such points exist. For instance, if extraverts are underrepresented in the sample, the association would only refer to differences in popularity between introverts and those who are average in terms of introversion-extraversion. The youth sample that thesis used is especially appropriate for testing such association because it includes all individuals of a certain cohort in a large Finnish city, and it therefore could be considered highly representative of the population under study.

Curvilinearity of the association between extraversion and popularity could also be expected based on the literature. It has been proposed that the two main dimensions of person perception, namely agency and communion (Abele \& Wojciszke, 2007), are not orthogonal to each other, contrary to common assumptions, and that these dimensions are also not linearly correlated (Imhoff \& Koch, 2017). Instead, the perceptions of communion in others (i.e. warmth, love, or, as Imhoff and Koch have stated, positive social evaluations) are maximized around the average levels of agency (i.e. potency, dominance, influence) and respectively minimized toward both high and low agency. Individual- and group-level data have supported this notion so that entities (i.e., groups, individuals, or animal species) with high and low perceived levels of agency are systematically perceived to be lower in communion than entities with average levels of agency (Imhoff \& Koch, 2017). If sociometric popularity is considered an indicator of positive social evaluations, and if extraversion is considered an individual attribute that maps to the agentic dimension of the interpersonal circumplex (DeYoung, Weisberg, Quilty, \& Peterson, 2013; McCrae \& Costa, 1989), this would suggest a curvilinear association between extraversion and popularity. In other words, those with average levels of extraversion would be most popular. However, unlike agency and communion, extraversion and popularity are frequently observed to be linearly associated; therefore, it is unlikely that there would not be any linearity to this association. According to this observation, curvilinearity would be observed in addition to linear association, so that the association is positive from introversion to the middle of the continuum but inflects to non-significant association toward the extraverted pole. In this case, the extraversion-popularity link would mostly reflect introversion-unpopularity, while at average and high levels, the association would be approximately equal and around zero. In addition to curvilinearly correlated interpersonal perceptions (Imhoff \& Koch, 2017), curvilinear features for the association could also be anticipated because of the curvilinear association between assertiveness (also considered as a facet of extraversion: John et al., 2008) and perceived leadership (Ames \& Flynn, 2007).

This thesis analyzes the dimensional continuity of the association between extraversion and popularity by testing whether linear terms are sufficient to explain this association or whether allowing for curvilinearity would more effectively explain the association. Literature on interpersonal perception and 
leadership suggests that the association could be more reflective of introversion-unpopularity association than of extraversion-popularity association. Because the power to detect a curvilinear effect is limited in Study II's sample of 181 military cadets (.46, with type I error rate .05, calculated as squared effect that would double/nullify the linear effect $-\mathrm{r}=.2 \mathrm{O}$ based at on the previous literature - at \pm 1 standard deviation from the mean), this curvilinearity is mostly investigated in Study III, which had a sufficient power to detect a similar effect (.85 with 549 participants).

\subsubsection{Socio-ecological sensitivity: Does the number of peers in a social network influence the association between extraversion and popularity?}

A socio-ecological approach considers larger-scale social environments and their role in psychological phenomena (Oishi, 2014). It differentiates itself from classical psychological approaches by utilizing objective social environments in its analysis instead of employing individual's opinions, construals, observations, and perceptions of the environment. On the other hand, it shifts away from the field of sociology by incorporating individual differences in psychological characteristics into the analysis. This integrative approach is significant in regard to how social structures influence various personality phenomena, and vice versa. For example, unilateral (e.g. popularity) or dyadic relationships (e.g. friendships) do not suddenly appear in a social vacuum but rather in the midst of complex social networks that consist of other individuals and social ties between those individuals (Adams \& Allan, 1998). Thus, examining the quantitative properties of social networks that surround individuals with different personal characteristics could crucially extend to some already established personality phenomena.

No studies have addressed the socio-ecological influences on the association between extraversion and popularity. Given that socio-ecological psychology has only recently been introduced as a research field (Oishi, 2014), only a few studies have assessed the socio-ecological sensitivity of extraversion in general. One study has demonstrated that the positive association between extraversion and life satisfaction does not vary as a function of properties such as population density, ethnic diversity, house prices, and green spaces of 156 residential areas in London, UK (Jokela, Bleidorn, Lamb, Gosling, \& Rentfrow, 2015). On the other hand, it has been observed that extraverts are more likely to move to more densely populated areas, which possibly indicates their preference for richer social opportunities (Jokela, Elovainio, Kivimäki, \& Keltikangas-Järvinen, 2008). Supporting this idea, it has additionally been observed that extraversion buffers against the negative effects of moving to a new area, as extraverts are more likely to form social relationships in the new places (Oishi \& Schimmack, 2010).

This thesis explores if the size of the whole social network influences the association between extraversion and popularity. It examines this among the 
youth sample of seven- to eight-year-old children who are embedded in classroom social networks of varying sizes. Although the size of classroom does not appear to vary tremendously, even small differences in the number of pupils could introduce notable variance in the complexity of the social network. For example, in classroom of 15 pupils, there are 105 unique dyads in the social network, whereas in classroom of 25 pupils, the number of dyads is 300. Thus, the complexity, diversity, and opportunities are already drastically different in the normal range of sizes of elementary school classrooms, and these attributes of the social environment may influence the role of extraversion in social relations.

Given that extraversion is thought to be related to sensitivity to social rewards (Smillie, 2013) as well as to preference for social attention (Ashton et al., 2002), it could lead to higher attained popularity in larger social networks compared to smaller ones. Supporting this possibility, extraversion is known to be more strongly associated with social network size at the right tail of networks size distribution (Ishiguro, 2016), which indicates not only a linear association and preference for larger networks of extraverts (Jokela et al., 2008) but also that extremely high extraverts may prefer exponentially larger environments. This in turn could imply that such environments provide superior functionality for their characteristics. Finally, more expansive social ecologies provide higher relational mobility, i.e. more opportunities for solving and dissolving social ties (Oishi, 2014; Schug, Yuki, Horikawa, \& Takemura, 2009). In view of such possibilities, extraverts could be enabled to achieve popularity in a larger social network. However, there are no studies to date that have examined if extraverts are actually able to utilize these environments by attaining higher popularity in richer social environments. This thesis tests this possibility in the sample of first and second graders in classrooms of varying sizes. The military platoons were not used for this research question because the sample contained less variance in size and a lower number (12) of social network units (platoons).

\subsubsection{WHY IS EXTRAVERSION ASSOCIATED WITH POPULARITY?}

The why question refers to the underlying mechanisms of the association between extraversion and popularity. This can entail either a behavior that mediates this association, such as an ability for fluent communication, or how smaller social units, such as dyadic relationships, accumulate to produce the observed association between extraversion and popularity at a group level.

\subsubsection{Is the association between extraversion and popularity driven by dyadic combinations of extraversion?}

Although numerous studies have already observed the unilateral association between extraversion and popularity (Anderson et al., 2001; DesJardins et al., 
2015; Lubbers et al., 2006), its bilateral basis has not yet been extensively pursued. Thus, the extraversion-popularity link has been understood only as an association at the between-person level, so extraverts tend to receive higher levels of popularity among their peers. However, in groups, each dyadic interpersonal relationship is a smaller-scale social unit, and aggregating the dyadic preference across all dyads in which a person is a member comprises the popularity score of that individual. In other words, the popularity of an individual in a group is a sum of the received dyadic preference.

An evident property of each dyad in regard to the extraversion-popularity association is the combination of extraversion scores of the particular dyad. There are extravert-introvert, introvert-introvert, and extravert-extravert dyads, though most dyads consist of members who score somewhere between these polar opposites. It is feasible that the specific combination of the extraversion of the recipient and the sender of the interpersonal preference may influence whether, how much, and in which direction popularity particles are granted in that particular dyad.

There are also some theoretical reasons to assume that different types of dyadic combinations could contribute uniquely to aggregate popularity. At least two types of dyadic extraversion effects could result in extraverts (introverts) being admitted higher (lower) popularity. First, although homophily (i.e. similarity breeds attraction; McPherson, Smith-Lovin, \& Cook, 2001; T. M. Newcomb, 1956) in the general sense could not explain this observation, it could function as a mechanism under the higher popularity of extraverts if the homophily effect would be stronger among extraverts than among introverts - in other words, if extraverts would prefer each other more strongly than introverts prefer each other. Second, heterophily (i.e. opposites attract; Dryer \& Horowitz, 1997) could also account for this association, but only if introverts again systematically admit higher popularity to extraverts, and not vice versa. These asymmetric homo- and heterophily effects both have a theoretical basis but have not been previously studied, at least not with statistical methodologies that could be harnessed to reveal these patterns (Edwards \& Parry, 1993; Shanock, Baran, Gentry, Pattison, \& Heggestad, 2010). Although the propositions of homophily and heterophily are antithetical to each other, they both inform statements about the dyadic optimum of extraversion in terms of giving and receiving popularity particles. Although these effects are contradictory, these propositions are not mutually exclusive; they can also both be false in that popularity particles of extraversion do not have any dyadic optima. This situation refers to a simple target effect: extraverts receive more popularity independent of extraversion levels of the other dyad member. In addition to ignoring dyadic popularity particles, studies that have generally considered (dis)similarity attraction in extraversion have also thus far been absent, with a few exceptions reviewed below.

There is ample evidence of homophily in various types of characteristics, such as age, ethnicity, gender, religion, and education (McPherson et al., 
2001). However, evidence for personality traits has been notably weaker. Indeed, cases that have detected similarity-attraction effects have associated perceived similarity, not actual similarity, with attraction (Montoya, Horton, \& Kirchner, 2008). In the case of extraversion as well, the pattern of results has been mixed. This ambiguity may result from differences between perceived and actual measures of similarity (van Zalk \& Denissen, 2015), but even more pertinently, similarity effects have not been examined with statistical methods that are suitable for detecting these dyadic effects. A longitudinal study of university students has found that actual dyadic similarity in extraversion predicted friendship nominations during the first year (Selfhout et al., 2010). However, because similarity was operationalized as absolute difference in extraversion scores, it may not have been a sufficient test of the general similarity-effect (Edwards, 2002) and could have been indicative of some other type of dyadic effect rather than of similarity (Barranti, Carlson, \& Côté, 2017). Another study conducted with three different samples of adolescents and young adults has concluded that perceived similarity in extraversion predicted friendship formation, but actual similarity did not (van Zalk \& Denissen, 2015). This study also operationalized similarity as absolute difference scores that were scaled with the maximum of absolute differences in the data. Such an approach does not address the problems with difference scores in understanding whether similarity predicts preference (Edwards, 2001). In short, the problem is that using absolute difference scores as predictors indicate similarity effects only under particular combinations of its components' signs. It is not automatically the wrong way to examine similarity effects, but the assumed constraints are rarely tested or understood, possibly because of the intuitive appeal of difference scores.

Van Zalk and Denissen (2015) have also investigated whether homophily in perceived extraversion would be stronger at the extraverted pole of the continuum, but they did not find any support for this. Thus, although perceived dyadic combinations of extraversion were associated with reciprocated sociometric nominations, such combinations could not serve as particles for why extraverts tend to be more popular. However, this study also suffered from methodological limitations, i.e. the dyads were categorized based on extraversion scores. Categorizing continuous or non-categorical psychological constructs could be considered an even more problematic approach than utilizing absolute difference scores as indicators of dyadic similarity (Royston, Altman, \& Sauerbrei, 2006).

Fortunately, the methodological approaches of polynomial regression analysis and response surface analysis (RSA), which organizational psychology (Yang, Levine, Smith, Ispas, \& Rossi, 2008) commonly employs, have also been recently suggested for studies in personality and social psychology (Barranti et al., 2017; Nestler, Grimm, \& Schönbrodt, 2015). In polynomial regression followed by RSA, there is no need to compromise important variance and reduce statistical power by categorizing continuous variables, and the conjoint use of these methods offers liberation from the 
implicit assumptions that are embedded in the absolute difference scores (Edwards \& Parry, 1993; Edwards, 2001; Edwards, 2002). This statistical method is introduced in detail in the method chapters for Study II (and is also used in Study III).

Because there is little direct research on the presence of dyadic extraversion effects, other evidence needs to be considered. There are some reasons to assume that asymmetric homophily could be a more probable observation than asymmetric heterophily. Introverts are more sensitive to interpersonal traits in others and tend to rate extraverts more negatively during interaction (Erez, Schilpzand, Leavitt, Woolum, \& Judge, 2015). Based on this, it is less likely that extraverts would be more popular because of asymmetric heterophily (introverts admitting popularity to extraverts). However, asymmetric homophily could still be feasible, as similarities are especially attractive at the extraverted pole. The organizational psychology literature on leaders and followers could also provide hints regarding the dyadic patterns. One study has proposed that similarities in extraversion can lead to more pleasant psycho-physiological responses during developmental discussions between subordinates and managers (Salminen, Henttonen, \& Ravaja, 2016). Moreover, other studies that have examined dyadic effects in leader-follower pairs have suggested that extraverts could especially prefer other extraverts. For example, similarities in proactive personality (resembling extraversion) have been associated with higher job satisfaction and performance (Zhang, Wang, \& Shi, 2012). In that study, RSA was used to detect specific dyadic patterns, and it was revealed that proactive personality in general was associated with these outcomes. Asymmetric homophily effects were, however, not detected. Another, more general dyadic observation is that different followers like different leaders (Ehrhart \& Klein, 2001), which could imply either a stronger mutual preference among extraverts or introverts preferring extraverts. Finally, extraverts could especially benefit from cooperation with another extravert in the competition for within-group status (Lukaszewski \& von Rueden, 2015). Thus, of the possible dyadic combinations, extravert-extravert combination seems most likely to function as popularity particle. Studies II (1368 unique dyads) and III (4559 unique dyads) evaluate this possibility by using dyadic polynomial regression and RSA.

\subsubsection{Mediating mechanisms: oral fluency as a mechanism under extraversion-popularity association in middle childhood}

The why question in personality research is vital for comprehension of the processes through which personality is expressed (Back et al., 2011). It is especially important to illustrate that these manifest behaviors are those related to the outcomes of interest, especially when such outcomes are social and the manifest behaviors are socially relevant. This type of research aims to explain the mechanisms that function under the association of interest by mediation. In a statistical sense, a mediator for an association is a third 
variable that can be thought to result from the independent variable, and which explains variance in the outcome variable (Baron \& Kenny, 1986). Because extraversion is associated with a multitude of social behaviors and outcomes (Asendorpf \& Wilpers, 1998; Magee, Heaven, \& Miller, 2013; Oishi \& Schimmack, 2010; Ozer \& Benet-Martínez, 2006), there should be some behaviors that extraverts exhibit in these social situations to influence their surroundings.

In the particular case that this thesis examines, the proposed mediator between extraversion and popularity is oral fluency, i.e. ability for fluent oral communication. This mediator was selected for the following reasons. Several studies have demonstrated that manifest behaviors of extraversion are often related to some form of verbal communication. For example, extraverts tend to talk more (Mehl et al., 2006) and have a more implicit speech style, a higher speech rate, and less verbal hesitation in stressful situations (Dewaele \& Furnham, 1999; Dewaele \& Furnham, 2000). Observers can also detect extraversion from audio snippets (Borkenau \& Liebler, 1992; Scherer, 1978), and word use of several forms is also associated with extraversion (Mehl et al., 2006; Pennebaker \& King, 1999). In addition, extraversion is associated with performance in verbal fluency tasks in all age groups across the life span (Sutin et al., 2011), and individual differences in speech production could be especially pronounced during earlier developmental stages. Certain kids are more capable of fluent communication, which may be partially due to their sociable and assertive approach to the social world. Thus, oral fluency could be a significant mechanism during middle childhood in view of the proposed developmental and evolutionary purposes for this period in human ontogeny, i.e. the ability to navigate networks of multiple social relationships, reflection of self-worth in relation to others, and gathering acceptance among peers (Del Giudice et al., 2009; Harter, 1999).

However, in order for oral fluency to function as a mediator, it must be associated with popularity. Verbal abilities have been associated with peer popularity among five-year-olds (Braza et al., 2009). It has also been observed that children who are disliked in a group are not as capable as liked children of contributing to coherent conversation (Black \& Hazen, 1990). Disfluency of communication has also been associated with an inability to reconcile conflicted peer relationships among children (Horowitz, Jansson, Ljungberg, \& Hedenbro, 2006), and several studies have indicated that child observers rate disfluent targets more negatively regardless of whether the targets are other children (Evans, Healey, Kawai, \& Rowland, 2008), adults (Franck, Jackson, Pimentel, \& Greenwood, 2003), or puppets (Ezrati-Vinacour, Platzky, \& Yairi, 2001). In sum, because abilities relating to verbal communication are associated with popularity among peers, they could also serve as a mediator between extraversion and popularity.

In relation to behavioral manifestations of extraversion in the social domain, it has been suggested that the superior working memory of extraverts facilitates their fluent speech production (Lieberman, 2000; Pearman, 2009). 
Thus, working memory could impact the associations between extraversion, oral fluency, and popularity. For example, extraverts who are skilled in speech production as a result of a better working memory could evidence that oral fluency is not so much a socially important feature in the extraversion domain as much as it correlates with extraversion because of working memory. On the other hand, if extraversion would be associated with oral fluency even when controlling for working memory, it would imply that extraversion is associated with oral fluency for reasons other than working memory. One such reason could be extraverts' sensitivity to social rewards and approach orientation to the social world (Ashton et al., 2002; Smillie, 2013), as they ultimately spend more time with other people (Wilson, Harris, \& Vazire, 2015) and may consequently become more capable of speaking fluently. Such ability could be valuable for peer relations and attaining popularity. To reveal these patterns, working memory is an important covariate to examine the mediational pathway from extraversion to oral fluency to popularity. Study I evaluates this in the sample of children. Because there are several variables of interest (extraversion, oral fluency, popularity, and working memory), it is essential to demonstrate that mediation is not a mere artifact of shared measurement methods. This examination minimizes possibilities for shared methods since different informants and methods are used for each variable. 


\section{STUDY OBJECTIVE AND RESEARCH QUESTIONS}

The central aim of this thesis is to investigate the association between extraversion and popularity. The thesis consists of three studies that consider key questions regarding this association. Each study focuses on a different set of when and why research questions, with some questions examined in two separate studies.

\subsection{WHEN IS EXTRAVERSION ASSOCIATED WITH POPULARITY?}

1)

Is extraversion already associated with popularity in middle childhood? (Study I)

Adding to the life-span generalizability of the link between extraversion and popularity, Study I examines this association among the youngest population context to date: seven- to eight-year-old children. Previous studies have found support for this association among adolescents (Ciarrochi \& Heaven, 2009; Jensen-Campbell et al., 2002; Jensen-Campbell \& Malcolm, 2007; Lubbers et al., 2006; Scholte et al., 1997; van der Linden et al., 2010) and young adults (Anderson et al., 2001; Asendorpf \& Wilpers, 1998; Wortman \& Wood, 2011), but the sample in Study I is the youngest in which this association has been examined with a sociometric nomination procedure that is reflective of the general popularity of a person. Although extraversion is known to be associated with popularity in older age groups, the setting for the presence of this association in regard to social environments (i.e. classrooms) and observable personality characteristics (Lönnqvist, Verkasalo, \& Vainikainen, 2011) is already present at the beginning of the school year. Therefore, gaining popularity (or at least avoiding unpopularity) in such spontaneously forming system of social relations (Fournier, 2009) early in school could be influenced by extraversion.

2)

Is extraversion associated with popularity in understudied and less talk-oriented cultures as well? (Studies I and II)

Study II provides another extension to the when of the extraversionpopularity link by analyzing this association among military cadets and their platoon-mates. For generalizability of the claim that extraversion and peer popularity are correlated in peer groups, it is important to illustrate not only that this correlation is not dependent on age but also that it generalizes beyond the populations that psychological research typically uses, such as American 
psychology undergraduates with imbalanced gender ratios (Henrich et al., 2010). The environment of a military platoon provides a useful opportunity for this, and Study II investigates the association between extraversion and sociometric popularity within all-male military cadet platoons. Together with Study I, this is the first study to examine this association in Finland and Nordic countries. Therefore, the objective is also to examine if the stereotypically introverted and less talk-oriented culture influences this association.

3)

Dimensional continuity: Are extraverts popular or introverts unpopular? (Studies II and III)

When also refers to the location on the introversion-extraversion continuum. To be generalizable across an entire construct continuum, the association between extraversion and popularity should exist at both ends and in the middle of a continuum that spans from extreme introversion to extreme extraversion (Paunonen \& Hong, 2015). Studies II and III address this question by testing whether the association between trait introversionextraversion and peer popularity is linear or if there is curvilinearity in the association whereby introverts are not unpopular in the same way that extraverts are popular, or vice versa.

4)

Socio-ecological sensitivity: Does the number of peers in a social network influence the association between extraversion and popularity? (Study III)

Study III assesses the socio-ecological sensitivity of the extraversionpopularity association. It specifically tests if extraverts can attain increased popularity in the presence of a higher number of peers. The study explores the possibility of this socio-ecological sensitivity by determining whether the classroom size of first- and second-grade children moderates this association. The social centrality and attention gathering of extraverts (Ashton et al., 2002) could be especially functional in environments that contain a larger audience and less functional in environments with only a few available social partners. In addition, in larger classrooms, it is probably easier to switch between friends and peer groups, so individuals are not constrained to spending their time with the same group of classmates if they do not want to.

\subsection{WHY IS EXTRAVERSION ASSOCIATED WITH POPULARITY?}

5)

Do dyadic combinations of extraversion drive the association between extraversion and popularity? (Studies II and III) 
Studies II and III concern the interpersonal sensitivity of the extraversionpopularity link. Dyadic combinations of introversion-extraversion could serve as explanations for the popularity (unpopularity) of extraverts (introverts) on a group level. There are two contradicting propositions that both expect extraverts to be more popular since conferring popularity to others is also dependent on the extraversion of those admitting popularity (or personal preference) to others. First, it could be that individuals who are similar in extraversion prefer each other, and extraverts prefer each other even more strongly than introverts do (Selfhout et al., 2010; van Zalk \& Denissen, 2015). This association would be revealed by an asymmetric homophily effect (McPherson et al., 2001) that would be stronger at the extraverted end of the introversion-extraversion continuum. Second, extraverts could be more popular because introverts tend to prefer extraverts (Dryer \& Horowitz, 1997), but this reciprocity would only exist from introversion to extraversion, not vice versa. Both propositions can be analyzed and demonstrated through polynomial regression analysis accompanied by RSA (Edwards, 2002), a statistical method that has not been previously used for dyadic personalitypopularity examinations.

Is extraversion associated with popularity because of the higher oral fluency of extraverts? (Study I)

Study I explores the potential mediating mechanism that underlies this association. In studies of the social consequences of personality, it is important to understand the processes of specific mediating mechanisms between personality traits and the social domain. The proposed mediator that intertwines in the process from extraversion to popularity in peer system is oral fluency, i.e. the capacity for fluent verbal communication. The potency of this mediator is likely to be strong among the young cohort in Study I (sevento eight-year-old children), which is likely to present individual differences in oral fluency. 


\section{STUDIES}

\subsection{STUDY I}

The purpose of this study is to test the association between extraversion and popularity in a youth sample of seven- to eight-year-old children in first and second grade of elementary school (research question 1). Moreover, it examines whether oral fluency mediates the association between extraversion and popularity (research question 6). The same participants are also involved in Study III of this thesis but are presented separately since the employed sample varies slightly as a result of different sets of variables in the analyses.

\subsubsection{METHODS}

\subsubsection{Participants and procedure}

The sample consisted of 760 children from 38 school classrooms. All subjects participated in the sociometric nomination procedure. Parent-provided personality ratings were available for 595 children, and teacher-provided ratings of children's oral fluency was available for 550 subjects. In addition, the working memory measure that was a control variable in the study was available for 699 subjects. Personality, oral fluency, and working memory were measured around half a year into the first grade, at age 7. Popularity was assessed via sociometric nominations one year later, when children were 8 years old.

\subsubsection{Measures}

Parents rated the children on 27 personality descriptive items on a scale from one to seven. The measure of extraversion was constructed as a factor score based on the previously published factor solution (see Table 1 in Lönnqvist et al., 2011). In this solution, extraversion was the broadest factor that explained more variance than other traits. Additionally, teacher ratings of personality were available for the subjects, but the study did not consult these ratings because of overlapping method variance with the measures of oral fluency and academic skills.

Teachers assessed the oral fluency, writing, reading, and mathematical skills of each child on a scale from one (the pupil has obvious difficulties) to seven (the pupil is clearly above the developmental norm).

Sociometric nominations were used for measuring the sociometric popularity of the children. Three nominations were given: "With whom of your 
classmates do you prefer to... 1. Work in class? 2. Spend time with between classes? 3. Spend time with after school/spend leisure time with?" Nominations were limited to five per item, and nominations of the same peer across different questions were permitted.

Working memory was measured by a count task that was conducted in the classroom. The teacher tapped his or her desk with pencil, knuckle, or palm, and the subject wrote down the number of knocks he or she heard. This measure of working memory was focused on short-term auditory memory. In total, there were 30 series of one to five taps in total, and each was coded on a pass-fail basis (o or 1). Thus, the total scores ranged from o to 30 but were highly skewed to the left, so a rescaled version of the variable was applied (as presented in Lönnqvist, Vainikainen, \& Verkasalo, 2012).

\subsubsection{Statistical analysis}

The model in Figure 1 was fitted to the data with structural equation modeling package Lavaan (Rosseel, 2012) in R version 3.0.2. Because certain variables had missing values, a full information maximum likelihood estimation was used. Popularity was constructed as a latent variable on which each of the three received nomination variables was loaded. In addition, academic skills was also modeled as a latent variable on which teacher-rated writing, reading, and mathematical skills were set to load. In this structural path model, the associations between extraversion, oral fluency, and popularity were controlled for working memory as well as for academic skills. The model fit was examined from a comparative fit index (CFI), Tucker-Lewis Index (TLI), root mean square error of approximation (RMSEA), and standardized root mean square residual (SRMR). All variables except for parent-rated personality traits were standardized to classroom means prior to analysis in order to control for teachers' rating bias and manner of test administration. From the model, it was assessed whether parent ratings of extraversion at age seven were associated with latent popularity based on received sociometric peer nominations at age eight (research question 1). In addition, it was determined if extraversion was also associated with oral fluency (path a), if oral fluency was also associated with popularity while controlling for extraversion (path $b$ ), and if the product of these paths would be indicative of mediation (research question 6). Because the sampling distribution for Sobel's test of the indirect effect $\left(\mathrm{a}^{*} \mathrm{~b}\right)$ is skewed, the data were resampled 5,000 times (bootstrap resampling) to construct the population distribution of the indirect effect (Preacher \& Hayes, 2008). The indirect effect was considered significant if the bootstrapped $95 \%$ confidence interval did not contain zero. 


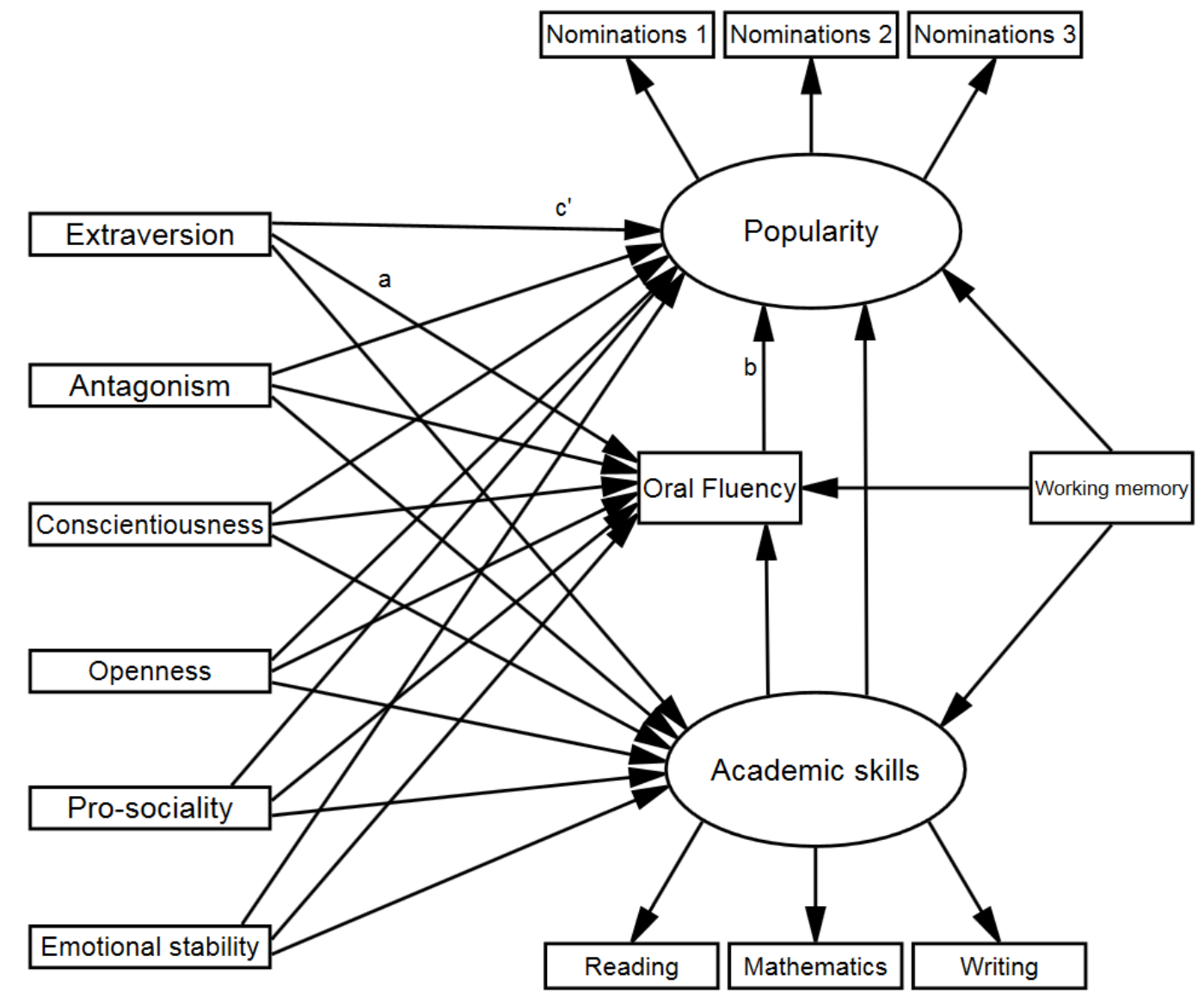

Figure 1 Structural path model from Study I

\subsubsection{RESULTS}

The direct association between extraversion and popularity was controlled for five other personality traits (antagonism, conscientiousness, openness, prosociality, and emotional stability) as well as for oral fluency, academic skills, and working memory (Figure 1). The model reflected acceptable fit to the data $(C F I=.98, T L I=.96, R M S E A=.04, S R M R=.026)$. Parameter estimates and tests of significance revealed that extraversion was associated with sociometric popularity in this sample of seven- to eight-year olds $(\beta=.14, p<.01$; zeroorder correlations between each of the nomination variables ranged from .10 to $.14, p<.05$ for all, indicating that the association was independent of nomination item and context).

Next, it was examined if oral fluency would mediate the association between extraversion and popularity. This effect was assessed from the same structural equation model as for research question 1 (Figure 2). Thus, the mediation was controlled for five other personality traits (antagonism, conscientiousness, openness, pro-sociality, and emotional stability) as well as for academic skills and working memory. In the model, alongside direct effect from extraversion to popularity, the path from extraversion to oral fluency was 
also significant $(\beta=.13, p<.01)$. Moreover, oral fluency was also associated with popularity ( $\beta=.16, p<.01)$, and Sobel's test and bootstrapped redraws from the data indicated a significant mediation for oral fluency between extraversion and popularity (estimate: .020, $p<.05$; 95\% confidence interval from .005 to .040). In addition, although working memory was directly associated with popularity $(\beta=.12, p<.01)$, oral fluency $(\beta=.12, p<.01)$, and academic skills $(\beta=.23, p<.001)$, it did not affect the associations between extraversion, oral fluency, and popularity. Thus, working memory did not impact the link between extraversion and popularity.

\subsubsection{DISCUSSION}

Study I evidences an association between extraversion and popularity among seven- to eight-year-old children that is mediated by oral fluency. Thus, even among young Finns, extraversion is associated with social popularity, and one reason that extraverts are more popular is their superior oral fluency at the beginning of elementary school.

The finding that the association between extraversion and popularity is also present in the young population of seven- to eight-year-old children extends previous findings for adolescence (Ciarrochi \& Heaven, 2009; JensenCampbell et al., 2002; Lubbers et al., 2006; Scholte et al., 1997; van der Linden et al., 2010) and young adulthood (Anderson et al., 2001; Asendorpf \& Wilpers, 1998; Stopfer et al., 2013; Wortman \& Wood, 2011) to the beginning of middle childhood. Because there are already selection effects for social environments and positions at this age, such initial selectivity can also have a long-lasting influence throughout development, as sociometric popularity tends to be relatively stable in childhood (Jiang \& Cillessen, 2005). Because there are several positive outcomes related to within-group status (von Rueden, 2014) this could mean that the initial attainment of popularity could cumulatively bear fruit for extraverts later in development as well (DiPrete \& Eirich, 2006). Thus, initial extraversion could be pronouncedly important. In more descriptivist terms, certain features in the domain of extraversion could provide desirable developmental pathways, and an ability to communicate fluently (research question 6) could be one such feature.

In addition, the pattern of associations between extraversion, oral fluency, and popularity was independent of working memory, which indicates that the higher oral fluency of extraverts could result from a higher amount of accumulated experience in social interaction. This would further situate reward sensitivity (Smillie, 2013) and seeking social attention (Ashton et al., 2002) as central features in the domain of extraversion. If such features would be functionally important for explaining this pattern, then the strong approach and motivation of extraverts toward the social world, whereby they ultimately learn to speak fluently at a relatively early age, is significant to understand why extraverts are more popular. It is important to note that the association between extraversion and popularity was not fully mediated, as indicated by 
the significant direct path from extraversion to popularity ( $c^{\prime}$ in Figure 1). Therefore, as may be expected, there are also other mediators for this association.

\subsection{STUDY II}

The purpose of this study is to determine if the extraversion-popularity correlation also generalizes to an all-male Finnish military cadet sample (research question 2). Moreover, this study examined the dimensional continuity (research question 3) and interpersonal sensitivity (research question 5) of the extraversion-popularity association with polynomial regression analysis followed by RSA. This method, which Study III also employed, is explained in detail below (Chapter 3.2.1.3).

\subsubsection{METHODS}

\subsubsection{Participants and procedure}

Subjects were 185 male military cadets (mean age 22) who were members of 12 platoons in the officer-training program at the National Defence College in Helsinki, Finland. All cadets in a platoon live, work, and study in the same facilities. The data were collected during one session, which was held in a large lecture hall and lasted less than two hours. Each cadet filled out a self-report questionnaire and received a sealed envelope. After completing the questionnaire, cadets were instructed to open the sealed envelope, which contained a list of each cadet's platoon-mates. Cadets were instructed to rate each platoon-mate ( 13 to 20 peers per rater) on the list in regard to whether he liked or disliked that person.

\subsubsection{Measures}

Extraversion according to the FFM (extraversion, agreeableness, conscientiousness, neuroticism, and openness to experience) was measured by Finnish translation of NEO-FFI (Costa \& McCrae, 1992). The extraversion measure contains 12 items, and each item is addressed on a five-point rating scale.

Popularity was measured by platoon-mates' ratings. Cadets rated all of their platoon-mates on a single visual analogue scale that was a line with 0,10 , $20, \ldots, 100$ evenly spaced beneath it. The midpoint (50) had a verbal anchor "average for the group," while the left side was labeled with "below the group average" and the right side with "above the group average." For each peer, cadets drew a slash through the line to indicate their preference for that 
specific peer. The specific instruction was, "he is a person with whom you would like to spend time." All platoon-mates were rated on the same line, and no ties were allowed. A popularity score for each rating was derived from the distance to the origin in terms of millimeters (range from o to 231, $M=129.4$, $S D=55.9)$.

\subsubsection{Statistical analysis: Polynomial regression analysis and RSA with the social relations model}

Study II investigates the association between extraversion and sociometric popularity among military cadet platoon-mates in a polynomial regression model, whereby the linear target effect ( $b 2$ in Equation 1 presented below) is indicative of this association. The parameter estimate for the target demonstrates how strongly the popularity is associated with levels of extraversion.

The polynomial regression analysis was conducted within the social relations model (SRM) framework (Kenny, Kashy, \& Cook, 2006). Therefore, random intercepts were modeled for perceiver (variance in preference ratings across perceivers) and dyad (variance in preference ratings across dyads, also indicating within-dyad reciprocity in preference ratings) in addition to target (variance in preference ratings across targets). Prior to entering dyadic extraversion variables as predictors in the model, the null SRM without predictors was examined to conclude how much of the variance in the popularity ratings is between perceivers, targets, and dyads, respectively (Kenny et al., 2006).

The question of whether dyadic combinations of extraversion serve as popularity particles was addressed with polynomial regression analysis followed by response surface methodology (Barranti et al., 2017; Edwards \& Parry, 1993; Edwards, 2002; Schönbrodt, 2016b; Shanock et al., 2010). Based on the contradictory theoretical views, which are founded on the idea that similarities and differences in extraversion are important (homophily; Selfhout et al., 2010; van Zalk \& Denissen, 2015) (heterophily; Dryer \& Horowitz, 1997), it could be intuitively assumed that examining dyadic difference scores in extraversion (i.e. absolute difference scores or squared difference scores) and correlating these on sociometric nominations would provide an answer to this question. However, difference scores introduce strong assumptions about the shape of such correlation that remain untested in difference score approaches (Barranti et al., 2017; Edwards, 1994, 2001). Dyadic polynomial regression is a method that may produce results that are similar to those from the use of difference scores in some cases but without implicit constraints in the regression model. Thus, it may simultaneously analyze the various types of dyadic combinations alongside sender and target effects. In addition, this approach can also assess the possibility of asymmetric dyadic homophily or heterophily effects as indicators of popularity particles. For example, it is feasible that nominations are influenced by a target's 
extraversion as well as by dyadic similarities (or dissimilarities) in extraversion. A regression model with an absolute difference score could only reveal such pattern in the event that the regression weights of both components that compose the difference score are of same sign; even in such case, it may not be a straightforward indication of similarity (Edwards, 2001, 2002). More importantly, using absolute difference scores does not enable an examination of asymmetric (dis)similarity-attraction patterns that polynomial regression models fully enable. Indeed, polynomial regression analysis followed by a statistical and visual inspection of three-dimensional response surfaces is suitable for revealing all types of patterns in the associations of dyadic combinations with popularity nominations. Therefore, it is appropriate choice of method to explore if the extraversion of peers systematically moderates the association between extraversion and popularity.

The general case of a polynomial regression model that this thesis employs is second-degree dyadic polynomial regression. In the model, popularity (given by sender, received by target) is regressed on extraversion of sender (EXs), extraversion of target $\left(\mathrm{EX}_{\mathrm{T}}\right)$, square of sender's extraversion score $\left(\mathrm{EX}_{\mathrm{S}^{2}}\right)$, square of target's extraversion score $\left(\mathrm{EX}_{\mathrm{T}^{2}}\right)$, and the interaction between sender's and target's extraversion $\left(\mathrm{EX}_{\mathrm{S}} \times \mathrm{EX}_{\mathrm{T}}\right)$. This general case indicates that no constraints are imposed on the dyadic combinations of extraversion, and therefore the regression weights for each variable are examined separately in the same model (see Edwards \& Parry, 1993; Edwards, 1994; Schönbrodt, 2016b for which types of constraints difference scores impose on a statistical model and how to analyze these). Because the modeling approach is dyadic, whereby each target is rated or has the potential to be nominated by multiple senders and each sender rates or has the possibility to nominate multiple targets, it is important to control for general sender and target propensities for rating and nominating. In addition, because of dyadic reciprocity, i.e. the ratings and nominations are often more similar to both directions between person $\mathrm{A}$ and person $\mathrm{B}$, dyadic tendencies in rating and nominating warrant inclusion in the model as well. This is a special case of SRM (Kenny et al., 2006) that utilizes polynomial regression parameters as predictors. Equation 1 gives the general dyadic polynomial regression model for preference $(Y)$ given by sender $\mathrm{i}$ to target $\mathrm{j}$ : $t+u+v+e$

where $b o$ is the intercept, $b 1$ is the term for sender effect, $b 2$ is the term for target effect, $b_{3}$ is the term for squared sender effect, $b_{4}$ is the interaction term, $b_{5}$ is the term for squared target effect, $t$ is random effect for sender, $u$ is random effect for target, $v$ is random effect for dyad, and $e$ is residual.

The parameters estimated ( $b 1$ to $b_{5}$ ) for different extraversion variables ( $E X_{S i}$ indicating extraversion of sender $\mathrm{i}$, and $E X_{T j}$ indicating extraversion of target $\mathrm{j}$ ) are employed in the RSA following the dyadic polynomial regression 
analysis. The response surface refers to a three-dimensional surface on which an outcome fluctuates as a result of two variables that represent the same construct in some way (Barranti et al., 2017). It extends to the polynomial regression analysis to ensure that the variables are the same, but it provides a more comprehensible, interpretative framework to investigate which kind of dyadic combinations in extraversion, if any, are associated with popularity particles at the dyadic level.

a)

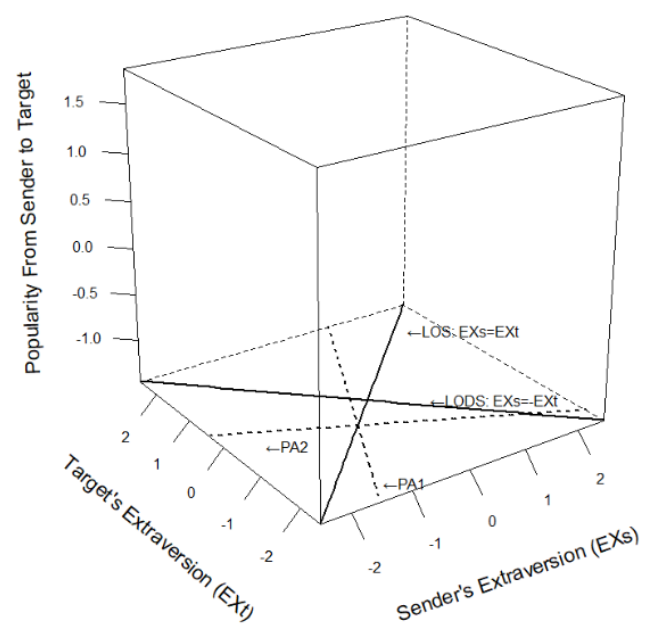

b)

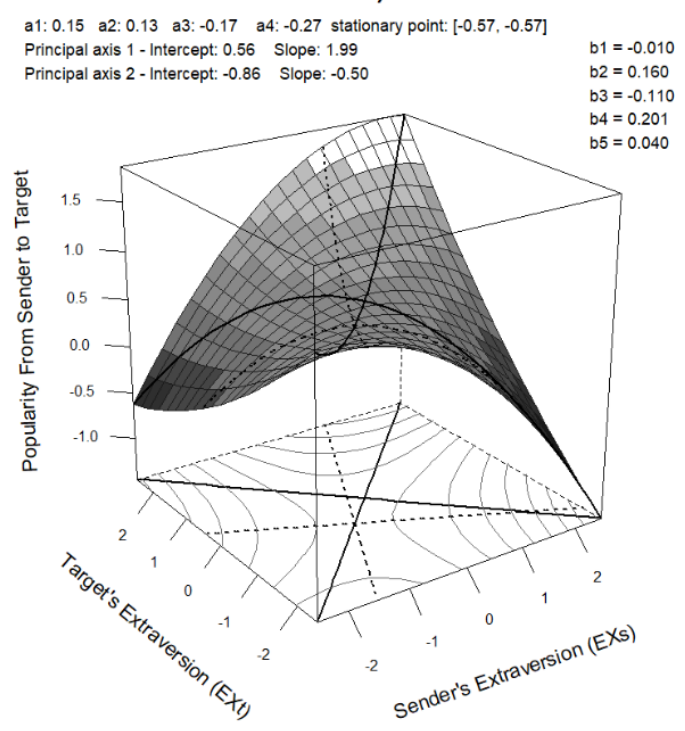

Figure 2 Example of utilizing three-dimensional response surface for testing patterns from dyadic polynomial regression analysis

There are several central, testable properties of response surfaces that are key for understanding how dyadic characteristic may influence an outcome. Figure 2a presents a response surface plot without the actual response surface to demonstrate the lines of interest. Figure $2 b$ demonstrates the actual response surface from the same analysis. In Figure 2a, the solid lines projected on the floor of the figure represent the line of similarity (LOS), along which the sender and target extraversion match exactly $\left(\mathrm{EX}_{\mathrm{S}}=\mathrm{EX}_{\mathrm{T}}\right)$. Perpendicular to LOS and crossing it at the origin is another solid line, the line of dissimilarity (LODS), along which the sender and target extraversion have the same values, but of opposite signs $\left(\mathrm{EX}_{\mathrm{S}}=-\mathrm{EX}_{\mathrm{T}}\right)$. The LOS and LODS are theoretical lines that do not vary based on data; they always indicate locations on the surface that signify similarity or dissimilarity. Crucially for questions regarding dyadic combinations, the observed data may warrant examination of the response surface along these lines. However, this needs to be tested prior to these interpretations (Edwards, 2002). The dashed lines in Figure 1a represent 
principal axes of the response surface that vary as a function of data, intersect at the stationary point of the response surface (in Figure 2a, around -0.57 for both sender and target), and represent the general orientation of the surface. In the case that the first principal axis (PA1) is orientated along LOS, the intercept (where PA1 crosses the $\mathrm{EX}_{\mathrm{T}}$-axis) is zero, and the slope is one. Significant to the interpretation of response surfaces, if PA1 deviates from these values, the response surface cannot be interpreted based on the parameters along LOS and LODS. However, if PA1 does not significantly deviate from LOS, the interpretation of the fluctuation of the surface along LOS and LODS is warranted.

When interpretation along LOS and LODS is warranted, the parameters of interest for LOS and LODS are slopes and curvatures along these lines. Figure $\mathrm{2b}$ depicts the response surface and demonstrates how the popularity from sender to target varies as a function of the target's extraversion, the sender's extraversion, and combinations of their extraversion scores. Solid lines again represent LOS and LODS, and dashed lines represent PA1 and PA2. Slope and curvature determine the shape of the surface along each of these lines. Along LOS and LODS, these parameters also have straightforward interpretations. Slope along LOS (a1) is given by $a 1=b 1+b 2$ and indicates how much the surface rises or declines as a function of dyadic extraversion as a combination (additively). Curvature along LOS (a2), given by $a 2=b_{3}+b_{4}+b_{5}$, indicates whether this line has a curvature by which the additivity is accelerated, slowed down, or both at certain points of the LOS. In Figure $2 b$, the function for the shape of the surface along LOS, $a_{1}+a 2$, is $0.15{ }^{*} \mathrm{EX}_{\mathrm{S}}+0.13{ }^{*} \mathrm{EX}_{\mathrm{s}}{ }^{2}$ (because this is LOS, $\mathrm{EXS}_{\mathrm{S}}=\mathrm{EX}_{\mathrm{T}}$ ). This indicates that extraversion is associated with popularity as well as that such association accelerates toward the extraverted end of the introversion-extraversion continuum and slows toward the introverted end, thereby rendering no association between the trait and the outcome at the low end. Slope and curvature parameters along LODS are known as $a_{3}$ and $a_{4}$. Slope along LODS is given by $a_{3}=b_{1}-b_{2}$ and indicates whether the outcomes increase and decline because of the distance between the sender's and the target's extraversion. Curvature along LODS, $a_{4}=b_{3}-$ $b_{4}+b_{5}$, reflects how much deviation from similar extraversion scores in either direction increases (if positive) or decreases (if negative) the outcome. This parameter is often most interesting in studies of (dis)similarity, wherein negative values for $a_{4}$ indicate that the highest values along the response surface occur when dyad members are more similar. Nevertheless, before examining whether such effect is indicated by a4, it is important to assess whether the principal axes do not deviate significantly from LOS and LODS. In Figure 2b, the function of the surface along LODS is $-0.17^{*} \mathrm{EX}_{\mathrm{s}}-0.27^{*} \mathrm{EX}_{\mathrm{s}^{2}}$, which demonstrates that the distance between the sender's and the target's extraversion decreases popularity (lower values when distance is higher), and there is a negative curvature whereby the surface has the highest values around the middle areas, thus indicating a similarity effect. In the Figure 2 examples, however, the principal axes are not precisely aligned with LOS and LODS. For 
example, the intercept and slope of the first principal axis are 0.56 and 1.99, respectively, which conveys that the surface is maximized along a line (PA1) that crosses the target's extraversion axis at 0.56 of the sender's extraversion, and which increases 1.99 units of the target's extraversion per one unit of the sender's extraversion. Thus, the popularity surface is maximized along a line that is, to some degree, indicative of a similarity effect, but which is weighted to achieve the optimum for popularity when targets have twice the amount of extraversion as senders. In practice, however, the rotation of the surface must be statistically tested, and if principal axes do not deviate from LOS and LODS, more straightforward interpretations along these lines are warranted.

Finally, for analyses of asymmetric (dis)similarity effects, third-degree polynomials of the sender's and target's extraversion are also entered in the dyadic polynomial regression equation: $b_{6} E X_{S i}^{3}+b_{7} E X_{S i}^{2} \times E X_{T j}+b_{8} E X_{T j}^{2} \times E X_{S i}+b_{9} E X_{T j}^{3}+t+u+v+e$

where terms $b 6, b 7, b 8$, and $b 9$ are the third-degree polynomials, and other terms are identical to the terms in Equation 1.

The third-degree polynomials are not of interest per se, but their addition allows for relaxation of the constraint that homophily or heterophily effects indicated by $a_{4}$ are of equal magnitude across the entire surface. Because it is especially relevant at which areas $a 4$ is significant, LODS is replaced by a line that is parallel to it but is positioned at distance $d$ from the LOS. This $d$ is also directly interpretable from extraversion levels of sender and target with Equation 3.

$$
d=\left(E X_{S}+E X_{T}\right) / \sqrt{2}
$$

By changing the value of $d$, it is possible to estimate $a 4 d$, which is given by Equation 4 .

$$
a_{4}(d)=b_{3}-b_{4}+b_{5}+b_{7} d-2 b_{8} d+3 b_{9} d
$$

Equation 5 gives the standard error for this curvature. 


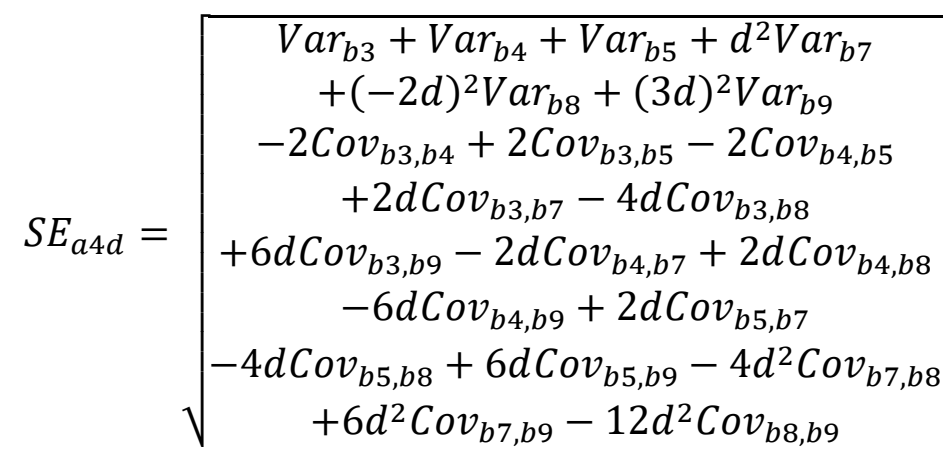

where Var and Cov terms can be extracted from the variance-covariance matrix of the parameter estimates in any third-degree polynomial regression model.

In addition to examining dyadic extraversion as a popularity particle, dyadic polynomial regression analysis also provides answers to questions of the dimensional continuity of the extraversion-popularity association. As a byproduct of the second-degree polynomial equation that yields response surface parameters, it is also possible to examine the curvilinearity of the association simply between the target's extraversion and popularity. Accompanying the linear target effect $b 2$ with the quadratic target effect $b_{5}$ reveals the shape of the association between extraversion and popularity. For example, a positive linear association accompanied by a positive quadratic association would indicate increased strength in the association at the extraverted end of the continuum and a decreased strength of the association at the lower end of the continuum. If a positive linear association is accompanied by a negative quadratic association, then the strength of the association is stronger at introverted end (but still positive so that increases in extraversion matter especially around the lower end) and weaker at the extraverted end. The equation for the association between extraversion and popularity could then be extracted from the total polynomial equation for popularity of target $j$,

$$
Y_{j}=b_{0}+b_{2} E X_{T_{-} j}+b_{5} E X_{T_{-} j}^{2}+u+e
$$

where $b o$ is the intercept, $b 2$ is the term for linear target effect, $b 5$ is the term for squared target effect, $u$ is random effect for target, and $e$ is residual.

In the case that $b_{5}$ is significant, it is further determined where the association is significant and its strength at various points along the trait continuum (for example, one standard deviation below and above the mean). The Johnson-Neyman technique for models with curvilinear effects estimates this area of significance (Miller, Stromeyer, \& Schwieterman, 2013). In this approach, boundary values for the target's extraversion for which the association is significant are given by selecting the critical t-value based on the degrees of freedom in the model. If the critical values for extraversion are outside the range of the data, the simple slope is either significant or nonsignificant across the entire range of the data. If only the other value is within 
the data, then the association is significant only at a certain range within the data. Finally, if both values for extraversion fall inside the data, then there are changes in the significance of the effect from significant to non-significant and back to significant, or to an opposite pattern (Miller et al., 2013).

All SRM and polynomial regression analyses in Study II were run with the lme4 package (Bates, Maechler, Bolker, \& Walker, 2015) in R version 3.1.o. In addition, an RSA package was employed to plot the response surfaces (Schönbrodt, 2016a). Study III of this thesis also utilized both methods, with certain differences in the modeling of the dependent variable.

\subsubsection{RESULTS}

The model without predictor variables indicated that $30 \%$ of the variance in preference ratings was between targets, thereby justifying the investigation of the association between the target's extraversion and his average preference among platoon-mates. In addition, 30\% of the variance occurred between dyads, and $5 \%$ was present between perceivers. Entering extraversion variables into the model revealed a significant target effect ( $b 2=9.90, p<$ .001). The effect size for target extraversion in the fully standardized version of the model was estimated to be $b 2=.18$.

The squared term for the target's extraversion was not significantly associated with the average preference conferred by platoon-mates (unstandardized $b_{5}=-0.89$, standardized $b_{5}=-0.02$, for both $p=.365$ ).

The general orientation of the surface, based on the intercept and slope of the first principal axis, was along and around LOS and LODS, $p 1 O=2.72,95 \%$ CI $[-16.00,18.95], p 11-1=0.46,95 \%$ CI $[-5.61,11.68]$. However, because the slope for the principal axis also did not deviate from zero, $p 11=1.45,95 \% \mathrm{CI}$ $[-4.61,12.68]$, it already indicated that there are no similarity or dissimilarity effects in the data. This was further supported by the observation that the curvature along the line of dissimilarity was non-significant, $a 4=-2.83, p=$ .134. Because the interaction term was also independently non-significant, $b 4$ $=1.76, p=.114$, more specific (mis)matched patterns were also absent. Moreover, the tests for algebraic distance between the perceiver's and the target's extraversion scores also failed to support dyadic effect: perceiver effect had same sign as target effect and was also non-significant, $b 1=1.27, p=.359$, based on which the additivity along LOS, $a 1=11.17, p<.001$, was only fueled by the target effect, which was supported also by a significant slope along LODS (directly interpreted as the difference between target and perceiver effects), $a_{3}=-8.60, p=.002$. Thus, it was concluded that only the target's extraversion was associated with popularity. Figure 3 a presents the response surface based on the second-degree polynomial regression. 

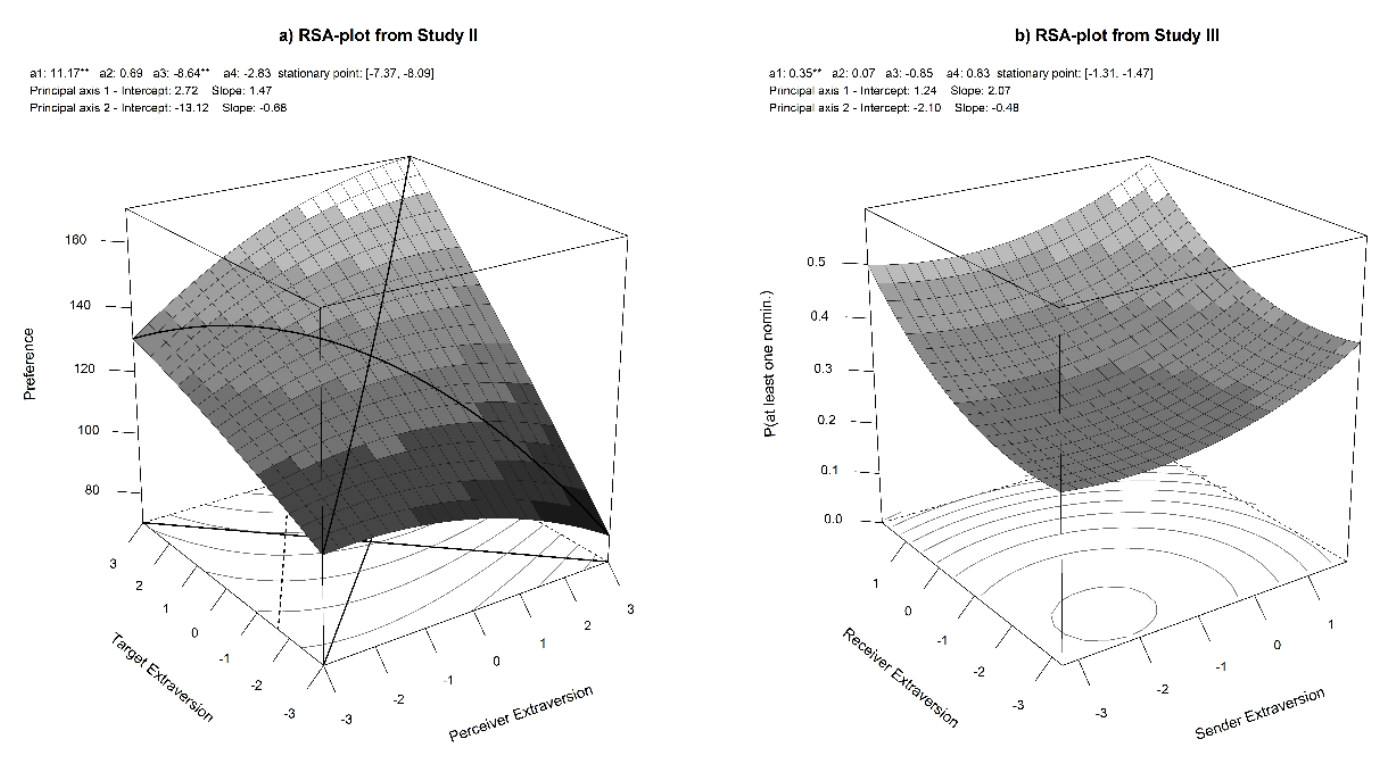

Figure 3 Response surface plots from Study II (a) and Study III (b).

\subsubsection{DISCUSSION}

Study II supports the generalizability of the extraversion-popularity association to the population of Finnish male military cadets (research question 2), and the lack of curvilinear association supports the dimensional continuity of the association (research question 3). In addition, the association was found to be unilateral, i.e. there were no dyadic combinations of extraversion that contributed to overall popularity scores (research question 5).

It initially seemed plausible that extraverts in Finnish culture, which is both stereotypically introverted (Realo et al., 2009) and empirically silent (Tryggvason, 2006; Tulviste et al., 2003), would not be liked as much as in other countries, or even that introverts would be more popular than extraverts. However, the findings of Study II have replicated results obtained in the United States (Anderson et al., 2001; Jensen-Campbell \& Malcolm, 2007) in noting a positive association between extraversion and popularity. Interestingly, other correlates of extraversion have been evidenced to be less culturally invariant. For instance, the association between extraversion and life satisfaction may be present only in North America (Kim et al., 2017). Of course, a wider range of cultures, and non-WEIRD cultures in particular, should be considered in order to more rigorously test this cultural invariance in the future.

In sum, the results from Study II suggest that the association between extraversion and popularity is linear and only dependent on the extraversion 
of the target person, for whom the dyadic preferences in a group accumulate to a higher popularity score.

\subsection{STUDY III}

This study concerned dimensional continuity (research question 2), interpersonal foundations of extraversion-popularity association (research question 5), and sensitivity of the association with classroom size (research question 4). Each questions was answered from the same set of polynomial regression analyses followed by RSA that was introduced in detail in the method section of Study II (Chapter 3.2.1.3.). However, the dependent variable was different, and the method section of this study separately explains the baseline variance component model.

\subsubsection{METHODS}

\subsubsection{Participants and procedure}

The subjects and measures were identical to those in Study I with the exception of stronger limits for the dyadic approach to this question and the RSA methodology to reach statistical convergence. The multilevel approach, including random components for receivers, senders, dyads, and classroom, specifically demanded that both members of a given dyad have data on all measured variables (Study III also included measures of cognitive ability). Moreover, the low number of participants who adhered to these criteria led to the elimination of six smaller classrooms from the dataset for the analysis. The final sample consisted of 549 children ( 280 girls) in 32 classrooms.

\subsubsection{Measures}

The personality rating procedure was same as in Study I. Parents rated the children on 27 personality descriptive items on a scale from one to seven. The measure of extraversion was constructed as a factor score based on the previously published factor solution (see Table 1 in Lönnqvist et al., 2011).

The sociometric nominations derived from the procedure for Study I were employed as dyad-level measures for each sender-receiver pair (in both ways) to indicate the number of nominations that sender $\mathrm{A}$ assigned to target $\mathrm{B}$. This number was a four-category ordinal measure (from one to three). In total, there were 9,118 sender-target combinations in the data, of which $75 \%$ contained no nominations, $7 \%$ contained one, $7 \%$ contained two, and $11 \%$ 
contained all three nominations (class work, recess time between classes, and leisure time outside the immediate school environment).

Classroom size was simply the number of children in the class. All children in the class were included in the determination of classroom size, regardless of whether such children were missing data for some variables. Class sizes ranged from 14 to $28(M=20.75, S D=3.38)$. The distribution of class size did not deviate from normal (Shapiro-Wilk statistic $=0.97, p=.57$ ).

\subsubsection{Statistical analysis}

The dyadic polynomial regression analysis followed by RSA that the method section of Study II outlines was used for statistical analysis. Because the dependent variable (number of nominations from sender to target) is ordinal, a cumulative logit link mixed model (Christensen, 2015) was applied to model the social relations structure (Kenny et al., 2006) in the nomination data.

The socio-ecological sensitivity of the link between extraversion and popularity was assessed via an extension of the polynomial regression equation to include polynomial regression parameters moderated by classroom size. For each polynomial regression parameter (b1 to $b_{5}$ ), a moderated version of the same parameter was added to the model ( $b 1 M$ to $\left.b_{5} M\right)$. Alongside analysis of whether extraversion has a stronger or weaker effect on received nominations in larger and smaller classrooms, this model would also reveal whether classroom size influences the dimensional continuity of the extraversion-popularity link or the effects of various types of dyadic combinations of extraversion, although not delineated as separate research questions.

\subsubsection{RESULTS}

In the model that included only control variables (gender and classroom size) as predictors, most variance in the nominations was between dyads (variance component 3.10), though some variance was also found between senders (0.42) and targets (0.92). There was no between-class variation in the probability to give and receive dyadic nominations.

In the second-degree polynomial regression model, the squared term for the target's extraversion was not significantly associated with receiving sociometric nominations ( $\log$ odds for receiving nominations in the next category from o to 1,1 to 2 , and 2 to 3 ), $b_{3}=0.03, p=.535$. The general orientation of the surface was along the LOS and LODS, $p 10=1.24,95 \%$ CI [$75.91,73.59], p 11-1=1.07,95 \%$ CI $[-15.04,12.72]$. However, similarly to Study II, the slope for the principal axis also did not deviate from o, $p 11=2.07$, 95\% CI [-14.04, 13.72]. Thus, there were no similarity or dissimilarity effects, as the non-significant curvature along LODS also demonstrates, $a 4=.083, p$ $=.497$. The interaction term was non-significant as well, $b 4=-0.01, p=.943$, 
thus indicating an absence of mismatch effects. Finally, the algebraic distance between the sender's and the receiver's extraversion was not associated with sociometric nominations, $a_{3}=-0.08, p=.275$. Still, the response surface parameter for linear additivity along LOS was statistically significant, $a 1=$ $0.34, p=.006$, whereas the curvature along LOS was not, $a 2=0.07, p=.556$. Because there was linear additivity and no differences between sender and receiver effect, as indicated by non-significant $a_{3}$, the extraversion of both sender and receiver contribute to giving and receiving sociometric nominations. However, this effect is merely additive and does not indicate that dyadic combinations matter - only that there are independent effects for sender and target. Figure $3 \mathrm{~b}$ presents the response surface for probability of at least one dyadic nomination (out of three possible) from sender to target as a function of dyadic extraversion.

Adding moderated polynomial regression parameters did not improve the model, $(-2 \log$ Likelihoodnon-moderated $)-(-2 \log$ Likelihood moderated $)=\Delta \chi^{2}=3.04$, $d f=5, p=.694$. In addition, all the moderated polynomial regression parameters (b1M to $\left.b_{5} M\right)$ were non-significant, $p \geq .162$ for all. Moderated effects were also separately calculated for slope and curvature along LOS (a1M and $a_{2} M$ ) and for slope and curvature along LODS ( $a_{3} M$ and $a_{4} M$ ), but these were also non-significant, $p \geq .481$, for all. Thus, the size of the surrounding social network did not moderate any individual-level or dyadic associations between extraversion and popularity. In small and large classrooms, extraverts tend to be more popular, and introverts are usually more unpopular.

\subsubsection{DISCUSSION}

The results of Study III replicate those from Study II with a higher number of participants. The finding that the association is linear supports the dimensional continuity of the association between extraversion and popularity (research question 3). Dyadic extraversion was again determined to be unimportant for popularity attainment, this time among a sample of young Finns (research question 5). Finally, an examination of differences between classroom networks has found that the higher popularity of extraverts was not a function of classroom size (research question 4). This finding suggests that the association between extraversion and popularity is pervasive in social ecologies of all sizes. 


\section{GENERAL DISCUSSION}

This thesis has synthesized results across three studies that address two main questions: when and why is extraversion associated with social popularity? The commonality of the findings is that there are no whens for this association. Testing the conditions that surround this already somewhat established finding (Ciarrochi \& Heaven, 2009; DesJardins et al., 2015; Feiler \& Kleinbaum, 2015; Jensen-Campbell et al., 2002; Jensen-Campbell \& Malcolm, 2007; Lubbers et al., 2006; Scholte et al., 1997; Stopfer et al., 2013; van der Linden et al., 2010; Wortman \& Wood, 2011) has thus revealed that there are not many conditions for the association between extraversion and popularity. Rather, it is present among both young children and adults as well as in stereotypically introverted and less talkative Finnish culture and in atypical and highly typical social networks of various sizes. Moreover, it is of a similar strength along the entire introversion-extraversion continuum. Evidence regarding the processes underlying this association was found in pursuing the why question. Among youth, abilities for fluent oral communication particularly mediate this association. Finally, the finding that dyadic extraversion is not an important mechanism under popularity supports the unilaterality of the association: there is neither a systematic preference for extraverts among other extraverts or introverts nor a mutual preference among introverts in social networks.

It is important to note that the association between extraversion and popularity is a statistical link. Hence, this thesis has labeled it as an association to indicate that there are no strong assumptions of causation for extraversion or popularity in this association. Most previous literature has adopted the view that extraversion precedes popularity in the causal order, mostly because personality measurement has occurred prior to measuring popularity or related concepts in social networks (Anderson et al., 2001). However, individuals have most frequently been members of other social networks prior to their entry into new social environments; therefore, it could be that popularity precedes extraversion or that this association is bi-directional. The following section discusses these causation possibilities before delineating how popularity could help to understand extraversion.

\subsection{DOES EXTRAVERSION PREDICT POPULARITY?}

Extraversion predicting popularity would dictate in a group formation process, during which some type of hierarchy is usually spontaneously established (Fournier, 2009), that extraverts tend to settle in higher positions while introverts assume lower positions. This thesis has tested one plausible explanation for this association, namely oral fluency, and has found that fluent 
speech production is an important predictor of popularity among children who are starting their school careers. Thus, it seems that those who are fluently talkative can attain the most popularity during the group formation process at the beginning of the elementary school. This process, however, is unlikely to be the only process that would function under this association, especially among the older population, wherein differences in oral fluency are smaller.

The more motivational constituents of extraversion might be key to the association between extraversion and popularity. Debate over the central features of extraversion has previously focused on reward sensitivity, preference for social interactions, and engagement and enjoyment of social attention (Ashton et al., 2002; Lucas et al., 2000; Smillie, 2013; Watson \& Clark, 1997). A strong case has been made that sensitivity toward social rewards could indeed be a significant feature of extraversion. Therefore, those who perceive the social domain as more rewarding may also aim to attain positions in which rewarding resources would be more available (Lukaszewski \& von Rueden, 2015; von Rueden, 2014), and they may also maintain these positions in social networks (popularity tends to be temporally stable; Anderson et al., 2001; Jiang \& Cillessen, 2005). This pursuit of higher status and aspiration for social rewards are further supported by the finding that extraversion is associated with valuing and aspiring for economic goals, such as high-status careers, prestigious occupations, interpersonal influence, and high standards of living (Roberts \& Robins, 2000). Such status goals are also apparent in the typical purchases of extraverts: based on bank account data, extraversion is associated with high-status purchases, but not with social spending (Landis \& Gladstone, 2017).

The literature has offered less evidence that extraverts attain and maintain higher popularity because they enjoy being sociable. For example, studies have demonstrated that no differences exist between extraverts' and introverts' enjoyment of typically extraverted behaviors (Fleeson, Malanos, \& Achille, 2002; Leikas \& Ilmarinen, 2017; Wilt, Noftle, Fleeson, \& Spain, 2012). Moreover, social activity may be a generally more peripheral constituent of extraversion, especially compared to reward sensitivity (Lucas et al., 2000) or social attention (Ashton et al., 2002). It has also been concluded that extraverts attain popularity to a similar degree in affiliative and competitive contexts (DesJardins et al., 2015), which also signifies that social rewards themselves could be important, not just the contexts in which they occur. Opposing this view, and in support of the view that extraverts enjoy social behaviors more than introverts do, is the finding that extraverts report higher job satisfaction in occupations that are characterized by extensive interpersonal interaction (Huang et al., 2016). Thus, examinations of the central motivational drivers of extraversion should not entirely exclude processes related to social enjoyment.

Finally, the enjoyment of social attention is arguably the central constituent of extraversion, whereas reward sensitivity is less central but nevertheless important (Ashton et al., 2002). This argument advances the idea that an 
ability to attract and sustain the attention of others is beneficial because it provides opportunities to participate in rewarding social situations, form alliances, make economic transactions, and attract possible mates. However, because it is possible to establish alliances, it may not be a proper strategy to attempt to get others to involuntarily grant attention (Ashton et al., 2002). Extraverts may be especially capable of non-coercive endeavors to prompt others to grant attention, which is also evident in their higher popularity in groups.

Another way to approach plausible mediators or processes in the future could be to focus more heavily on why introverts are unpopular rather than on the mechanism that underlies the extraversion-popularity link. For example, introverts have made affective forecasting errors for future extraverted behaviors by under-predicting the positive affect and over-predicting the negative affect in these situations (Zelenski et al., 2013). This error has influenced the less frequent emergence of introverts as leaders (Spark, Stansmore, \& O'Connor, 2018), and it could therefore function in the popularity domain as well.

There is also a possibility that an initially higher popularity within groups feeds itself, which would suggest that the personality characteristics of agents matter mostly at initial stages of group formation, after which a person's degree of preference becomes more dependent on his or her past popularity than on personality characteristics (Gould, 2002). Given that extraversion is associated with attraction and preference among previously unacquainted individuals (Back, Schmukle, \& Egloff, 2011) and tends to influence social status in groups of previously unacquainted individuals (Anderson et al., 2001), this could be the case: during initial phases of group formation, those who are able to capture attention in positive manner can populate the highest positions in the group. Furthermore, the maintenance of popularity may be a function of different processes than attainment of popularity. Interestingly, individuals who score highly in another personality characteristic, namely narcissism, also initially attain high status in groups but generally wane in their popularity over time (Carlson \& DesJardins, 2015; Paulhus, 1998). Extraversion could differ in this regard, possibly in that certain processes belonging to the domain, such as being positive and sociable and evoking positive affect in others (Eaton \& Funder, 2003) and being able to hold social attention (Ashton et al., 2002), could be more central in maintaining rather than attaining popularity. This may also explain why extraverts enjoy jobs with social interaction more (Huang et al., 2016). Another possibility is that initially attaining higher popularity allows extraverts to have more friendship opportunities and therefore more friends (Asendorpf \& Wilpers, 1998), which would then solidify their popularity in the group. Although there are indeed popularity differences based on extraversion, these should not examined independently from dyadic relationships.

In view of the evidence of this thesis, there is less dyadic interpersonal importance for extraversion than has been previously proposed (Dryer \& 
Horowitz, 1997; Lukaszewski \& von Rueden, 2015; Selfhout et al., 2010; van Zalk \& Denissen, 2015). It is therefore possible that popularity mediates the associations between extraversion and specific dyadic relationships that were found in the literature. If so, unilateral popularity could be more of an antecedent of bilateral and reciprocated friendships than the reverse. This would also offer more leeway for extraverts in friendship selection, as highpopularity extraverts have more possibilities in friendship selection and could therefore be more selective about whom to engage in a deeper relationship. This could be also expected to lead to higher relationship satisfaction (Neyer \& Asendorpf, 2001) after a successful pair selection, assuming that popular people are able to utilize these opportunities. Such pattern, however, is not apparent in romantic relationships, as individual or dyadic extraversion is not associated with self or partner relationship satisfaction (Leikas, Ilmarinen, Verkasalo, Vartiainen, \& Lönnqvist, 2018; Weidmann, Schönbrodt, Ledermann, \& Grob, 2017). Therefore, if extraverts also have more opportunities in selecting romantic partners, they would not be utilizing this benefit. Regardless, relationship satisfaction may not be a pivotal goal of extraverts given that they often have more sexual partners, more offspring, and more divorces than introverts (Nettle, 2005).

Another explanation for the lack of influence of the dyads on popularity could be that popularity may nevertheless result more from dyadic relationships, but this cannot be detected by examining the extraversion of others in the social network. There are potentially mutual relationship niches for individual who complement each other in different personality characteristics (e.g. extraversion and agreeableness, according to operationalizing other people as environments; Asendorpf, 2017). For example, people who have strong need to belong to a group prefer the faces of extraverts (Brown \& Sacco, 2017), and because a need to belong may correspond more to the domains of agreeableness or neuroticism than to the domain of extraversion (Leary, Kelly, Cottrell, \& Schreindorfer, 2013), other personality characteristics may be more decisive for the popularity to extraverts.

\subsection{DOES POPULARITY PREDICT EXTRAVERSION?}

There have always been groups, and it is likely that there has always been a within-group rank in status and popularity as well (von Rueden, 2014) whereby some individuals in groups are more popular and some are less popular. Behavioral genetics have illustrated that there is substantial variance in extraversion that is explained by non-shared environments (Briley \& Tucker-Drob, 2014; Hill et al., 2018). Given that non-shared environments refer to environments that are not shared by the children of the same family, social peer networks could be a more prominent example of such environments and therefore explain development in extraversion (Harris, 
1995). For example, an individual's popularity in a group could define how he or she behaves in the group to maintain this popularity and to safeguard group membership. Such behaviors for highly popular people could include more assertive, sociable, or positive actions, influencing others, taking initiative, and assuming leadership responsibilities, especially in inter-group conflicts and negotiation; each of these is conceptually a constituent of extraversion.

It is slightly more difficult to explain why low popularity would influence introversion, but research has demonstrated that behaving above one's status is often severely punished (e.g. by means of ostracism) (Anderson, Srivastava, Beer, Spataro, \& Chatman, 2006; Anderson, Ames, \& Gosling, 2008). This could account for why those with low rank in a group take less risky social initiatives and avoid leadership (Spark et al., 2018). These insights are also supported by the view that social power increases approach tendencies (e.g. positive affect, disinhibited behavior), whereas lack of power increases avoidance tendencies (e.g. attention to punishment, negative affect) (Keltner, Gruenfeld, \& Anderson, 2003). Also, in support of the view that unpopularity could partially cause introversion, the social rank theory of psychopathology suggests that depression and inhibited behaviors develop as adaptive strategies to respond to defeats in a competition of social positions in enduring peer environments (Gilbert \& Allan, 1998). To summarize, popularity in a group could guide behavior to maintain the popularity (extraverted behavior) or to safeguard group membership (introverted behavior); therefore, experiences in social peer groups, especially those that endure for many years (e.g. school classrooms), may explain the development of extraversion.

\subsection{IS THE CAUSATION BETWEEN EXTRAVERSION AND POPULARITY BI-DIRECTIONAL?}

A final statement regarding causality is that this association between extraversion and popularity could be bi-directional, whereby each influences the other. Such patterns are known as person-environment transactions (Denissen, Ulferts, Lüdtke, Muck, \& Gerstorf, 2014) or person-relationship transactions (Mund \& Neyer, 2014; Neyer \& Asendorpf, 2001). They can also be understood as transactions between a person and his or her relationship with the group (Back et al., 2011). Moreover, a corresponsive principle is a pattern of associations whereby the same environment influences the same characteristics that initially influenced the selection of such environment (Neyer, Mund, Zimmermann, \& Wrzus, 2014; Roberts, Caspi, \& Moffitt, 2003). Corresponsive transactions between extraversion and environments have been previously observed for dominant behaviors (extraversion constituent) and work-life experience (Roberts et al., 2003) as well as for extraversion and occupational role demands (Denissen et al., 2014). 
It is plausible that the association between extraversion and popularity is indicative of a bi-directional positive feedback loop. Through the corresponsive transaction, extraversion predicts higher popularity among peers, and this higher popularity then influences extraversion. If such pattern would exist, it would entail that the magnitudes of cross-sectional correlations between extraversion and popularity should increase throughout development. Therefore, during development, extraverts might become even more extraverted and gain further popular as a result of this corresponsive pattern, which indicates cumulative advantages for those who are initially more extraverted or popular (DiPrete \& Eirich, 2006). On the other hand, this could pose cumulative disadvantages for introverts throughout the life span, or at least during the presence of informal peer networks that endure for at least a decade in industrial societies.

Given that there is nevertheless already a general trend of lower popularity among introverts during the earlier school years, it is worthwhile to consider the types of developmental pathways to which this could lead. Because peer groups are crucial developmental environments (Back et al., 2011; Harris, 1995) and social popularity or status among peers is associated with many beneficial life outcomes (von Rueden, 2014), early personality-driven peer relations may have long-term consequences even outside the personality domain.

\subsection{WHAT CAN THE RESULTS REVEAL ABOUT EXTRAVERSION?}

Independent of the causation between extraversion and popularity, scoring highly on extraversion (popularity) is not a guarantee of high popularity (extraversion) given the small-to-moderate effect sizes that have been noted here and elsewhere in the literature (Ciarrochi \& Heaven, 2009; Scholte et al., 1997). Despite support for a positive association between extraversion and popularity, the average magnitude of this association hovers from $\mathrm{r}=.15$ to $\mathrm{r}$ $=.20$, which is a small effect, though not particularly small in psychology (Richard, Bond, \& Stokes-Zoota, 2003: average $r=.21$ ). Still, these average estimates are probably inaccurate because of too-small sample sizes (Schönbrodt \& Perugini, 2013) and because only studies with results are published (Ioannidis, 2005). However, the importance of an effect should also be interpreted in terms of how many people it impacts. When an effect is highly generalizable, as the current finding seems to be, it is applied to almost an entire population and therefore affects many people at some point during their life span.

If the true effect would be $r=.20$, this would be roughly equal to $d=.40$ transferred to a Cohen's d effect size. This indicates that a difference of one standard deviation in extraversion would prompt a difference of 0.40 standard deviations in popularity (this example assumes the causation from 
extraversion to popularity). However, if comparing introverts (one standard deviation below the mean) and extraverts (one standard deviation above the mean), a difference of 0.80 in standard deviations in popularity would be expected. This conveys, for example, that by randomly picking two persons, one extravert and one introvert, the probability that the extravert would have higher popularity than the introvert would be 71.4\% (Magnusson, 2014). This contextualizes the magnitude of this effect and highlights that there are many popular introverts and many unpopular extraverts. It is also important to remember that most people are not strongly introverted or extraverted but instead exist between these polar opposites.

In any case, it is encouraging to observe replicated findings, such as the extraversion-popularity link in this thesis, since many effects in psychology fail to replicate (Open Science Collaboration, 2015). This widely observed failure to replicate is also known as the "replication crisis." Such crisis has already spurred measures to improve psychological science by correcting old procedures of scientific reporting as well as inventing new approaches to obtain more reliable and reproducible results. It remains uncertain if the extraversion-popularity association is also driven by publication bias, whereby only significant positive findings enter the published literature (Rothstein, Sutton, \& Borenstein, 2006). However, other problems also underpin this association with regard to the ontological status of broad personality traits. The section below discusses what extraversion certainly is not, how to explain its emergence, and whether peer popularity could be instrumental in this attempt. Alongside the replication crisis, this "coalescence of traits" question is vital for the future of personality psychology (Baumert et al., 2017).

The concept of extraversion has existed in general for almost a century and as a psychometric construct for at least 80 years. From Cattell's work in 1940s (Cattell, 1943) followed the idea that extraversion is the causal unit that explains its association with a certain outcome as well as why traits in the extraversion domain co-occur. It was assumed that, with psychological science advancements, neurobiological brain areas and neurotransmitters that also could be pinpointed to certain genes could be established for this factor, which systematically emerged from factor analyses. The conclusion that this factor is easily observable, temporally stable, quantitatively heritable, and almost universal in its emergence has intensified this belief, and general biological theories have been proposed for extraversion (Cloninger et al., 1993; Gray, 1970). However, the status of such beliefs and expectations now seems starkly different. The problem is the lack of a unitary or common cause for extraversion. It does not arise as replicable candidate genes (Munafò \& Flint, 2011) or even as replicable findings from the more powerful and exploratory method of GWAS (Lo et al., 2016; van den Berg et al., 2016). The particles that have been envisioned as merely observable indicators of the latent factor of extraversion have the same properties as extraversion (temporal consistency, observability, quantitative heritability), even after controlling for the common variance between the items, i.e. the variance that reflects extraversion (Mõttus 
et al., 2017; Mõttus, Kandler et al., 2017). Thus, there are likely hundreds of narrow traits that cannot be embedded in larger trait domains based on common etiology. This clearly prompts the question of defining the broad traits, or more relevant for the subject of this thesis, of defining extraversion.

For an illustrative example of how to understand extraversion from the viewpoint of the network approach to personality (Cramer et al., 2012), a reanalysis was conducted of correlations between seven self-reported facet-level constituents of extraversion (affiliation, ascendance, venturesomeness, behavioral activation system, positive affect, social attention, and social interaction) that Ashton et al. (2002) employed to study the central features of extraversion. In this re-analysis, the correlations between the constituents were disattenuated for scale reliabilities (each scale had at least six items, and alpha reliabilities ranged from .68 to .88: Ashton et al., 2002, p. 249), after which partial correlations between such constituents were calculated. These partial correlations indicate unique covariance that is shared only between a pair of constituent traits. Based on these partial correlations, a network model that depicts the unique associations was constructed in $\mathrm{R}$ by qgraph package (Epskamp, Cramer, Waldorp, Schmittmann, \& Borsboom, 2012) (model was calculated by lasso based on an extended BIC criterion that reduces redundant partial correlations to zero; Costantini et al., 2015). The darker, solid park of Figure 4 depicts the network. Each node in the graph represents one of the constituent traits, and edges between traits indicate their correlation while controlling for all other variables in the network (partial correlation coefficients).

The between-trait associations in Figure 4 indicate that some of the constituents are moderately to strongly correlated beyond common variance. This is in line with the view that there is not a single unitary etiology underlying different trait constituents (Mõttus \& Allerhand, 2017). Moreover, the unique associations may indicate that these traits have a causal influence on each other that could even be bi-directional. These direct causal influences between traits (of which there are possibly several, even in this network of seven constituents) that are not shared by other traits could explain why a phenomenon like extraversion emerges (Mõttus \& Allerhand, 2017). In short, such influences produce covariance patterns that, when analyzed by dimensional reduction methods, would illuminate an extraversion factor.

In addition, the lack of unique associations between some of the traits could indicate that they share a cause. This cause could be one of the more functional constituents of extraversion, as opposed to behavioral constituents. as some more functional traits, such as motivations, goals, evaluations, expectancies, and efficacies, could lead to several types of behaviors that co-occur because of shared functionality (Mõttus \& Allerhand, 2017; Wood et al., 2015). For example, social attention and positive affect tend to co-occur (disattenuated zero-order correlation: .59), but the association is notably weaker in the network (partial $\mathrm{r}=.16$ ), which indicates that the network may include functional variation that partially explains this co-occurrence. In this example, 
ascendance or affiliation could be this functionality or at least encompass some of it (these are also facet-level traits, and therefore possibly sums of many narrow constituents). Thus, shared functionality may account for the coalescence of traits. It is again important to note that this is only an illustrative example and by no means a test of such hypothesis. Nevertheless, this network model supports the conclusion of Ashton et al. (2002) that social attention is a central feature of extraversion. In the network approach, however, the centrality of a trait does not signify that it is the cause of all other traits (Mõttus \& Allerhand, 2017). It may also be a more behavioral and easily perceived trait that may have unique inputs from many other traits in the network (Wood et al., 2015).

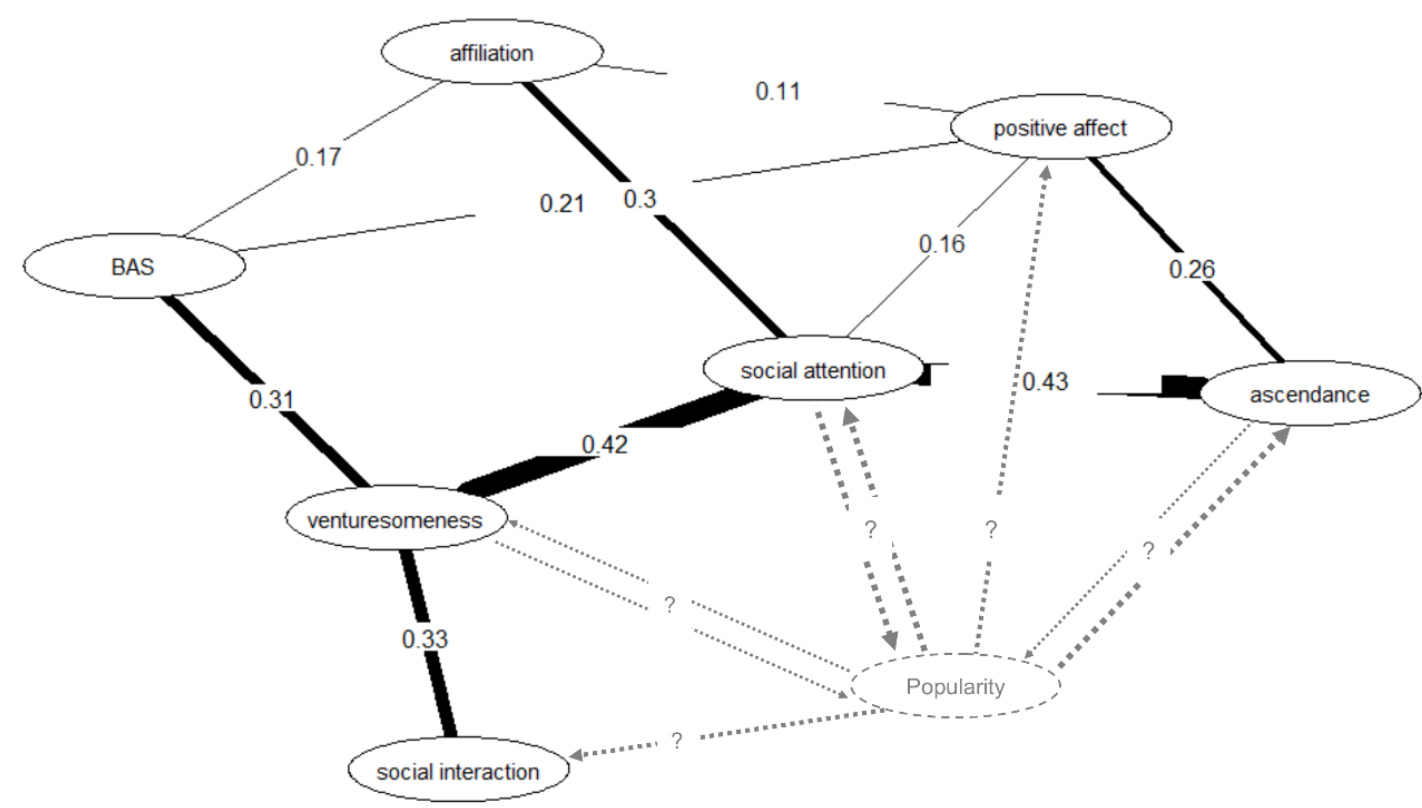

Figure 4 Undirected cross-sectional network model of extraversion constituents based on optimal sparse estimates of partial correlations corrected for attenuation in reanalysis of correlations reported by Ashton et al. (2002, p. 249). BAS = Behavioral approach system. Dashed/gray popularity node and arrows were not included in the estimation but illustrate the hypothetical role of popularity in understanding the covariation of extraversion constituents.

Figure 4 also features a hypothetical part that was not used in the estimation of the network but depicts the plausible role of peer popularity in explaining the coalescence of traits in the extraversion domain. The width and direction of the arrows are somewhat arbitrary and dictated by the locations at which there are no unique association edges in the estimated part of the network graph. Still, this illustration may clarify why traits in the extraversion domain could co-occur as a function of popularity. If the model would include the dashed edges in the model (and there would also be multiple data points allowing for longitudinal modeling), following which some of the unique associations in the network would be diminished or notably weakened, popularity could be considered an explanation for the coalescence of traits. In 
other words, popularity in peer networks would increase or decrease many different behaviors that are thought to belong to the domain of extraversion (discussed in Chapter 4.2.). It is also likely that certain constituents would have a causal effect on popularity (as discussed in Chapter 4.1). The most important feature of peer popularity in this illustrative network would be that it is another type of variable incorporated in the functional approach to trait covariation (Wood et al., 2015). It directly indicates the average perceiver's perceptions of the target individual - e.g. whether that person popular, likeable, or preferable - and as Wood et al. (2015) have stated, this perceptional domain could be useful to understand the emergence of the five broad factors. In short, the broad personality factors summarize how an individual's traits impact his or her interpersonal environment. Peer popularity would be a direct indicator of such impact of traits on interpersonal environment in the extraversion domain.

To summarize the idea of the network approach for constituents of extraversion, it is important to include measures from social networks to understand personality trait networks, especially given that non-shared environments are likely to be decisive in personality development (Briley \& Tucker-Drob, 2014; Harris, 1995). To comprehend the causal mechanisms and direction of influence, these networks should be based on longitudinal examinations and should feature all types of variables, including plausible genetic inputs, measures of neurobiological endophenotypes, other personality traits from other broad trait domains, functionality indicators, and various types of environments (Mõttus \& Allerhand, 2017). Fortunately, the network approach allows for such inclusions as well as for analysis of withinperson processes alongside individual differences (Epskamp, Waldorp, Mõttus, \& Borsboom, 2016). In view of the ubiquity of social networks and the generalizability of the association between extraversion and popularity, popularity and other parameters of peer networks could offer a starting point for the construction of a network model to define extraversion and understand its emergence. 


\section{CONCLUSIONS}

Popular culture has featured the empowerment of introverts, a movement spearheaded by Susan Cain's book Quiet: The Power of Introverts in a World That Can't Stop Talking (Cain, 2013) and Ted Talk (Cain, 2012). Despite the ease of supporting one of Cain's central points that introverts should not be discouraged or punished for their typical behaviors, this thesis has replicated the finding that introverts lack social power. Importantly, the results add to this observation by emphasizing that this is not due to extraverted cultures or because extraverts especially dislike, punish, or ignore introverts. Moreover, it is not that introverts prefer other introverts more or generally dislike extraverts, and introverts were not more unpopular in larger compared to smaller classrooms. Other research has demonstrated that introverts do enjoy extraverted behaviors to a similar degree that extraverts enjoy them (Fleeson et al., 2002; Leikas \& Ilmarinen, 2017; Wilt et al., 2012).

However, given that a unitary common cause of broad traits is unlikely, the main concern in personality psychology is to identify the broad trait factors and to determine why certain personality traits, such as sociability, assertiveness, and positive emotionality, constantly occur together. Therefore, statements relating to the secret power of introverts or the cumulative advantages of extraverts also address these questions. The findings of this thesis could facilitate a better understanding of extraversion. By establishing the importance of peer popularity for extraversion, it is possible to integrate information of peer relations into each level of analysis: understanding processes, structure, and development in the extraversion domain (Baumert et al., 2017). Furthermore, it could advance the integration of these various fields of personality research to include parameters from social networks of peers in the analysis. 


\section{REFERENCES}

Abele, A. E., \& Wojciszke, B. (2007). Agency and communion from the perspective of self versus others. Journal of Personality and Social Psychology, 93, 751-763.

Adams, R. G., \& Allan, G. (1998). Contextualizing friendship. In R. G. Adams, \& G. Allan (Eds.), Placing friendship in context (pp. 1-17). Cambridge, UK: Cambridge university press.

Allport, G. W. (1937). Personality: A psychological interpretation. Oxford, England: Holt.

Allport, G. W., \& Odbert, H. S. (1936). Trait-names: A psycho-lexical study. Psychological Monographs, 47, i-171.

Ames, D. R., \& Flynn, F. J. (2007). What breaks a leader: The curvilinear relation between assertiveness and leadership. Journal of Personality and Social Psychology, 92, 307-324.

Anderson, C., Ames, D. R., \& Gosling, S. D. (2008). Punishing hubris: The perils of overestimating one's status in a group. Personality and Social Psychology Bulletin, 34, 90-101.

Anderson, C., Hildreth, J. A. D., \& Howland, L. (2015). Is the desire for status a fundamental human motive? A review of the empirical literature. Psychological Bulletin, 141, 574-602.

Anderson, C., John, O. P., Keltner, D., \& Kring, A. M. (2001). Who attains social status? Effects of personality and physical attractiveness in social groups. Journal of Personality and Social Psychology, 81, 116-132.

Anderson, C., Srivastava, S., Beer, J. S., Spataro, S. E., \& Chatman, J. A. (2006). Knowing your place: Self-perceptions of status in face-to-face groups. Journal of Personality and Social Psychology, 91, 1094-1110.

Andrei, F., Mancini, G., Mazzoni, E., Russo, P. M., \& Baldaro, B. (2015). Social status and its link with personality dimensions, trait emotional intelligence, and scholastic achievement in children and early adolescents. Learning and Individual Differences, 42, 97-105.

Asendorpf, J. B. (2016). Causal unity of broader traits is an illusion. [Peer commentary on "Towards more rigorous personality trait-outcome research" by R. Mõttus]. European Journal of Personality, 30, 304-305.

Asendorpf, J. B. (2017). Personality as a situation: A target-centered perspective on social situations. In D. C. Funder, J. F. Rauthmann \& R. A. Sherman (Eds.), The oxford handbook of psychological situations. New York, NY: Oxford University Press.

Asendorpf, J. B., \& Wilpers, S. (1998). Personality effects on social relationships. Journal of Personality and Social Psychology, 74, 1531-1544.

Ashton, M. C., \& Lee, K. (2007). Empirical, theoretical, and practical advantages of the HEXACO model of personality structure. Personality and Social Psychology Review, 11, 150-166.

Ashton, M. C., Lee, K., \& Paunonen, S. V. (2002). What is the central feature of extraversion? social attention versus reward sensitivity. Journal of Personality and Social Psychology, 83, 245-252.

Back, M. D., Baumert, A., Denissen, J. J. A., Hartung, F. M., Penke, L., Schmukle, S. C., . . . Wrzus, C. (2011). PERSOC: A unified framework for understanding the dynamic interplay of personality and social relationships. European Journal of Personality, 25, 90-107. 
Back, M. D., Schmukle, S. C., \& Egloff, B. (2011). A closer look at first sight: Social relations lens model analysis of personality and interpersonal attraction at zero acquaintance. European Journal of Personality, 25, 225238.

Barenbaum, N. B., \& Winter, D. G. (2008). History of modern personality theory and research. In O. P. John, R. W. Robins \& L. A. Pervin (Eds.), Handbook of personality (3rd ed., pp. 3-26). New York, US: Guilford Press.

Baron, R. M., \& Kenny, D. A. (1986). The moderator-mediator variable distinction in social psychological research. Conceptual, strategic, and statistical considerations. Journal of Personality and Social Psychology, 51, 1173-1182.

Barranti, M., Carlson, E. N., \& Côté, S. (2017). How to test questions about similarity in personality and social psychology research. Social Psychological and Personality Science, 8, 465-475.

Bates, D., Maechler, M., Bolker, B., \& Walker, S. (2015). Fitting linear mixedeffects models using lme4. Journal of Statistical Software, 67, 1-48.

Baumert, A., Schmitt, M., Perugini, M., Johnson, W., Blum, G., Borkenau, P., . . . Grafton, B. (2017). Integrating personality structure, personality process, and personality development. European Journal of Personality, $31,503-528$.

Black, B., \& Hazen, N. L. (1990). Social status and patterns of communication in acquainted and unacquainted preschool children. Developmental Psychology, 26, 379-387.

Borkenau, P., \& Liebler, A. (1992). Trait inferences: Sources of validity at zero acquaintance. Journal of Personality and Social Psychology, 62, 645-657.

Braza, F., Azurmendi, A., Muñoz, J. M., Carreras, M. R., Braza, P., García, A., . . . Sánchez-Martín, J. R. (2009). Social cognitive predictors of peer acceptance at age 5 and the moderating effects of gender. British Journal of Developmental Psychology, 27, 703-716.

Briley, D. A., \& Tucker-Drob, E. (2014). Genetic and environmental continuity in personality development: A meta-analysis. Psychological Bulletin, 140, 1303-1331.

Briley, D. A., \& Tucker-Drob, E. M. (2017). Comparing the developmental genetics of cognition and personality over the life span. Journal of Personality, 85, 51-64.

Brown, M., \& Sacco, D. F. (2017). Greater need to belong predicts a stronger preference for extraverted faces. Personality and Individual Differences, 104, 220-223.

Bukowski, W. M., Pizzamiglio, M. T., Newcomb, A. F., \& Hoza, B. (1996). Popularity as an affordance for friendship: The link between group and dyadic experience. Social Development, 5, 189-202.

Cain, S. (2012). The power of introverts [video file]. Retrieved from TED Talk: https://www.ted.com/talks/susan_cain_the_power_of_introverts

Cain, S. (2013). Quiet: The power of introverts in a world that can't stop talking. New York, NY: Broadway Books.

Campbell, D. T., \& Fiske, D. W. (1959). Convergent and discriminant validation by the multitrait-multimethod matrix. Psychological Bulletin, 56, 81-105.

Campbell, L., Simpson, J. A., Stewart, M., \& Manning, J. (2003). Putting personality in social context: Extraversion, emergent leadership, and the availability of rewards. Personality and Social Psychology Bulletin, 29, 1547-1559. 
Carbaugh, D., Berry, M., \& Nurmikari-Berry, M. (2006). Coding personhood through cultural terms and practices: Silence and quietude as a Finnish "natural way of being". Journal of Language and Social Psychology, 25, 203-220.

Carlson, E. N., \& DesJardins, N. M. L. (2015). Do mean guys always finish first or just say that they do? Narcissists' awareness of their social status and popularity over time. Personality and Social Psychology Bulletin, 41, 901917.

Cattell, R. B. (1943). The description of personality: Basic traits resolved into clusters. The Journal of Abnormal and Social Psychology, 38, 476-506.

Catterson, A. D., Eldesouky, L., \& John, O. P. (2017). An experience sampling approach to emotion regulation: Situational suppression use and social hierarchy. Journal of Research in Personality, 69, 33-43.

Chabris, C. F., Lee, J. J., Benjamin, D. J., Beauchamp, J. P., Glaeser, E. L., Borst, G., ... Laibson, D. I. (2013). Why it is hard to find genes associated with social science traits: Theoretical and empirical considerations. American Journal of Public Health, 103, 152-166.

Christensen, R. H. B. (2015). Ordinal-regression models for ordinal data. R package version 2015.6-28. Retrieved from https://cran.rproject.org/web/packages/ordinal/

Ciarrochi, J., \& Heaven, P. C. L. (2009). A longitudinal study into the link between adolescent personality and peer-rated likeability and adjustment: Evidence of gender differences. Journal of Research in Personality, 43, 978-986.

Cillessen, A. H., \& Mayeux, L. (2004). From censure to reinforcement: Developmental changes in the association between aggression and social status. Child Development, 75, 147-163.

Cillessen, A. H., \& Rose, A. J. (2005). Understanding popularity in the peer system. Current Directions in Psychological Science, 14, 102-105.

Cloninger, C. R., Svrakic, D. M., \& Przybeck, T. R. (1993). A psychobiological model of temperament and character. Archives of General Psychiatry, 50, 975-990.

Connelly, B. S., \& Ones, D. S. (2010). An other perspective on personality: Meta-analytic integration of observers' accuracy and predictive validity. Psychological Bulletin, 136, 1092-1122.

Costantini, G., Epskamp, S., Borsboom, D., Perugini, M., Mõttus, R., Waldorp, L. J., \& Cramer, A. O. (2015). State of the aRt personality research: A tutorial on network analysis of personality data in R. Journal of Research in Personality, 54, 13-29.

Cramer, A. O. J., Sluis, S., Noordhof, A., Wichers, M., Geschwind, N., Aggen, S. H., . . Borsboom, D. (2012). Dimensions of normal personality as networks in search of equilibrium: You can't like parties if you don't like people. European Journal of Personality, 26, 414-431.

De Raad, B., Barelds, D. P., Timmerman, M. E., De Roover, K., Mlačić, B., \& Church, A. T. (2014). Towards a pan-cultural personality structure: Input from 11 psycholexical studies. European Journal of Personality, 28, 497510 .

Del Giudice, M., Angeleri, R., \& Manera, V. (2009). The juvenile transition: A developmental switch point in human life history. Developmental Review, 29, 1-31.

Denissen, J. J. A., \& Penke, L. (2008). Motivational individual reaction norms underlying the five-factor model of personality: First steps towards a 
theory-based conceptual framework. Journal of Research in Personality, 42, 1285-1302.

Denissen, J. J. A., Ulferts, H., Lüdtke, O., Muck, P. M., \& Gerstorf, D. (2014). Longitudinal transactions between personality and occupational roles: A large and heterogeneous study of job beginners, stayers, and changers. Developmental Psychology, 50, 1931-1942.

Depue, R. A., \& Collins, P. F. (1999). Neurobiology of the structure of personality: Dopamine, facilitation of incentive motivation, and extraversion. Behavioral and Brain Sciences, 22, 491-517.

DesJardins, N. M. L., Srivastava, S., Küfner, A. C., \& Back, M. D. (2015). Who attains status? Similarities and differences across social contexts. Social Psychological and Personality Science, 6, 692-700.

Dewaele, J. M., \& Furnham, A. (1999). Extraversion: The unloved variable in applied linguistic research. Language Learning, 49, 509-544.

Dewaele, J. M., \& Furnham, A. (2000). Personality and speech production: A pilot study of second language learners. Personality and Individual Differences, 28, 355-365.

DeYoung, C. G., Weisberg, Y. J., Quilty, L. C., \& Peterson, J. B. (2013). Unifying the aspects of the big five, the interpersonal circumplex, and trait affiliation. Journal of Personality, 81, 465-475.

Digman, J. M. (1997). Higher-order factors of the big five. Journal of Personality and Social Psychology, 73, 1246-1256.

DiPrete, T. A., \& Eirich, G. M. (2006). Cumulative advantage as a mechanism for inequality: A review of theoretical and empirical developments. Annual Review of Sociology, 32, 271-297.

Dryer, D. C., \& Horowitz, L. M. (1997). When do opposites attract? Interpersonal complementarity versus similarity. Journal of Personality and Social Psychology, 72, 592-603.

Eaton, L. G., \& Funder, D. C. (2003). The creation and consequences of the social world: An interactional analysis of extraversion. European Journal of Personality, 17, 375-395.

Eccles, J. S. (1999). The development of children ages 6 to 14. The Future of Children, 9, 30-44.

Edwards, J. R. (1994). The study of congruence in organizational behavior research: Critique and a proposed alternative. Organizational Behavior and Human Decision Processes, 58, 51-100.

Edwards, J. R. (2001). Ten difference score myths. Organizational Research Methods, 4, 265-287.

Edwards, J. R. (2002). Alternatives to difference scores: Polynomial regression and response surface methodology. In F. Drasgow, \& N. Schmitt (Eds.), Measuring and analyzing behavior in organizations: Advances in measurement and data analysis (pp. 350-400). San Francisco, CA: JosseyBass.

Edwards, J. R., \& Parry, M. E. (1993). On the use of polynomial regression equations as an alternative to difference scores in organizational research. Academy of Management Journal, 36, 1577-1613.

Ehrhart, M. G., \& Klein, K. J. (2001). Predicting followers' preferences for charismatic leadership: The influence of follower values and personality. The Leadership Quarterly, 12, 153-179.

Elphick, E., Halverson, C. F., \& Marzal-Wisniewska, M. (1998). Extraversion: Toward a unifying description from infancy to adulthood. In G. A. Kohnstamm, C. F. Halverson Jr., I. Mervielde \& V. L. Havill (Eds.), Parental 
descriptions of child personality: Developmental antecedents of the big five? (pp. 21-48). Mahwah, NJ: Lawrence Eribaum.

Epskamp, S., Cramer, A. O. J., Waldorp, L. J., Schmittmann, V. D., \& Borsboom, D. (2012). qgraph: Network visualizations of relationships in psychometric data. Journal of Statistical Software, 48(4), 1-18.

Epskamp, S., Waldorp, L. J., Mõttus, R., \& Borsboom, D. (2016). Discovering psychological dynamics: The gaussian graphical model in cross-sectional and time-series data. Unpublished manuscript. Retrieved December 19, 2017, from https://arxiv.org/abs/1609.04156

Erez, A., Schilpzand, P., Leavitt, K., Woolum, A. H., \& Judge, T. A. (2015). Inherently relational: Interactions between peers' and individuals' personalities impact reward giving and appraisal of individual performance. Academy of Management Journal, 58, 1761-1784.

Evans, D., Healey, E. C., Kawai, N., \& Rowland, S. (2008). Middle school students' perceptions of a peer who stutters. Journal of Fluency Disorders, 33, 203-219.

Eysenck, H. J. (1963). Biological basis of personality. Nature, 199, 1031-1034.

Eysenck, H. J. (1985). Decline and fall of the freudian empire. New York, US: Viking.

Eysenck, H. J. (1991). Dimensions of personality: 16, 5 or 3 ?-Criteria for a taxonomic paradigm. Personality and Individual Differences, 12, 773-790.

Ezrati-Vinacour, R., Platzky, R., \& Yairi, E. (2001). The young child's awareness of stuttering-like disfluency. Journal of Speech, Language, and Hearing Research, 44, 368-380.

Feiler, D. C., \& Kleinbaum, A. M. (2015). Popularity, similarity, and the network extraversion bias. Psychological Science, 26, 593-603.

Fleeson, W. (2001). Toward a structure-and process-integrated view of personality: Traits as density distributions of states. Journal of Personality and Social Psychology, 80, 1011-1027.

Fleeson, W., Malanos, A. B., \& Achille, N. M. (2002). An intraindividual process approach to the relationship between extraversion and positive affect: Is acting extraverted as" good" as being extraverted? Journal of Personality and Social Psychology, 83, 1409-1422.

Fournier, M. A. (2009). Adolescent hierarchy formation and the social competition theory of depression. Journal of Social and Clinical Psychology, 28, 1144-1172.

Franck, A. L., Jackson, R. A., Pimentel, J. T., \& Greenwood, G. S. (2003). School-age children's perceptions of a person who stutters. Journal of Fluency Disorders, 28, 1-15.

Freese, J. (2016). What we talk about when we talk about causes: The case of personality traits. [Peer commentary on "Towards more rigorous personality trait-outcome research" by R. Mõttus]. European Journal of Personality, 30, 304-305.

Gilbert, P., \& Allan, S. (1998). The role of defeat and entrapment (arrested flight) in depression: An exploration of an evolutionary view. Psychological Medicine, 28, 585-598.

Goldberg, L. R. (1990). An alternative "description of personality": The bigfive factor structure. Journal of Personality and Social Psychology, 59, 1216-1229.

Gould, R. V. (2002). The origins of status hierarchies: A formal theory and empirical test. American Journal of Sociology, 107, 1143-1178. 
Gray, J. A. (1970). The psychophysiological basis of introversion-extraversion. Behaviour Research and Therapy, 8, 249-266.

Guilford, J. P., \& Braly, K. W. (1930). Extroversion and introversion. Psychological Bulletin, 27, 96-107.

Gurven, M., von Rueden, C., Massenkoff, M., Kaplan, H., \& Lero Vie, M. (2013). How universal is the big five? Testing the five-factor model of personality variation among forager-farmers in the bolivian amazon. Journal of Personality and Social Psychology, 104, 354-370.

Hair, J. F., Anderson, R. E., Tatham, R. L., \& Black, W. C. (1998). Multivariate data analysis (Fifth ed.). Upper Saddle River, NJ: Prentice hall.

Harris, J. R. (1995). Where is the child's environment? A group socialization theory of development. Psychological Review, 102, 458-489.

Harter, S. (1999). The construction of the self: A developmental perspective. New York, NY: Guilford Press.

Heller, D., Komar, J., \& Lee, W. B. (2007). The dynamics of personality states, goals, and well-being. Personality and Social Psychology Bulletin, 33, 898910.

Henrich, J., Heine, S. J., \& Norenzayan, A. (2010). Most people are not WEIRD. Nature, 466, 29.

Hill, W. D., Arslan, R. C., Xia, C., Luciano, M., Amador, C., Navarro, P., . . . Penke, L. (2018). Genomic analysis of family data reveals additional genetic effects on intelligence and personality. Molecular psychiatry.

Horowitz, L., Jansson, L., Ljungberg, T., \& Hedenbro, M. (2006). Interaction before conflict and conflict resolution in pre-school boys with language impairment. International Journal of Language and Communication Disorders, 41, 441-466.

Huang, J. L., Bramble, R. J., Liu, M., Aqwa, J. J., Ott-Holland, C. J., Ryan, A. M., . . . Wadlington, P. L. (2016). Rethinking the association between extraversion and job satisfaction: The role of interpersonal job context. Journal of Occupational and Organizational Psychology, 89, 683-691.

Hubers, M. D., Burk, W. J., Segers, E., Kleinjan, M., Scholte, R. H., \& Cillessen, A. H. (2016). Personality and problem behaviours as predictors of adolescents' social status: Academic track and gender as moderators. Educational Psychology, 36, 1443-1461.

Imhoff, R., \& Koch, A. (2017). How orthogonal are the big two of social perception? on the curvilinear relation between agency and communion. Perspectives on Psychological Science, 12, 122-137.

Ioannidis, J. P. (2005). Why most published research findings are false. PLoS Medicine, 2.

Ishiguro, I. (2016). Extroversion and neuroticism affect the right side of the distribution of network size. Social Networks, 44, 219-225.

Jensen-Campbell, L. A., Adams, R., Perry, D. G., Workman, K. A., Furdella, J. Q., \& Egan, S. K. (2002). Agreeableness, extraversion, and peer relations in early adolescence: Winning friends and deflecting aggression. Journal of Research in Personality, 36, 224-251.

Jensen-Campbell, L. A., \& Malcolm, K. T. (2007). The importance of conscientiousness in adolescent interpersonal relationships. Personality and Social Psychology Bulletin, 33, 368-383.

Jiang, X. L., \& Cillessen, A. H. N. (2005). Stability of continuous measures of sociometric status: A meta-analysis. Developmental Review, 25, 1-25.

Joffe, T. H. (1997). Social pressures have selected for an extended juvenile period in primates. Journal of Human Evolution, 32, 593-605. 
John, O. P., Naumann, L. P., \& Soto, C. J. (2008). Paradigm shift to the integrative big five trait taxonomy: History, measurement, and conceptual issues. In O. P. John, R. W. Robins \& L. A. Pervin (Eds.), Handbook of personality (3rd ed., pp. 114-158). New York, US: Guilford Press.

Johnson, W., Penke, L., \& Spinath, F. M. (2011). Heritability in the era of molecular genetics: Some thoughts for understanding genetic influences on behavioural traits. European Journal of Personality, 25, 254-266.

Jokela, M., Bleidorn, W., Lamb, M. E., Gosling, S. D., \& Rentfrow, P. J. (2015). Geographically varying associations between personality and life satisfaction in the london metropolitan area. Proceedings of the National Academy of Sciences of the United States of America, 112, 725-730.

Jokela, M., Elovainio, M., Kivimäki, M., \& Keltikangas-Järvinen, L. (2008). Temperament and migration patterns in Finland. Psychological Science, $19,831-837$.

Jonas, K. G., \& Markon, K. E. (2016). A descriptivist approach to trait conceptualization and inference. Psychological Review, 123, 90-96.

Jung, C. G. (2014). General description of the types. In H. Read Sir, M. Fordham \& G. Adler (Eds.), Psychological types [Psychologische Typen] (H. G. Baynes Trans.). (pp. 330-407). Princeton, New Jersey: Princeton University Press.

Kadushin, C. (2012). Understanding social networks: Theories, concepts, and findings. New York, US: Oxford University Press.

Keltner, D., Gruenfeld, D. H., \& Anderson, C. (2003). Power, approach, and inhibition. Psychological Review, 110, 265-284.

Kenny, D. A., Kashy, D. A., \& Cook, W. L. (2006). The analysis of dyadic data. New York, NY: Guilford.

Kim, H., Schimmack, U., Oishi, S., \& Tsutsui, Y. (2017). Extraversion and life satisfaction: A cross-cultural examination of student and nationally representative samples. Journal of Personality, Advance online publication, 1-15.

Landis, B., \& Gladstone, J. J. (2017). Personality, income, and compensatory consumption: Low-income extraverts spend more on status. Psychological Science, 28, 1518-1520.

Lansford, J. E., Yu, T., Pettit, G. S., Bates, J. E., \& Dodge, K. A. (2014). Pathways of peer relationships from childhood to young adulthood. Journal of Applied Developmental Psychology, 35, 111-117.

Leary, M. R., Kelly, K. M., Cottrell, C. A., \& Schreindorfer, L. S. (2013). Construct validity of the need to belong scale: Mapping the nomological network. Journal of Personality Assessment, 95, 610-624.

Lee, K., \& Ashton, M. C. (2004). Psychometric properties of the HEXACO personality inventory. Multivariate Behavioral Research, 39(2), 329-358.

Leikas, S., \& Ilmarinen, V. J. (2017). Happy now, tired later? Extraverted and conscientious behavior are related to immediate mood gains, but to later fatigue. Journal of Personality, 85, 603-615.

Leikas, S., Ilmarinen, V. J., Verkasalo, M., Vartiainen, H. L., \& Lönnqvist, J. E. (2018). Relationship satisfaction and similarity of personality traits, personal values, and attitudes. Personality and Individual Differences, 123, 191-198.

Lieberman, M. D. (2000). Introversion and working memory: Central executive differences. Personality and Individual Differences, 28, 479-486.

Lo, M., Hinds, D. A., Tung, J. Y., Franz, C., Fan, C., Wang, Y., . . . Chen, C. (2016). Genome-wide analyses for personality traits identify six genomic 
loci and show correlations with psychiatric disorders. Nature Genetics, 49, 152-156.

Locke, J. L., \& Bogin, B. (2006). Language and life history: A new perspective on the development and evolution of human language. Behavioral and Brain Sciences, 29, 259-280.

Lombardo, G. P., \& Foschi, R. (2002). The European origins of" personality psychology". European Psychologist, 7, 134-145.

Lubbers, M. J., van der Werf, M. P. C., Kuyper, H., \& Offringa, G. J. (2006). Predicting peer acceptance in Dutch youth: A multilevel analysis. Journal of Early Adolescence, 26, 4-35.

Lucas, R. E., Diener, E., Grob, A., Suh, E. M., \& Shao, L. (2000). Cross-cultural evidence for the fundamental features of extraversion. Journal of Personality and Social Psychology, 79, 452-468.

Luciano, M., Hagenaars, S. P., Davies, G., Hill, W. D., Clarke, T., Shirali, M., . . . Deary, I. J. (2017). Association analysis in over 329,000 individuals identifies 116 independent variants influencing neuroticism. Nature Genetics.

Lukaszewski, A. W., \& von Rueden, C. R. (2015). The extraversion continuum in evolutionary perspective: A review of recent theory and evidence. Personality and Individual Differences, 77, 186-192.

Lönnqvist, J. E., Paunonen, S., Verkasalo, M., Leikas, S., Tuulio-Henriksson, A., \& Lönnqvist, J. (2007). Personality characteristics of research volunteers. European Journal of Personality, 21, 1017-1030.

Lönnqvist, J. E., Vainikainen, M., \& Verkasalo, M. (2012). Teacher and parent ratings of seven-year-old children's personality and psychometrically assessed cognitive ability. European Journal of Personality, 26, 504-514.

Lönnqvist, J. E., Verkasalo, M., \& Vainikainen, M. (2011). Parent-teacher agreement on 7-year-old children's personality. European Journal of Personality, 25, 306-316.

Magee, C. A., Heaven, P. C., \& Miller, L. M. (2013). Personality change predicts self-reported mental and physical health. Journal of Personality, 81, 324334 .

Magnusson, K. (2014). Interpreting Cohen's d effect size an interactive visualization. Retrieved from http://rpsychologist.com/d3/cohend/

Mayeux, L., Houser, J. J., \& Dyches, K. D. (2011). Social accpetance and popularity: Two distinct forms of peer status. In A. H. Cillessen, D. Schwartz \& L. Mayeux (Eds.), Popularity in the peer system (pp. 79-103). New York, NY: Guilford Press.

McCrae, R. R. (2015). A more nuanced view of reliability: Specificity in the trait hierarchy. Personality and Social Psychology Review, 19, 97-112.

McCrae, R. R., \& Costa, P. T. (1989). The structure of interpersonal traits: Wiggins's circumplex and the five-factor model. Journal of Personality and Social Psychology, 56, 586-595.

McCrae, R. R., \& Costa, P. T. (2008). The five-factor theory of personality. In O. P. John, R. W. Robins \& L. A. Pervin (Eds.), Handbook of personality (3rd ed., pp. 159-181). New York, NY: Guilford Press.

McCrae, R. R., \& John, O. P. (1992). An introduction to the five-factor model and its applications. Journal of Personality, 60, 175-215.

McCrae, R. R., Terracciano, A., \& 78 Members of the Personality Profiles of Cultures Project. (2005). Universal features of personality traits from the observer's perspective: Data from 50 cultures. Journal of Personality and Social Psychology, 88, 547-561. 
McPherson, M., Smith-Lovin, L., \& Cook, J. M. (2001). Birds of a feather: Homophily in social networks. Annual Review of Sociology, 27, 415-444.

Mehl, M. R., Gosling, S. D., \& Pennebaker, J. W. (2006). Personality in its natural habitat: Manifestations and implicit folk theories of personality in daily life. Journal of Personality \& Social Psychology, 90, 862-877.

Miller, J. W., Stromeyer, W. R., \& Schwieterman, M. A. (2013). Extensions of the Johnson-Neyman technique to linear models with curvilinear effects: Derivations and analytical tools. Multivariate Behavioral Research, 48, 267-300.

Montoya, R. M., Horton, R. S., \& Kirchner, J. (2008). Is actual similarity necessary for attraction? A meta-analysis of actual and perceived similarity. Journal of Social and Personal Relationships, 25, 889-922.

Mõttus, R. (2016). Towards more rigorous personality trait-outcome research. European Journal of Personality, 30, 292-303.

Mõttus, R., \& Allerhand, M. (2017). Why do traits come together? The underlying trait and network approaches. In V. Zeigler-Hill, \& T. K. Shackelford (Eds.), The SAGE handbook of personality and individual differences: Volume 1. The science of personality and individual differences. London, UK: SAGE.

Mõttus, R., Bates, T. C., Condon, D. M., Mroczek, D., \& Revelle, W. (2017). Your personality data can do more: Items provide leverage for explaining the variance and co-variance of life outcomes. Unpublished manuscript. Retrieved December 21, 2017 from https://psyarxiv.com/4q9gv/.

Mõttus, R., Kandler, C., Bleidorn, W., Riemann, R., \& McCrae, R. R. (2017). Personality traits below facets: The consensual validity, longitudinal stability, heritability, and utility of personality nuances. Journal of Personality and Social Psychology, 112, 474-490.

Mõttus, R., Sinick, J., Terracciano, A., Hřebíčková, M., Kandler, C., Ando, J., . .. Jang, K. L. (2017). Personality characteristics below facets: A replication and meta-analysis of cross-rater agreement, rank-order stability, heritability and utility of personality nuances. Unpublished manuscript. Retrieved December 21, 2017 from https://osf.io/wjmb3/

Munafò, M. R., \& Flint, J. (2011). Dissecting the genetic architecture of human personality. Trends in Cognitive Sciences, 15, 395-400.

Mund, M., \& Neyer, F. J. (2014). Treating personality-relationship transactions with respect: Narrow facets, advanced models, and extended time frames. Journal of Personality and Social Psychology, 107, 352-368.

Nagel, M., Jansen, P. R., Stringer, S., Watanabe, K., de Leeuw, C. A., Bryois, J., . . . Posthuma, D. (2017). GWAS meta-analysis of neuroticism $(\mathrm{N}=449,484)$ identifies novel genetic loci and pathways. Unpublished manuscript. Retrieved December 21, 2017 from https://www.biorxiv.org/content/early/2017/o9/05/184820

Nestler, S., Grimm, K. J., \& Schönbrodt, F. D. (2015). The social consequences and mechanisms of personality: How to analyse longitudinal data from individual, dyadic, round-robin and network designs. European Journal of Personality, 29, 272-295.

Nettle, D. (2005). An evolutionary approach to the extraversion continuum. Evolution and Human Behavior, 26, 363-373.

Newcomb, A. F., Bukowski, W. M., \& Pattee, L. (1993). Children's peer relations: A meta-analytic review of popular, rejected, neglected, controversial, and average sociometric status. Psychological Bulletin, 113, 99-128. 
Newcomb, T. M. (1956). The prediction of interpersonal attraction. American Psychologist, 11, 575-586.

Neyer, F. J., \& Asendorpf, J. B. (2001). Personality-relationship transaction in young adulthood. Journal of Personality and Social Psychology, 81, 11901204.

Neyer, F. J., Mund, M., Zimmermann, J., \& Wrzus, C. (2014). Personalityrelationship transactions revisited. Journal of Personality, 82, 539-550.

Oishi, S. (2014). Socioecological psychology. Annual Review of Psychology, 65, 581-609.

Oishi, S., \& Schimmack, U. (2010). Residential mobility, well-being, and mortality. Journal of Personality and Social Psychology, 98, 980-994.

Open Science Collaboration. (2015). Estimating the reproducibility of psychological science. Science, 349.

Ozer, D. J. (2016). Prediction and personality-related outcomes. [Peer commentary on "Towards more rigorous personality trait-outcome research” by R. Mõttus]. European Journal of Personality, 30, 321-322.

Ozer, D. J., \& Benet-Martínez, V. (2006). Personality and the prediction of consequential outcomes. Annual Review of Psychology, 57, 401-421.

Pace, V. L., \& Brannick, M. T. (2010). How similar are personality scales of the "same" construct? A meta-analytic investigation. Personality and Individual Differences, 49, 669-676.

Parker, J. G., Rubin, K. H., Erath, S. A., Wojslawowicz, J. C., \& Buskirk, A. A. (2006). Peer relationships, child development, and adjustment: A developmental psychopathology perspective. In D. Cicchetti, \& D. J. Cohen (Eds.), Developmental psychopathology. Theory and method / volume 1 (2nd ed. ed., pp. 419-493). Hoboken, NJ: John Wiley \& Sons.

Parkhurst, J. T., \& Hopmeyer, A. (1998). Sociometric popularity and peerperceived popularity two distinct dimensions of peer status. The Journal of Early Adolescence, 18, 125-144.

Paulhus, D. L. (1998). Interpersonal and intrapsychic adaptiveness of trait self-enhancement: A mixed blessing? Journal of Personality and Social Psychology, 74, 1197-1208.

Paunonen, S. V., \& Hong, R. Y. (2015). On the properties of personality traits. In M. Mikulincer, P. R. Shaver, M. L. Cooper \& R. J. Larsen (Eds.), APA handbook of personality and social psychology, volume 4: Personality processes and individual differences (pp. 233-259). Washington, DC: American Psychological Association.

Pearman, A. (2009). Basic cognition in adulthood: Combined effects of sex and personality. Personality and Individual Differences, 47, 357-362.

Pennebaker, J. W., \& King, L. A. (1999). Linguistic styles: Language use as an individual difference. Journal of Personality and Social Psychology, 77, 1296-1312.

Pennebaker, J. W., Mehl, M. R., \& Niederhoffer, K. G. (2003). Psychological aspects of natural language use: Our words, our selves. Annual Review of Psychology, 54, 547-577.

Pervin, L. A. (1994). A critical analysis of current trait theory. Psychological Inquiry, 5, 103-113.

Plomin, R. (2013). Child development and molecular genetics: 14 years later. Child Development, 84, 104-120.

Polderman, T. J. C., Benyamin, B., de Leeuw, C. A., Sullivan, P. F., van Bochoven, A., Visscher, P. M., \& Posthuma, D. (2015). Meta-analysis of the 
heritability of human traits based on fifty years of twin studies. Nature Genetics, 47, 702-709.

Preacher, K. J., \& Hayes, A. F. (2008). Asymptotic and resampling strategies for assessing and comparing indirect effects in multiple mediator models. Behavior Research Methods, 40, 879-891.

Price, M. E., \& Van Vugt, M. (2014). The evolution of leader-follower reciprocity: The theory of service-for-prestige. Frontiers in Human Neuroscience, 8, 1-17.

Realo, A., Allik, J., Lönnqvist, J. E., Verkasalo, M., Kwiatkowska, A., Kööts, L., ... Karpinski, K. (2009). Mechanisms of the national character stereotype: How people in six neighbouring countries of Russia describe themselves and the typical Russian. European Journal of Personality, 23, 229-249.

Revelle, W., \& Elleman, L. G. (2016). Factors are still fictions. [Peer commentary on "Towards more rigorous personality trait-outcome research" by R. Mõttus]. European Journal of Personality, 30, 304-305.

Richard, F. D., Bond, C. F., \& Stokes-Zoota, J. J. (2003). One hundred years of social psychology quantitatively described. Review of General Psychology, 7, 331-363.

Roberts, B. W., Caspi, A., \& Moffitt, T. E. (2003). Work experiences and personality development in young adulthood. Journal of Personality and Social Psychology, 84, 582-593.

Roberts, B. W., \& DelVecchio, W. F. (2000). The rank-order consistency of personality traits from childhood to old age: A quantitative review of longitudinal studies. Psychological Bulletin, 126, 3-25.

Roberts, B. W., \& Robins, R. W. (2000). Broad dispositions, broad aspirations: The intersection of personality traits and major life goals. Personality and Social Psychology Bulletin, 26, 1284-1296.

Rodkin, P. C., Ryan, A. M., Jamison, R., \& Wilson, T. (2012). Social goals, social behavior, and social status in middle childhood. Developmental Psychology, 49, 1139-1150.

Rolland, J. (2002). The cross-cultural generalizability of the five-factor model of personality. In R. R. McCrae, \& J. Allik (Eds.), The five factor model of personality across cultures (pp. 7-28). New York, US: Kluwer.

Rosenberg, M. (Ed.). (1979). Conceiving the self. New York, US: Basic Books.

Rosseel, Y. (2012). lavaan: An R package for structural equation modeling (version 0.6-1.1122). Journal of Statistical Software, 48, 1-36.

Rothstein, H. R., Sutton, A. J., \& Borenstein, M. (Eds.). (2006). Publication bias in meta-analysis: Prevention, assessment and adjustments. Chichester, UK: John Wiley \& Sons.

Royston, P., Altman, D. G., \& Sauerbrei, W. (2006). Dichotomizing continuous predictors in multiple regression: A bad idea. Statistics in Medicine, 25, 127-141.

Salminen, M., Henttonen, P., \& Ravaja, N. (2016). The role of personality in dyadic interaction: A psychophysiological study. International Journal of Psychophysiology, 109, 45-50.

Sanchez-Roige, S., Gray, J. C., MacKillop, J. K., Chen, C., \& Palmer, A. A. (2017). The genetics of human personality. Genes, Brain and Behavior.

Saucier, G., \& Ostendorf, F. (1999). Hierarchical subcomponents of the big five personality factors: A cross-language replication. Journal of Personality and Social Psychology, 76, 613-627.

Scherer, K. R. (1978). Personality inference from voice quality: The loud voice of extroversion. European Journal of Social Psychology, 8, 467-487. 
Schmitt, D. P., Allik, J., McCrae, R. R., \& Benet-Martínez, V. (2007). The geographic distribution of big five personality traits: Patterns and profiles of human self-description across 56 nations. Journal of Cross-Cultural Psychology, 38, 173-212.

Scholte, R. H. J., van Aken, Marcel A. G., \& Van Lieshout, C. F. M. (1997). Adolescent personality factors in self-ratings and peer nominations and their prediction of peer acceptance and peer rejection. Journal of Personality Assessment, 69, 534-554.

Schönbrodt, F. D. (2016a). RSA: An R package for response surface analysis (version 0.9.10). Retrieved from https://cran.r-project.org/package=RSA

Schönbrodt, F. D. (2016b). Testing fit patterns with polynomial regression models. Unpublished manuscript. Retrieved December 21, 2017, from https://osf.io/ndggf

Schönbrodt, F. D., \& Perugini, M. (2013). At what sample size do correlations stabilize? Journal of Research in Personality, 47, 609-612.

Schug, J., Yuki, M., Horikawa, H., \& Takemura, K. (2009). Similarity attraction and actually selecting similar others: How cross-societal differences in relational mobility affect interpersonal similarity in japan and the USA. Asian Journal of Social Psychology, 12, 95-103.

Selfhout, M., Burk, W., Branje, S., Denissen, J. J. A., van Aken, Marcel A. G., \& Meeus, W. (2010). Emerging late adolescent friendship networks and big five personality traits: A social network approach. Journal of Personality, 78, 509-538.

Shanock, L. R., Baran, B. E., Gentry, W. A., Pattison, S. C., \& Heggestad, E. D. (2010). Polynomial regression with response surface analysis: A powerful approach for examining moderation and overcoming limitations of difference scores. Journal of Business and Psychology, 25, 543-554.

Smillie, L. D. (2013). Extraversion and reward processing. Current Directions in Psychological Science, 22, 167-172.

Spark, A., Stansmore, T., \& O'Connor, P. (2018). The failure of introverts to emerge as leaders: The role of forecasted affect. Personality and Individual Differences, 121, 84-88.

Spengler, M., Gottschling, J., \& Spinath, F. M. (2012). Personality in childhood - A longitudinal behavior genetic approach. Personality and Individual Differences, 53, 411-416.

Stopfer, J. M., Egloff, B., Nestler, S., \& Back, M. D. (2013). Being popular in online social networks: How agentic, communal, and creativity traits relate to judgments of status and liking. Journal of Research in Personality, 47, 592-598.

Sun, J., Stevenson, K., Kabbani, R., Richardson, B., \& Smillie, L. D. (2017). The pleasure of making a difference: Perceived social contribution explains the relation between extraverted behavior and positive affect. Emotion, 17, 794-810.

Sutin, A. R., Terracciano, A., Kitner-Triolo, M. H., Uda, M., Schlessinger, D., \& Zonderman, A. B. (2011). Personality traits prospectively predict verbal fluency in a lifespan sample. Psychology and Aging, 26, 994-999.

Tryggvason, M. T. (2006). Communicative behavior in family conversation: Comparison of amount of talk in finnish, SwedishFinnish, and swedish families. Journal of Pragmatics, 38, 1795-1810.

Tulviste, T., Mizera, L., De Geer, B., \& Tryggvason, M. T. (2003). A silent Finn, a silent Finno-Ugric, or a silent Nordic? A comparative study of Estonian, Finnish, and Swedish mother-adolescent interactions. Applied Psycholinguistics, 24, 249-265. 
Turkheimer, E., Pettersson, E., \& Horn, E. E. (2014). A phenotypic null hypothesis for the genetics of personality. Annual Review of Psychology, $65,515-540$.

van den Berg, S. M., de Moor, M. H. M., Verweij, K. J. H., Krueger, R. F., Luciano, M., Arias Vasquez, A., . . Boomsma, D. I. (2016). Meta-analysis of genome-wide association studies for extraversion: Findings from the genetics of personality consortium. Behavior Genetics, 46, 170-182.

van der Linden, D., Scholte, R. H. J., Cillessen, A. H. N., Nijenhuis, J. T., \& Segers, E. (2010). Classroom ratings of likeability and popularity are related to the big five and the general factor of personality. Journal of Research in Personality, 44, 669-672.

Van der Werff, J. J. (1985). Heymans' temperamental dimensions in personality research. Journal of Research in Personality, 19, 279-287.

van Zalk, M., \& Denissen, J. J. A. (2015). Idiosyncratic versus social consensus approaches to personality: Self-view, perceived, and peer-view similarity. Journal of Personality and Social Psychology, 109, 121-141.

Visscher, P. M., Wray, N. R., Zhang, Q., Sklar, P., McCarthy, M. I., Brown, M. A., \& Yang, J. (2017). 10 years of GWAS discovery: Biology, function, and translation. The American Journal of Human Genetics, 101, 5-22.

von Rueden, C. (2014). The roots and fruits of social status in small-scale human societies. In J. T. Cheng, J. L. Tracy \& C. Anderson (Eds.), The psychology of social status (pp. 179-200). New York, NY: Springer.

Vukasović, T., \& Bratko, D. (2015). Heritability of personality: A meta-analysis of behavior genetic studies. Psychological Bulletin, 141, 769-785.

Watson, D., \& Clark, L. A. (1997). Extraversion and its positive emotional core. In R. Hogan, J. A. Johnson \& S. R. Briggs (Eds.), Handbook of personality psychology (pp. 767-793). San Diego, CA, US: Academic Press.

Weidmann, R., Schönbrodt, F. D., Ledermann, T., \& Grob, A. (2017). Concurrent and longitudinal dyadic polynomial regression analyses of big five traits and relationship satisfaction: Does similarity matter? Journal of Research in Personality, 70, 6-15.

Weiss, A., Baselmans, B. M., Hofer, E., Yang, J., Okbay, A., Lind, P. A., . . Hagenaars, S. P. (2016). Personality polygenes, positive affect, and life satisfaction. Twin Research and Human Genetics, 19, 407-417.

Wilson, R. E., Harris, K., \& Vazire, S. (2015). Personality and friendship satisfaction in daily life: Do everyday social interactions account for individual differences in friendship satisfaction? European Journal of Personality, 29, 173-186.

Wilt, J. A., Bleidorn, W., \& Revelle, W. (2017). Velocity explains the links between personality states and affect. Journal of Research in Personality, $69,86-95$.

Wilt, J. A., Noftle, E. E., Fleeson, W., \& Spain, J. S. (2012). The dynamic role of personality states in mediating the relationship between extraversion and positive affect. Journal of Personality, 80, 1205-1236.

Wilt, J. A., \& Revelle, W. (2017). Extraversion. In T. A. Widiger (Ed.), The oxford handbook of the five factor model. New York, NY: Oxford University Press.

Wolters, N., Knoors, H., Cillessen, A. H. N., \& Verhoeven, L. (2014). Behavioral, personality, and communicative predictors of acceptance and popularity in early adolescence. The Journal of Early Adolescence, 34, 585605 . 
Wood, D., Gardner, M. H., \& Harms, P. D. (2015). How functionalist and process approaches to behavior can explain trait covariation. Psychological Review, 122, 84-111.

Wortman, J., \& Wood, D. (2011). The personality traits of liked people. Journal of Research in Personality, 45, 519-528.

Xie, H., Li, Y., Boucher, S. M., Hutchins, B. C., \& Cairns, B. D. (2006). What makes a girl (or a boy) popular (or unpopular)? African American children's perceptions and developmental differences. Developmental Psychology, 42, 599-612.

Yang, L., Levine, E. L., Smith, M. A., Ispas, D., \& Rossi, M. E. (2008). Personenvironment fit or person plus environment: A meta-analysis of studies using polynomial regression analysis. Human Resource Management Review, 18, 311-321.

Zelenski, J. M., Whelan, D. C., Nealis, L. J., Besner, C. M., Santoro, M. S., \& Wynn, J. E. (2013). Personality and affective forecasting: Trait introverts underpredict the hedonic benefits of acting extraverted. Journal of Personality and Social Psychology, 104, 1092-1108.

Zhang, Z., Wang, M., \& Shi, J. (2012). Leader-follower congruence in proactive personality and work outcomes: The mediating role of leader-member exchange. Academy of Management Journal, 55, 111-130. 